برنامج تدريبي قائم على المنصات التعليمية عن بعد لتنمية

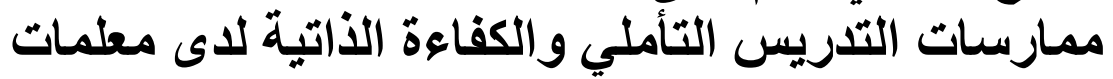

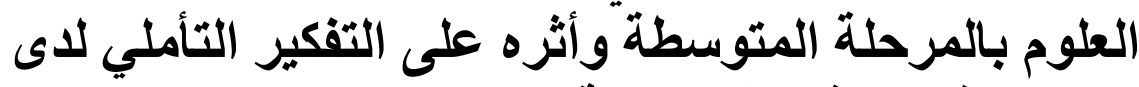

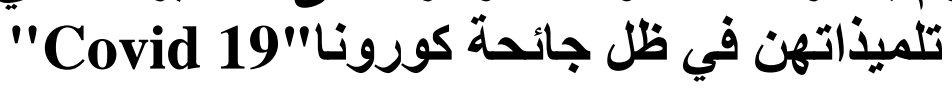

\author{
إعداد \\ د/ إيمان صابر عبد القادر العزب إب

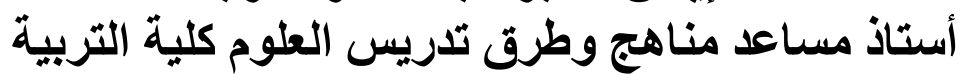 \\ جامعة بنها/ جامعة بيشة تشرين العزو \\ dremansaber@gmail.com
}

E. ISSN: 2735-4245

ISSN: 2536 - 914

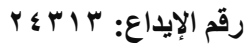

المجلة معرفة علي دوريات بنك المعرفة المصرى، و Edu Search دار المنظومة 


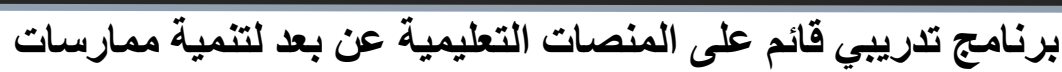

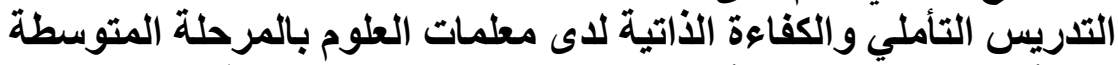

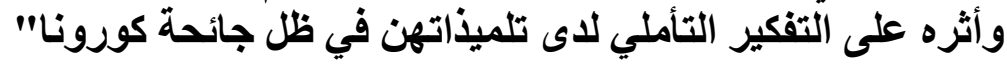

\section{"Covid 19}

د./ إيمان صابر عبد القادر العزب*

هدف البحث إلى تعرف فاعلية برنامج تدريبي مقترح من خلال استخدام منصات

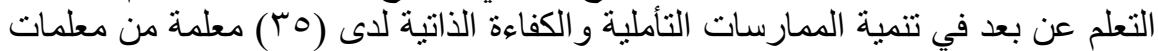

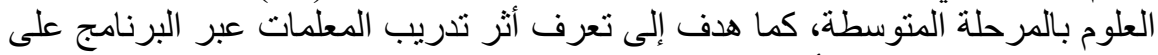

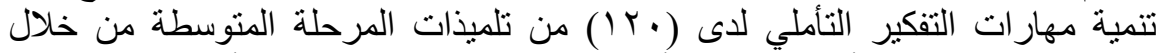

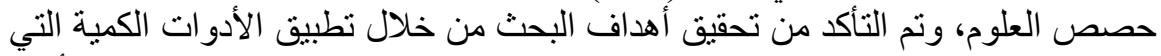

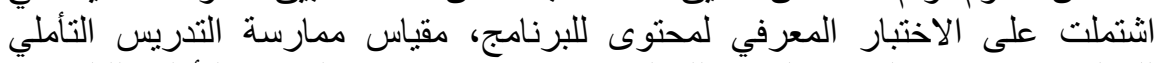

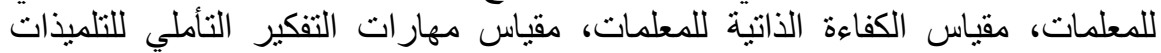
بالمرحلة المتوسط، وادوات التحليل الكيفي وتضمنت استبانة الممارسات التأملية الذاتية

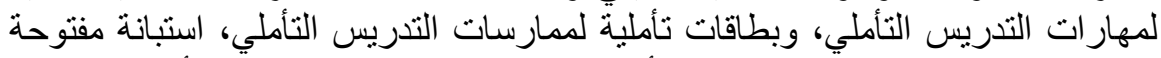

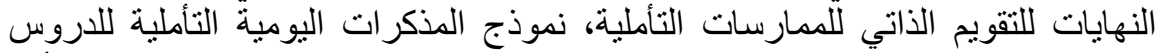

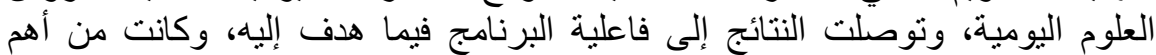

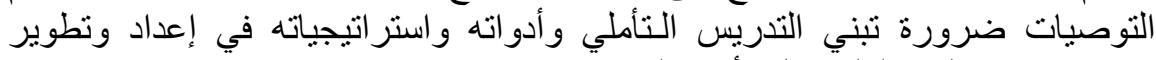
بر امج إعداد معلمي العلوم قبل و أثناء الخدمة.

الكلمات المفتاحية: برنامج تدريبي ـ التعلم عن بعد - التدريس التأملي - الممارسات

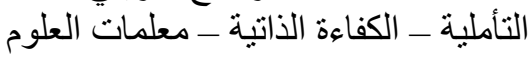

" أستاذ مساعد مناهج وطرق تدريس العلوم كلية التربية - جامعة بنها/ جامعة بيشة

\footnotetext{
E. ISSN: 2735-4245

ISSN: 2536 - 914

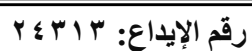

المجلة معرفة علي دوريات بنك المعرفة المصرى، و Edu Search دار المنظومة
} 


\section{A training program based on distance learning platforms to develop reflective teaching practices and self-efficacy among middle school science teachers and its impact on the contemplative thinking of their students under the Corona pandemic "Covid 19"}

\section{Dr. Eman Saber Abdelkader Elazzab*}

\section{Abstract}

the aim of the research is to identify the effectiveness of a proposed training program using distance learning platforms in developing contemplative practices and self-efficacy of (35) middle science teachers. It also aimed to identify the effect of training teachers through the program on developing reflective thinking skills at (120) of middle school students, and it was ensured that the research objectives were achieved through the application of quantitative tools that included the cognitive test of the content of the program, the measure of contemplative teaching practice for female teachers, the scale of self-efficacy of female teachers, the scale of reflective thinking skills for intermediate school students, and tools The qualitative., and the results reached the program's effectiveness in what it aimed to, among the most important recommendations was the need to adopt contemplative teaching. Its tools and strategies in developing programs for preparing science teachers pre and during service

Key words: training program - distance learning - reflective teaching - contemplative practices - self-efficacy - science teachers

"Assistant Professor of Curricula and Science Teaching Methods, Faculty of Education Benha Universit/ Bisha University

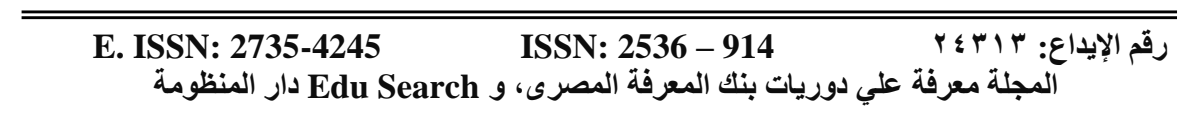




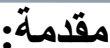

تعد التنمية المهنية للمعلمين في ظل التغيرات المتسـار عة، وتطور النظريات

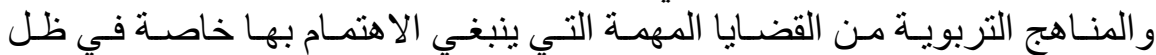

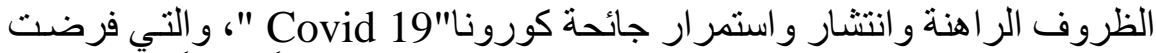

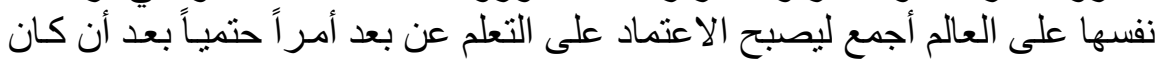

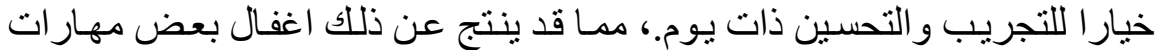

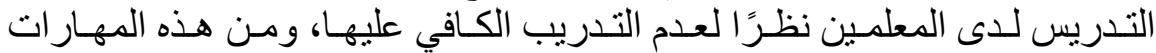

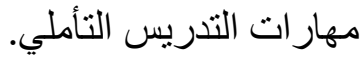

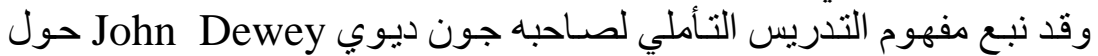

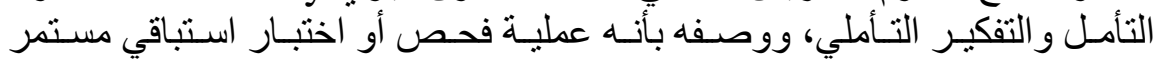

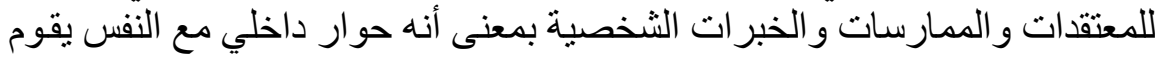

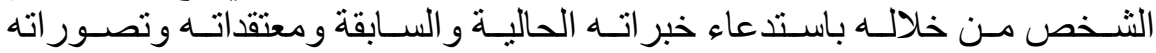

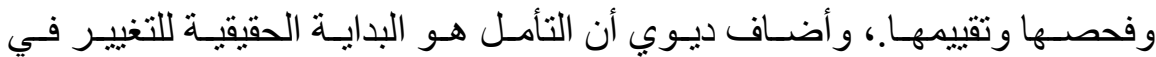

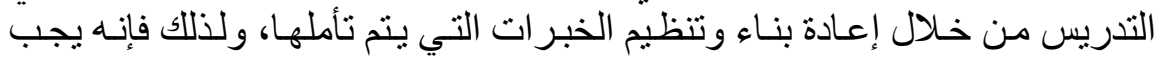

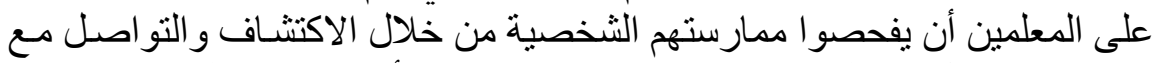

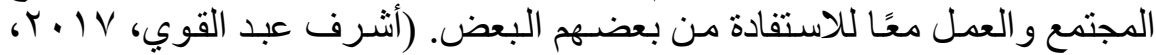

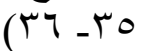

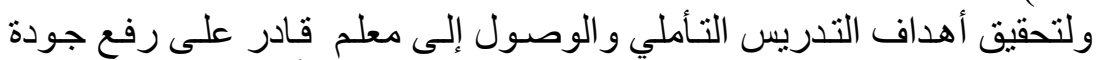

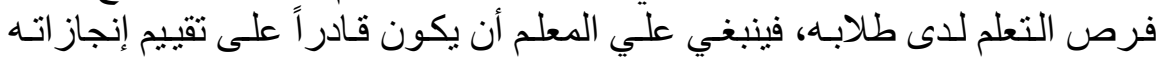

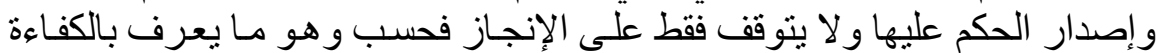

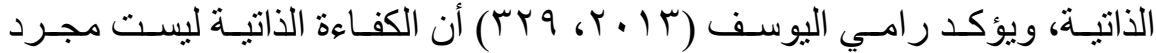

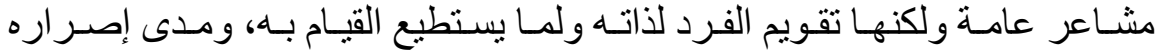

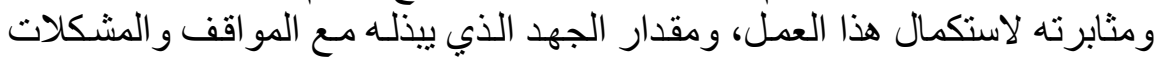

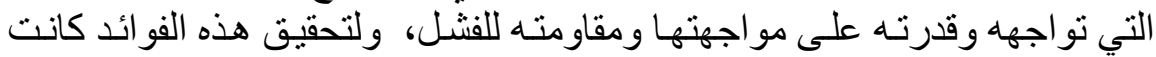
الحاجة لإجر اء هذا البحث.

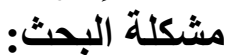

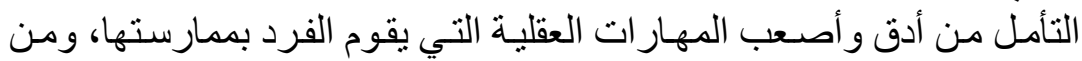

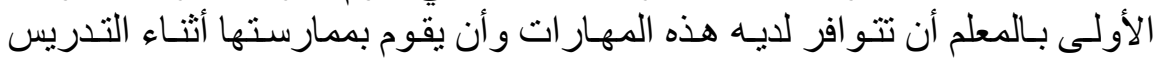

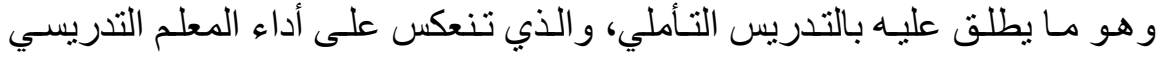

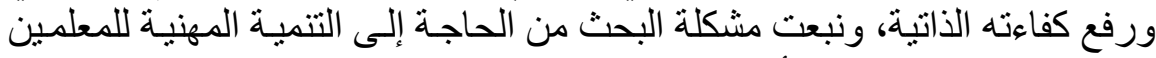

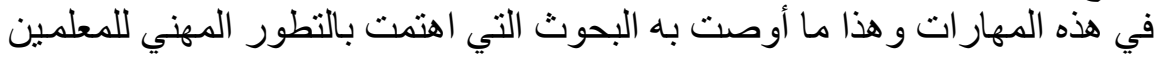

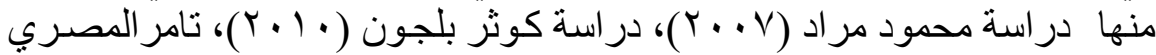

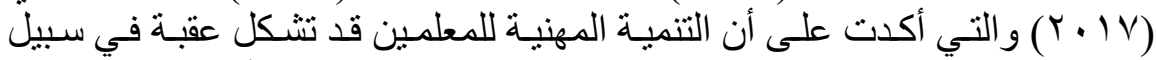

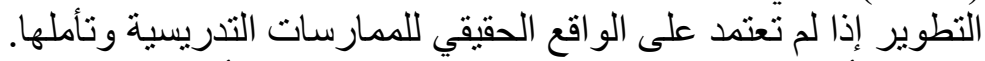

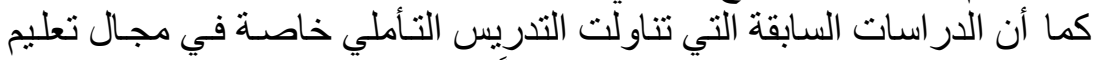

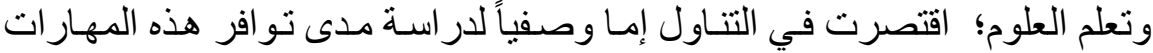
E. ISSN: 2735-4245
ISSN: 2536 - 914

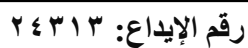
المجلة معرفة علي دوريات بنك المعرفة المصرى، و Edu Search دار المنظومة 
لدى معلمي العلوم ومعلمي تخصصسات الأخرى مثنل در اسـة أشـرف عبد القوى

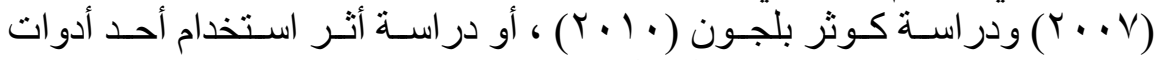

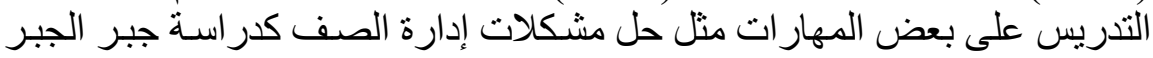

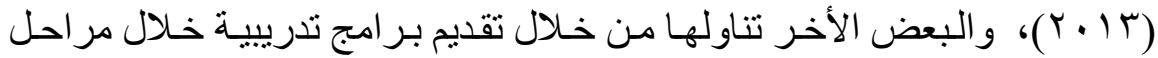

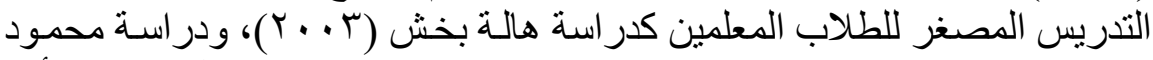

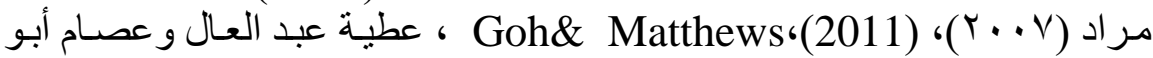

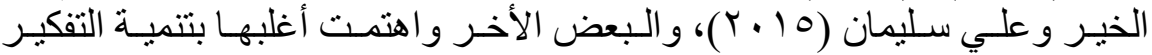

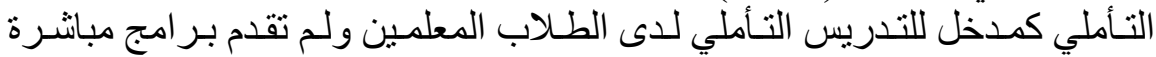

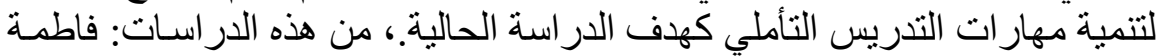

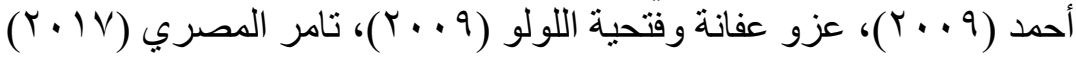

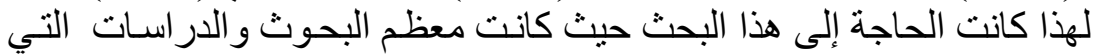
تناولت متغير ات هذا البحث على الطلاب المعلمين.، ولم تتناول أي من منهـا سواء سواء

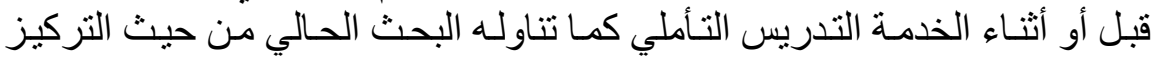

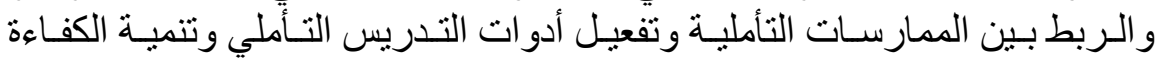

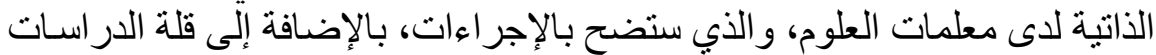

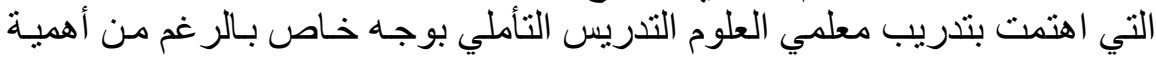

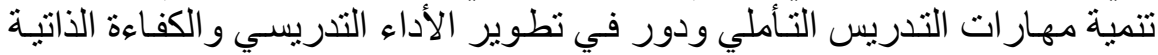

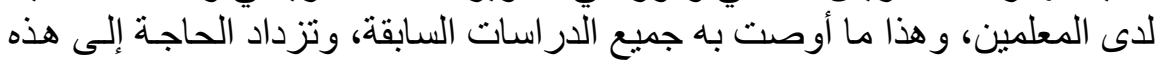

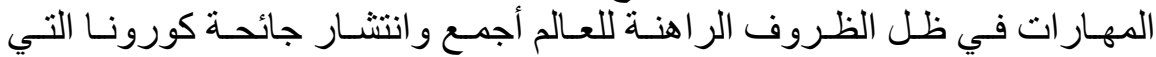

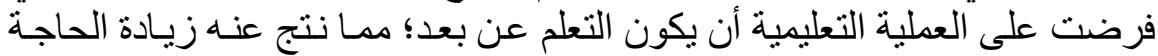

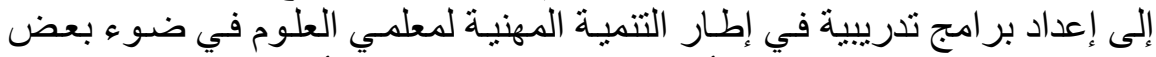

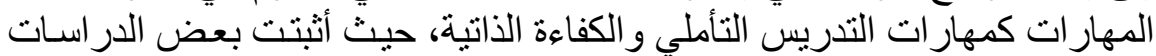

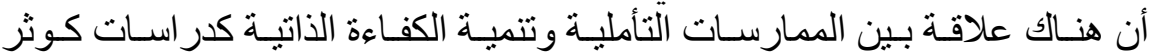

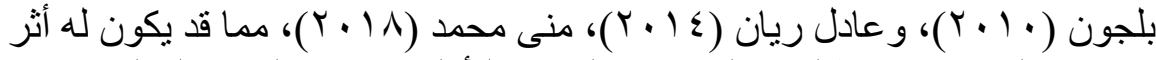

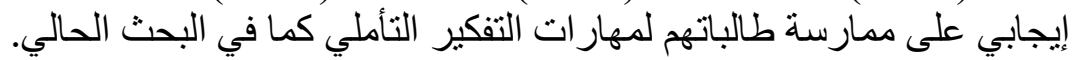

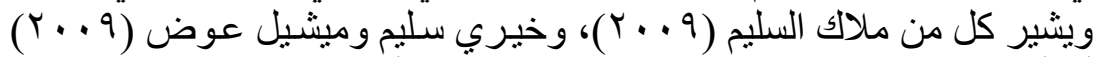

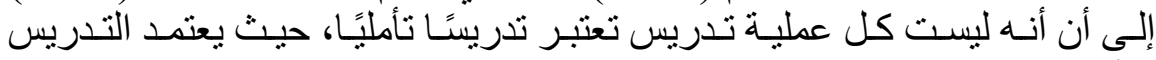

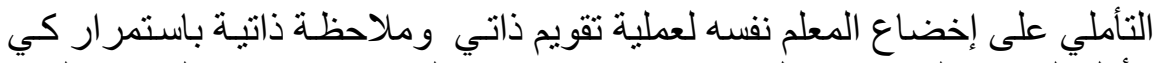
يتأمل الموقف التدريسي بكل عناصره.، مما بيؤدي إلى تحسين نمـوه المهني وليس وليس

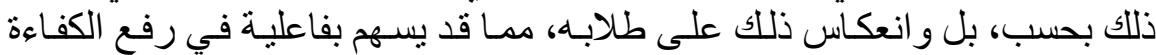

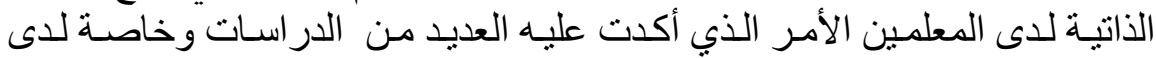

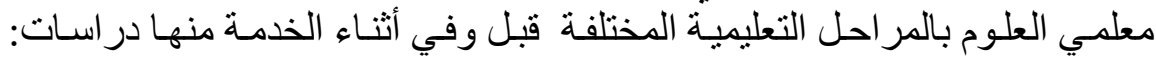
·Al-Zoubi\& Abdel Rahman (2011) ،Ahmed \& Alkhalili (2013) ولهذا كان من أهداف البحث الحالي قياس أثر تدريب معلمات العلوم بالبرنامج على التى مستوى التفكير التأملي لدى طافي الباتهم.

\footnotetext{
E. ISSN: 2735-4245

ISSN: 2536 - 914

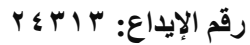

المجلة معرفة علي دوريات بنك المعرفة المصرى، و Edu Search دار المنظومة
} 
تحددت مشكلة البحث في " الحاجة إلى تعرف فاعلية برنـامج تدريبي مقتر ح

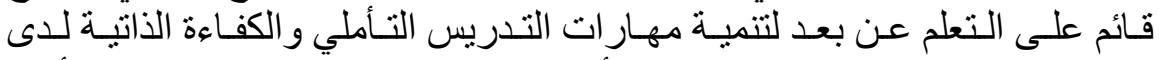

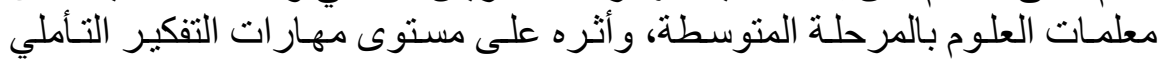

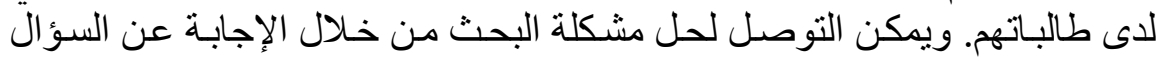

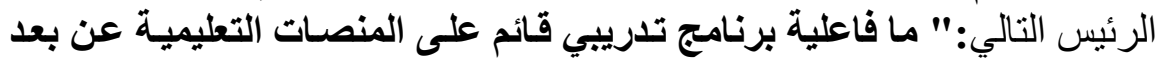

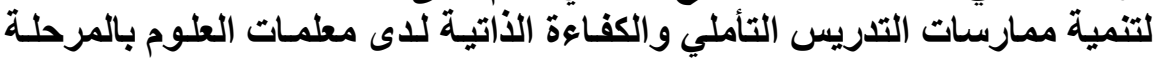

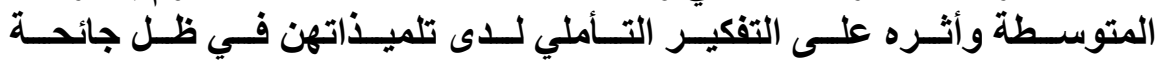

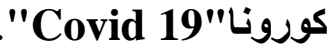
ويتفرع من هذا السؤال الأسئلة الفرعية التالية:

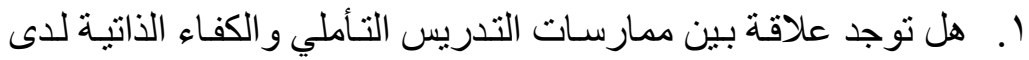

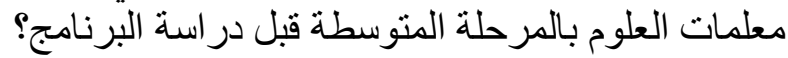

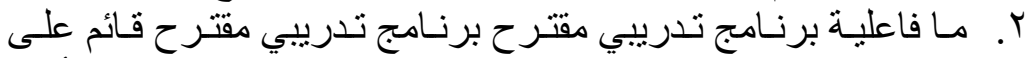

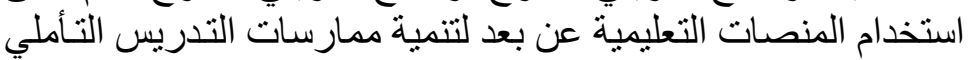
لدى معلمات العلوم بالمرحلة المتوسطة في ظل جائحة 19 Covid

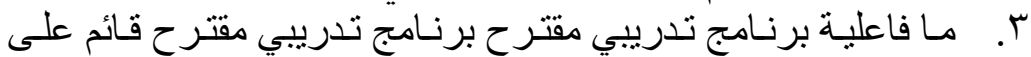

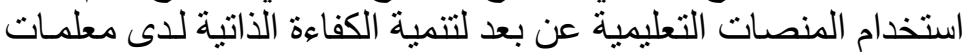

العلوم بالمرحلة المتوسطة في ظل جائحة 19 Covid

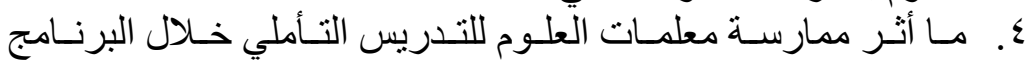
التدريبي المقترح على تنميـة مهار ات التفكير الـتأملي لدى معلى تلميذاتهن بالمر حلة المتوسطة فروض الإحث:

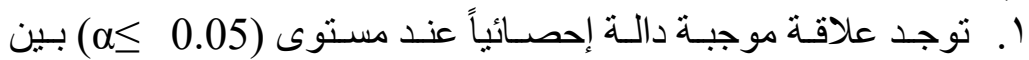

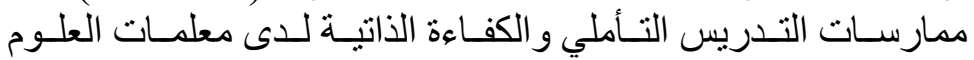
بالمرحلة المتوسطة.

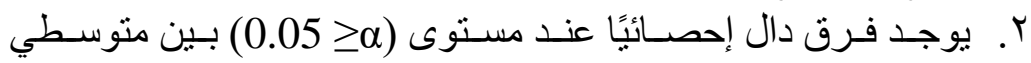

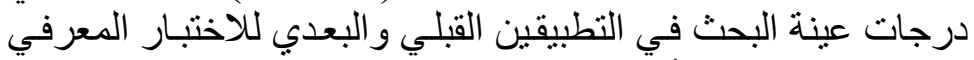

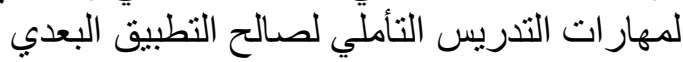

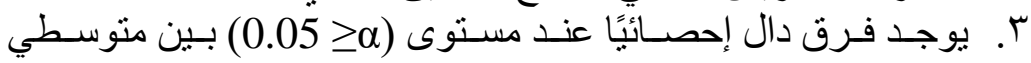

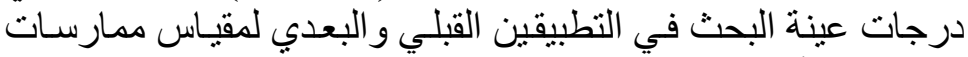

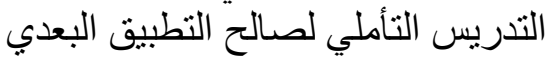

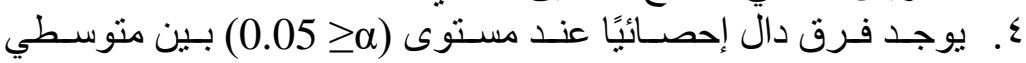

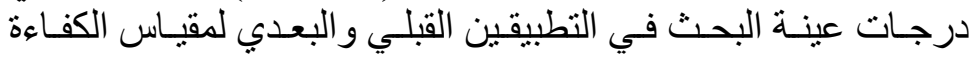
الذاتية لصالح التطبيق البعدي.

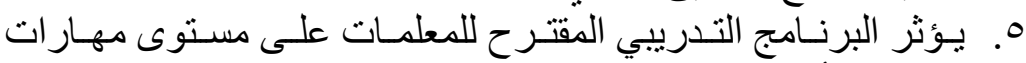
التفكير التأملي لدى تلميذات معلمات العلوم عينة البحث.

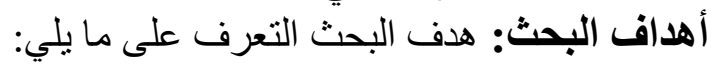


ا ـ العلاقة بين ممارسات التدريس التأملي و الكفاء الذاتيـة لدى معلمـات العلوم

$$
\text { بالمر حلة المتوسطة. }
$$

r ـ فاعلية برنـامج تدريبي مقتر ح برنـامج تدريبي مقتر ح قائم على استخدام

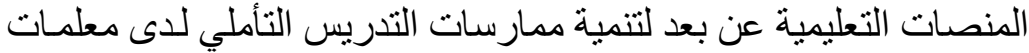

العلوم بالمرحلة المتوسطة في ظل جائحة 19 Covid.

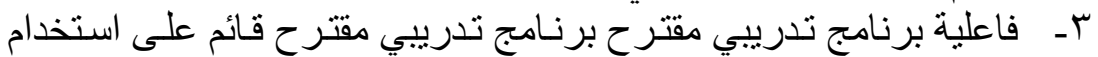

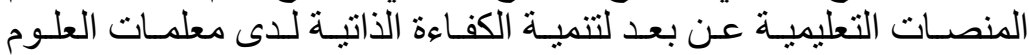

بالمر حلة المتوسطة في ظل جائحة 19 Covid .

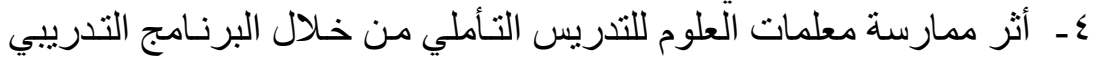

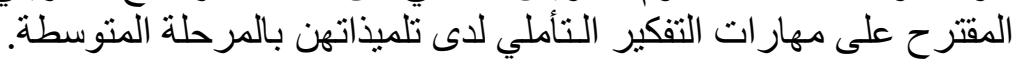

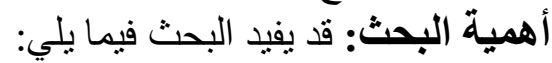

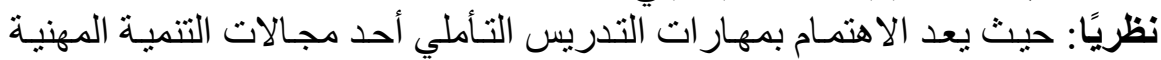

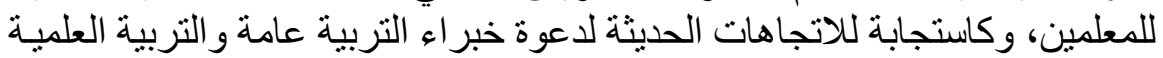

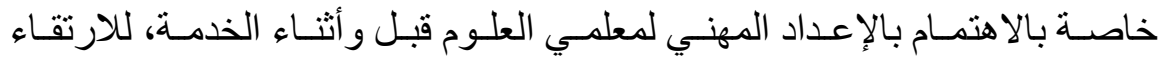

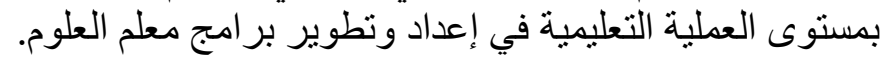

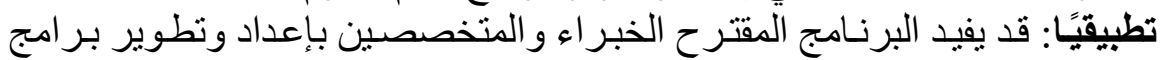

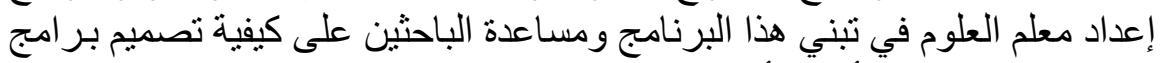

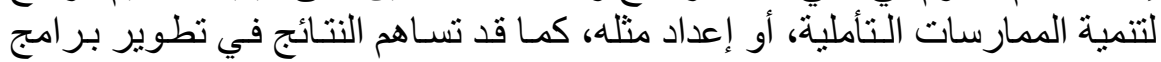

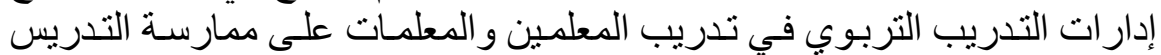

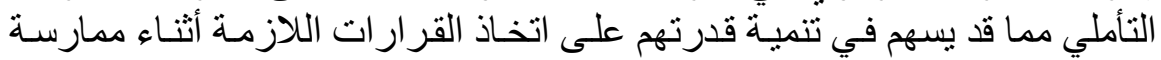

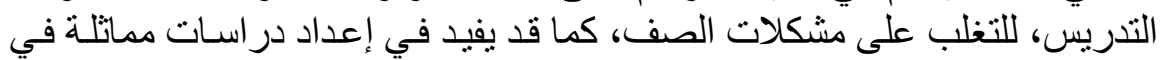

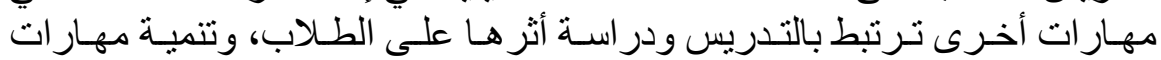

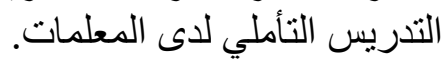
حدود البحث: اقتصر البحث على الحدود التالية:

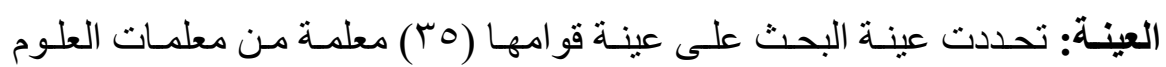

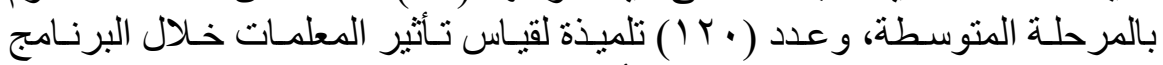
على تتمية ممارسة مهار ات التفكير التأملي لديهن.

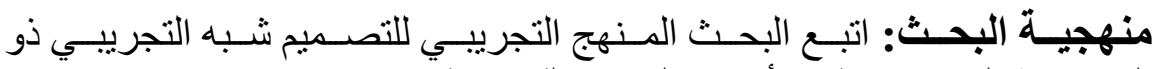
المجمو عة الواحدة وتطبيق أدو ات البحث ثبليًا وبعديًا.

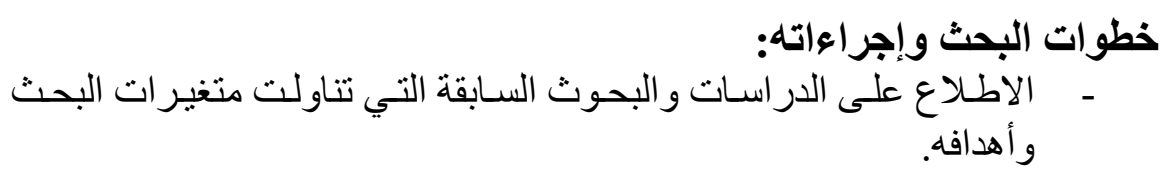

E. ISSN: 2735-4245

ISSN: 2536 - 914

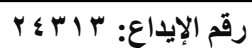

المجلة معرفة علي دوريات بنك المعرفة المصرى، و Edu Search دار المنظومة 
- إعداد مواد البحث التي اشتملت على البرنامج المقترح ودليل المعلمة، و عرضها على المحكمين.

- إعداد أدوات البحث و اشتملت أدوات التحليل الكمي وهي: الاختبار

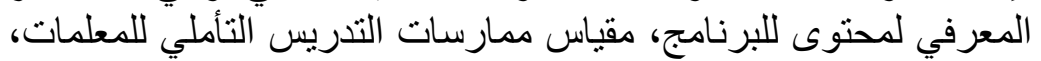

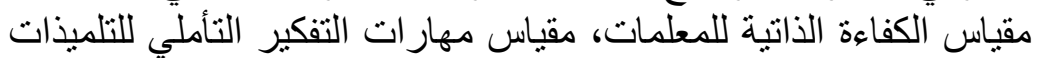

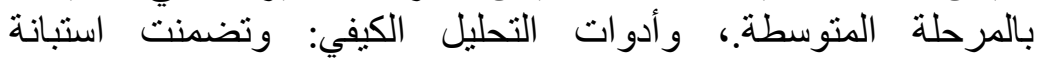

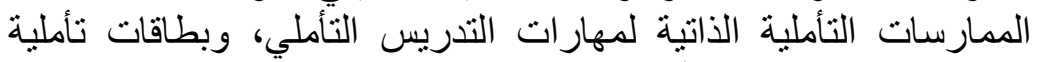

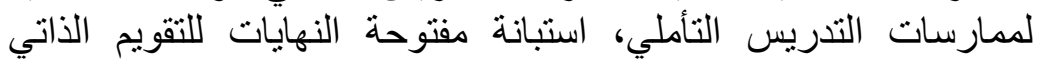
للممارسات التأملية، نموذج المذكرات اليومية التأملية للاروس التوسية العلوم

$$
\text { تطبيق أدوات اليوات الدراسة قبلياً. }
$$

ـ تتفيذ البرنامج المقترح و اقتصر تطبيق البرنامج على التعلم عن بعد، من

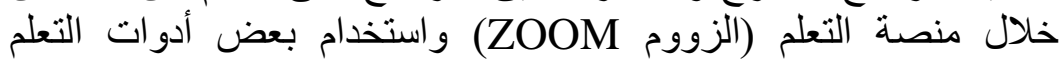
الالكتروني المساندة مثل الواتساب، والإيميل واليوتيوب والعروض

\section{التقديمية.}

$$
\begin{aligned}
& \text { - - مبيق أدوات الدر اسة بعديَا. } \\
& \text { - رصد النتائج ومعالجتها إحصائيًا. }
\end{aligned}
$$$$
\text { - }
$$

$$
\text { مصطلحاث البحث: }
$$

البرنامج التدريبي المقترح القائم على المنصـات التعليمية عن بعد: يمكن تعريفه

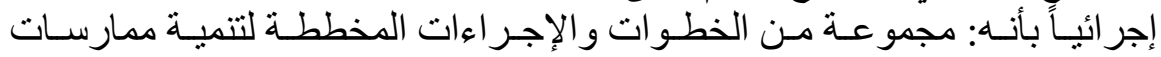

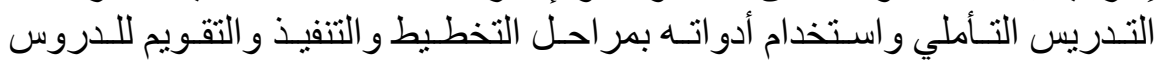

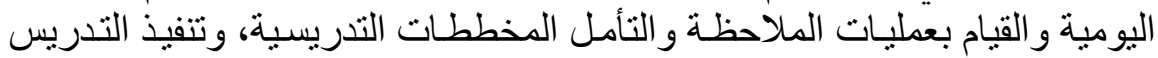

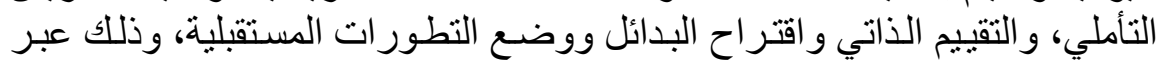

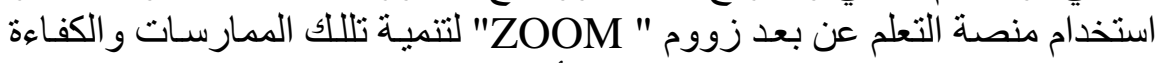

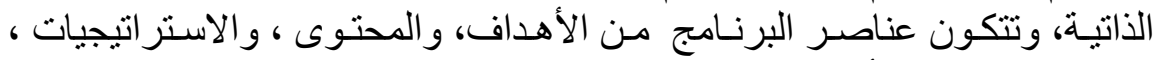

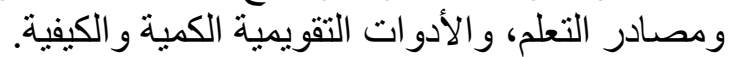

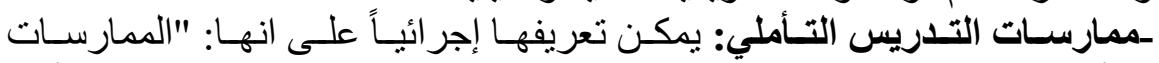

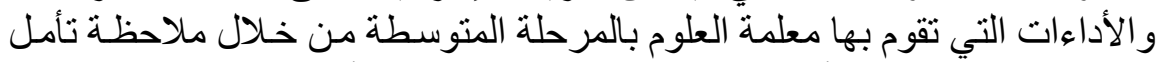

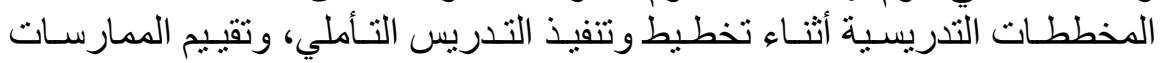

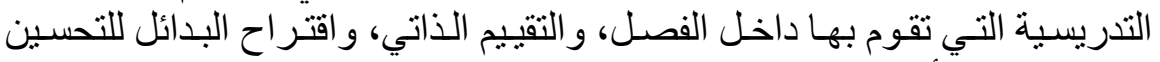

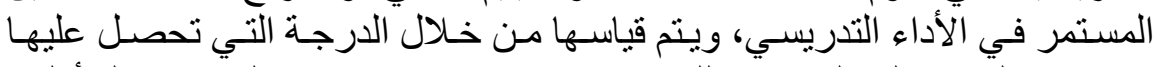

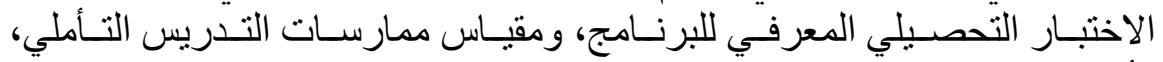

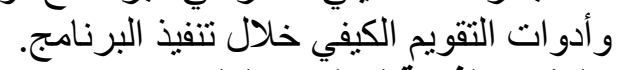

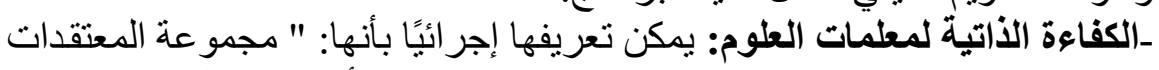
التي تساعد معلمة العلوم بالمرحلة المتوسطة على إصدار أحكامًا حول قدرتها على على بعلى
E. ISSN: 2735-4245
ISSN: 2536 - 914

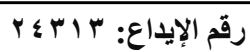
المجلة معرفة علي دوريات بنك المعرفة المصرى، و Edu Search دار المنظومة 
إنجاز المهام من خـال التخطيط و التنفيذ من خلال الممارسـات التدريسية التأملية

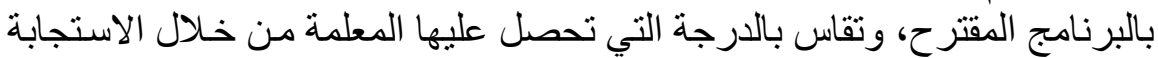
عن مقياس الكفاءة الذاتية.

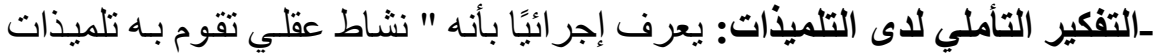

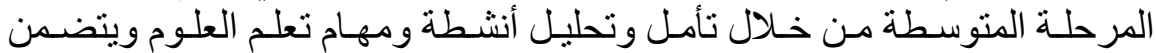

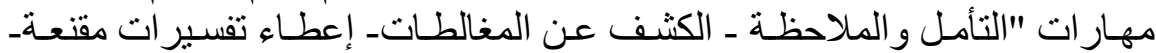

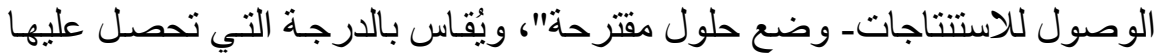
التلميذة في مقياس مهار ات التفنئ التفير التأملي.

\section{الإطار النظري والإراسات السابقة:}

أولاً: الإطار النظري

المحور الأول: التدريس التأملي والمماريسات التأملية:

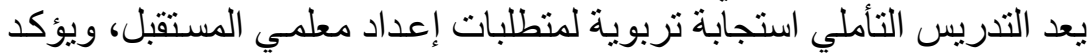

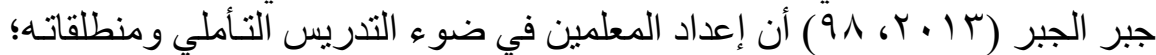

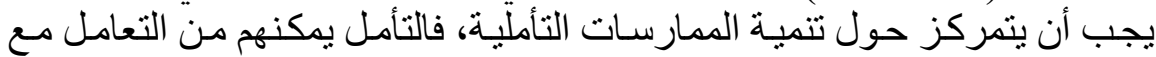

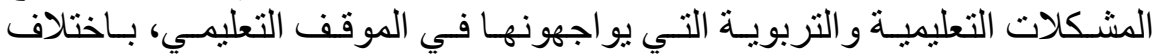

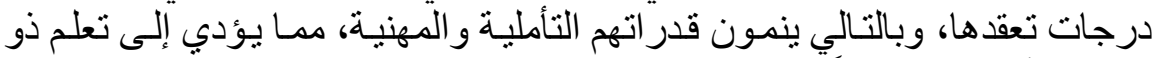
معنى، و أكثر ، وضوها، وضوحاً، وتحديدًا.

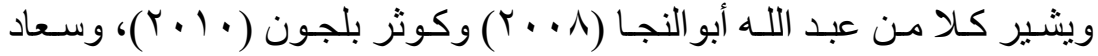

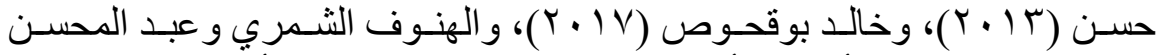

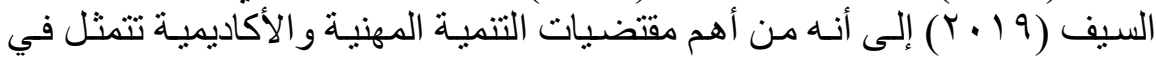

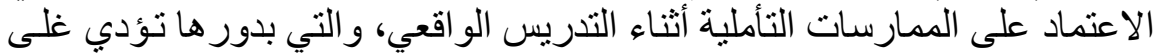

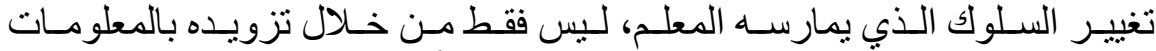

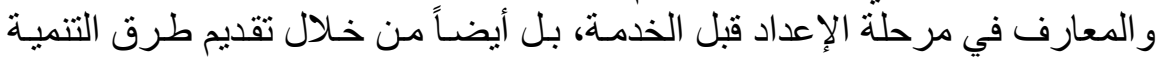

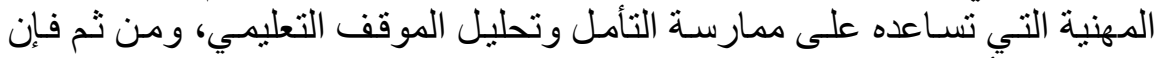

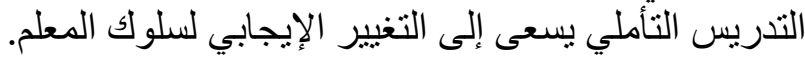

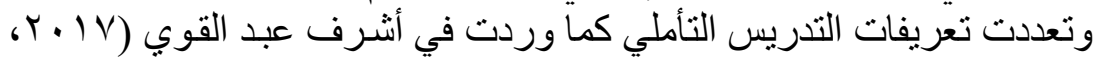

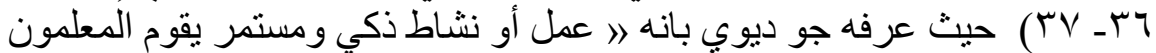

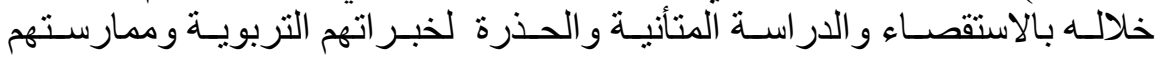

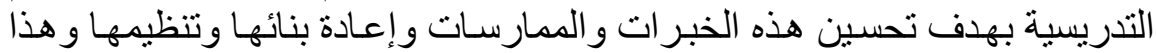

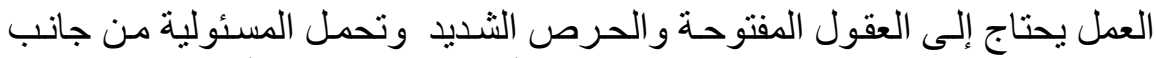
المعلمين، بينما عرفه Andrew Pollard بأنه 》" عملية دورية أو تصـاعدية يقوم

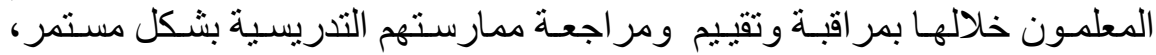

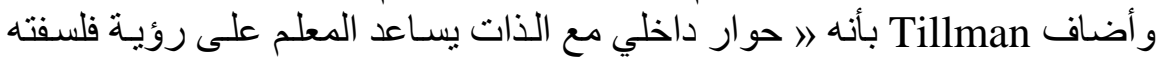

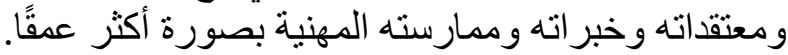

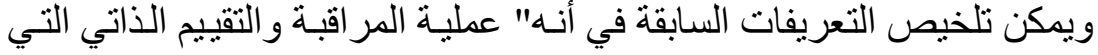
تتضمن عدد من الممارسات التي تقوم بها المعلمة وما تتضمنه هذه الممارسـات من
E. ISSN: 2735-4245
ISSN: 2536 - 914

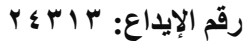
المجلة معرفة علي دوريات بنك المعرفة المصرى، و Edu Search دار المنظومة 
تخطيط وتنفيذ وتقويم لعمليـة التدريس بهدف إحداث تغييـر تحسين وتطوير هذه

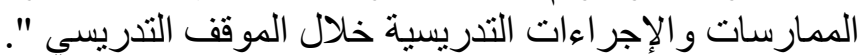

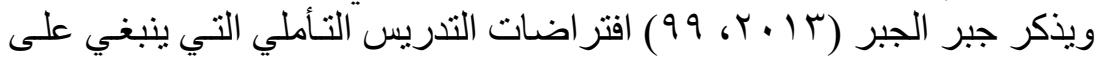

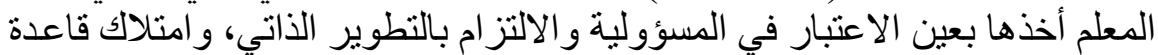

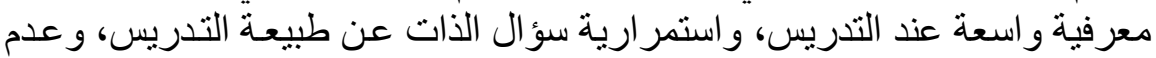

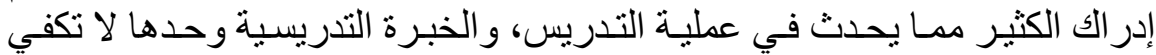
لاستمر ار النمو المهني، و التأمل الناقد المتأني للممارسات التدريسية يؤدي إلى فئ فهم أعمق للتدريس و المتعلمين.

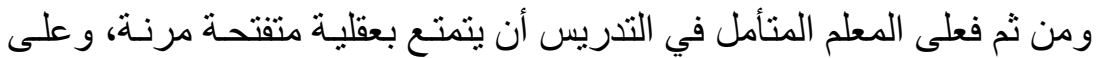

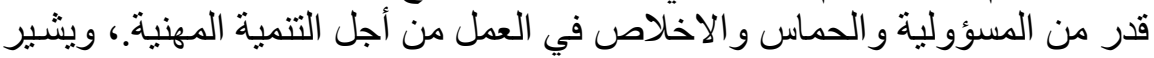

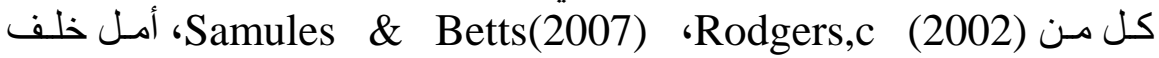

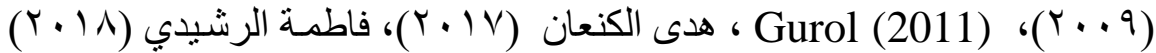

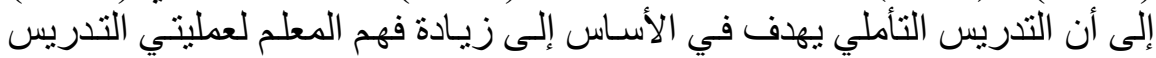

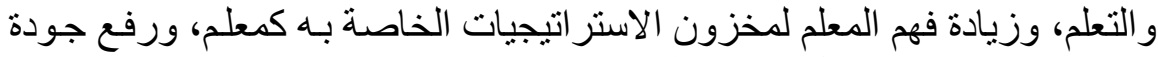
فرص التعلم لطلابه داخل الصف فئ الدرة اسي.

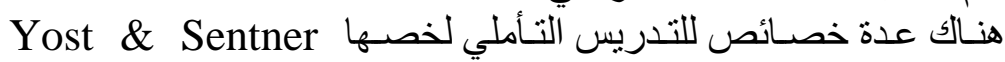

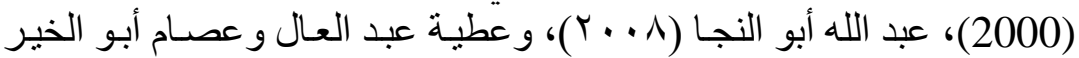

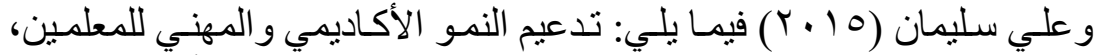

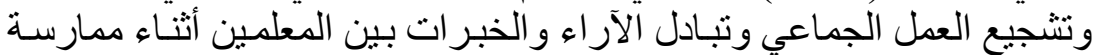

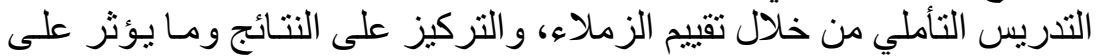

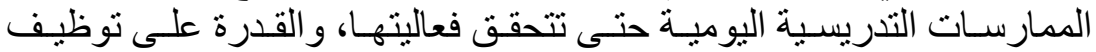

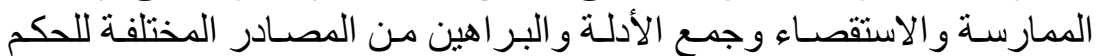

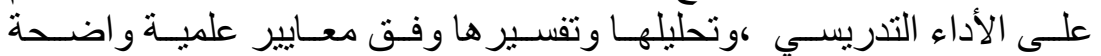

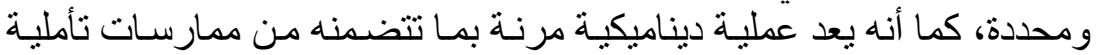

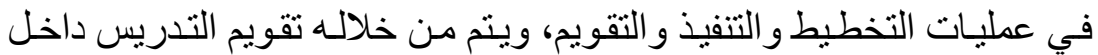

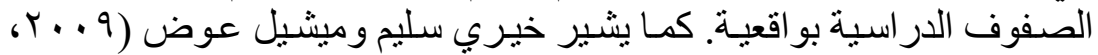

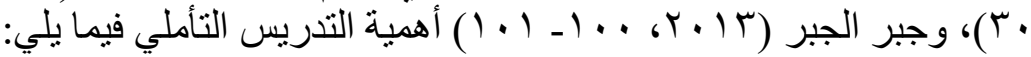

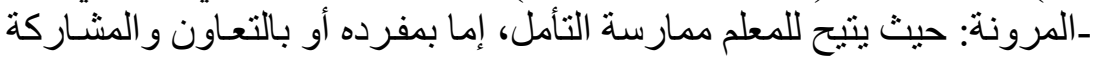

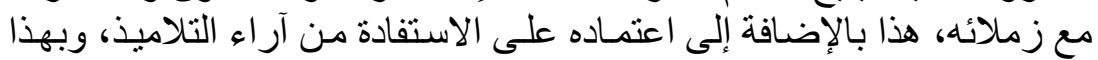

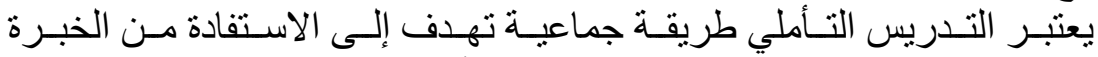
الشخصية للمعلم إلى جانب خبرة ومساهمة الأخرين.

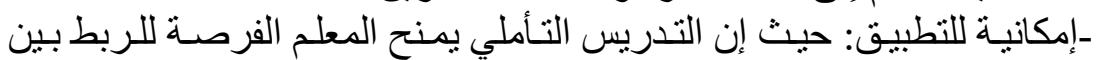
النظريات التربوية وكيفية تطبيقها فالو اقع الفعلي داخل حجرة التهبة الدر اسة.

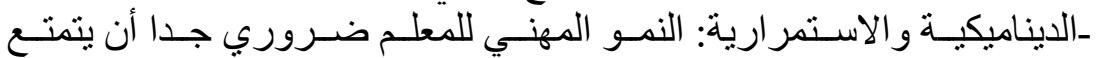

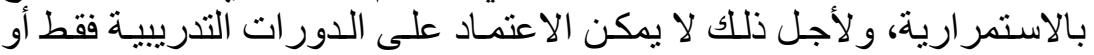
E. ISSN: 2735-4245
ISSN: 2536 - 914

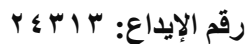
المجلة معرفة علي دوريات بنك المعرفة المصرى، و Edu Search دار المنظومة 
المـؤتمر ات وورش العمـل، بـل يسـعى التـدريس التـأملي للانخـر اط في العمـل

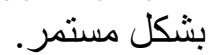

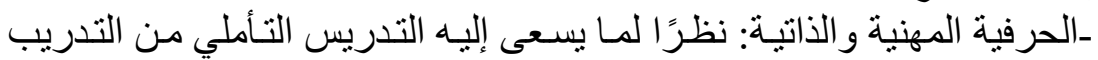

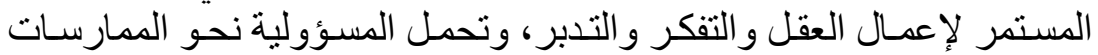

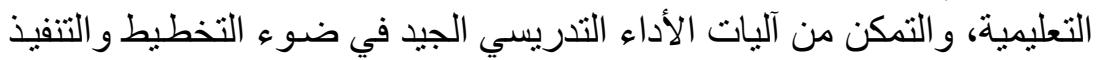

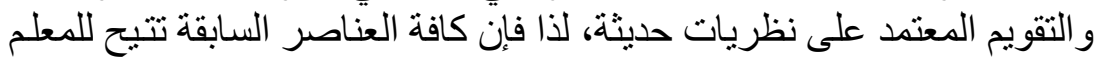
احتر اف المهنة واستيعاب كافة مستجداتها، ومن ثم تتميـة الكفايـات التدريسية

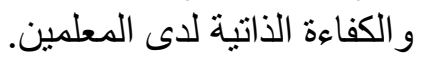

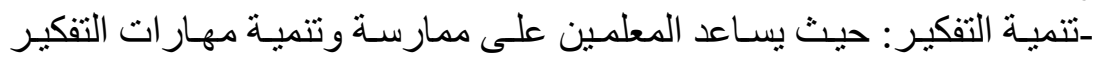

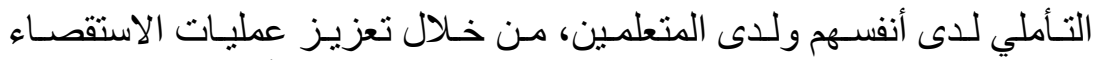

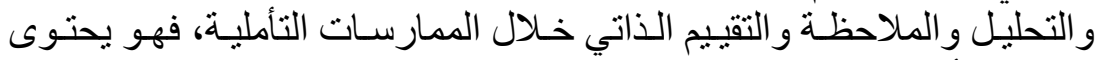
على عدة أنواع من التفكير منها الناقد و التحليلي و الإبداعي التهي.

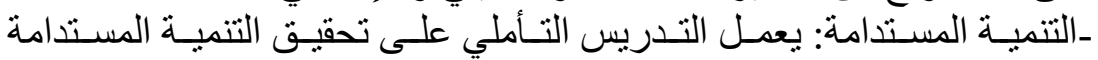

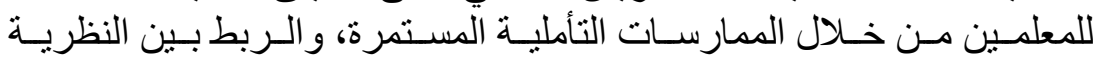

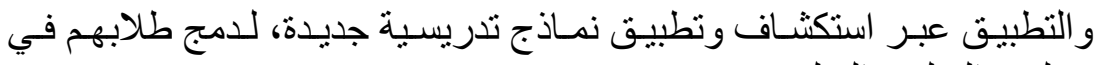

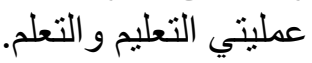

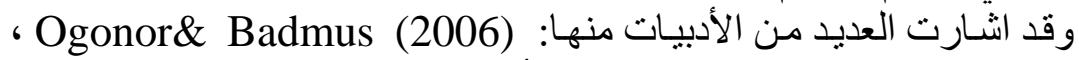

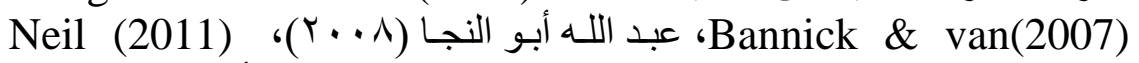

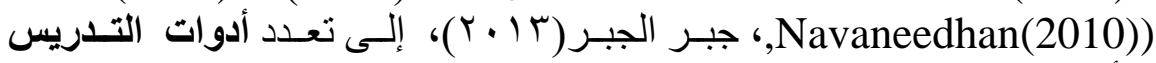

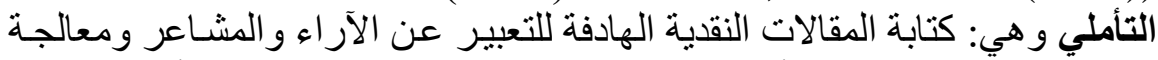

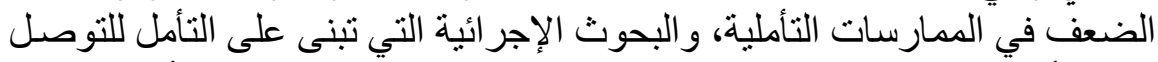

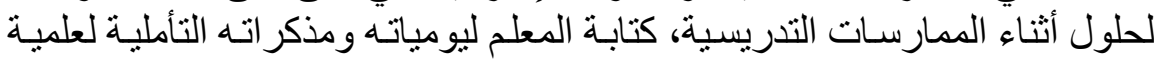

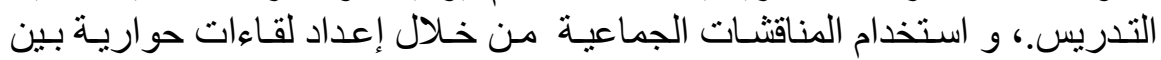

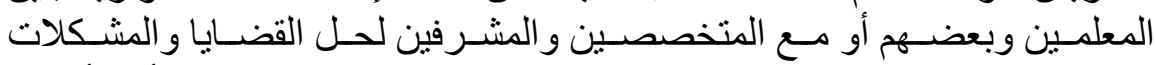

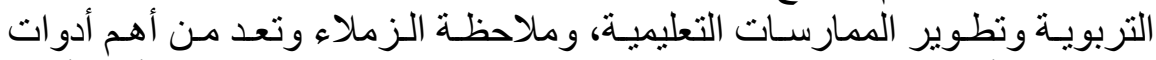

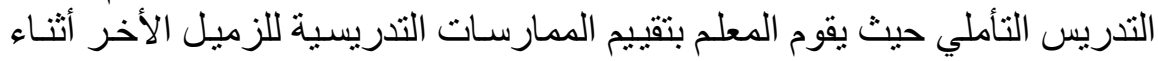
التدريس وتقديم التغذيـة الر اجعـة لضـمان استمر ار النمـو المهني، وكذلك استخدام

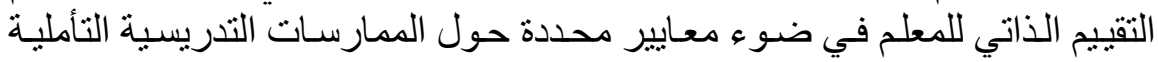

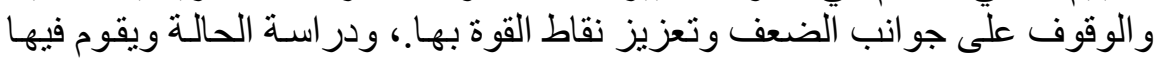

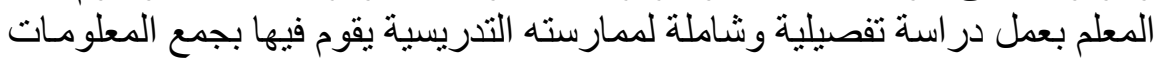

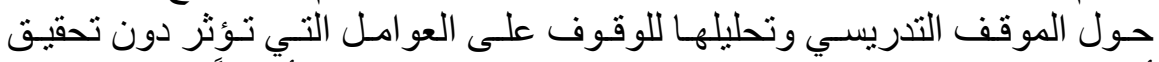

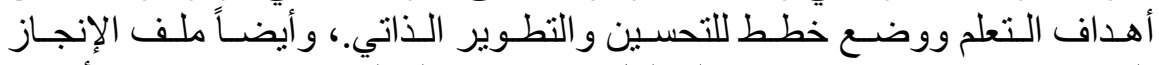

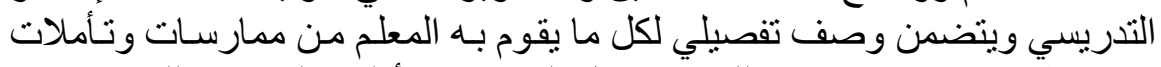

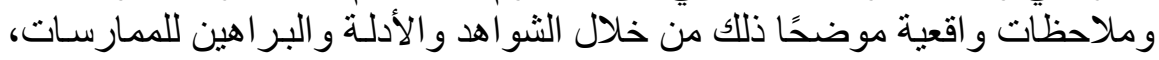
ووثائق النقد التأملي لهذه الممارسية موفحات والخطط التحسينية و التطويرية.

\footnotetext{
E. ISSN: 2735-4245

ISSN: 2536 - 914

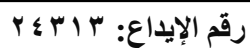

المجلة معرفة علي دوريات بنك المعرفة المصرى، و Edu Search دار المنظومة
} 


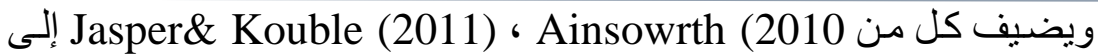

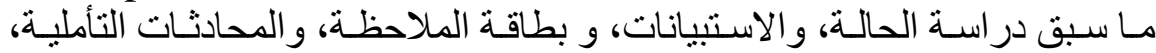

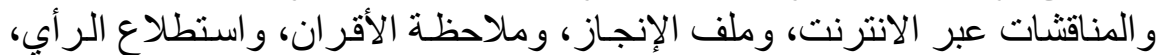

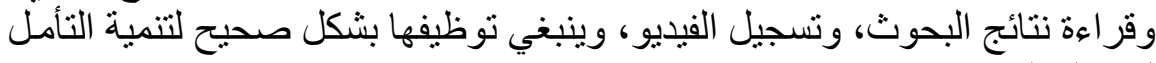

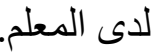

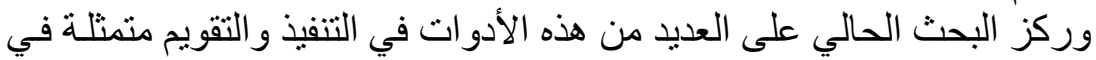

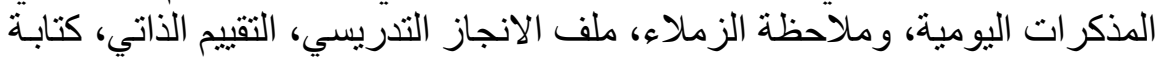

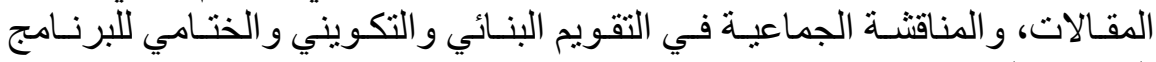

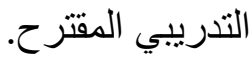
تانيًا: الكفاءة الأتية للمعلمين:

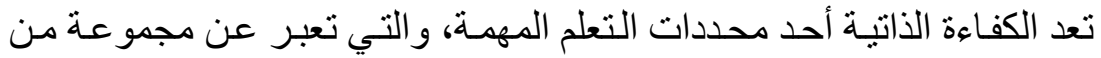

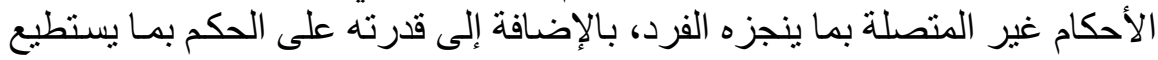

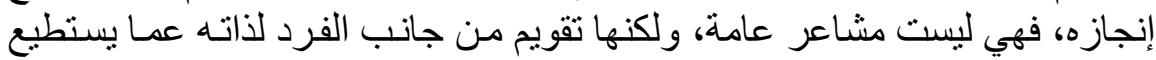

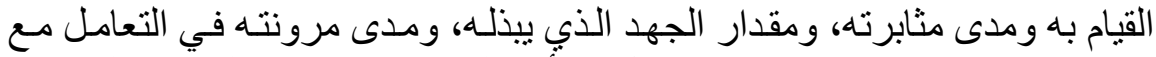

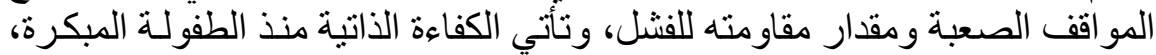

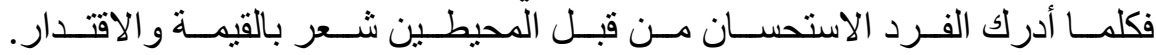

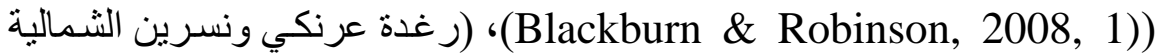

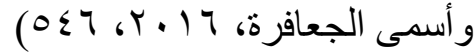

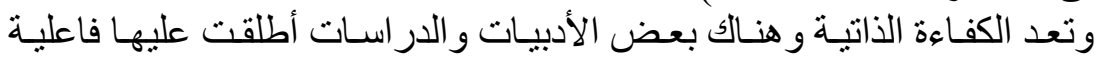

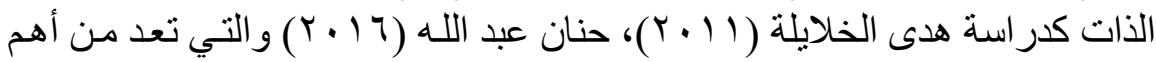

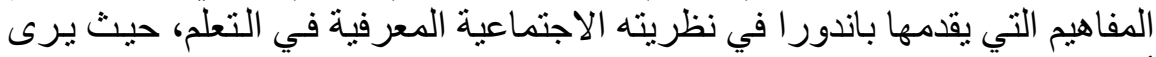

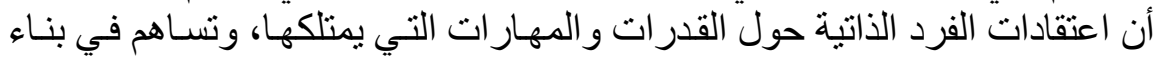
تقييماته الايجابية.

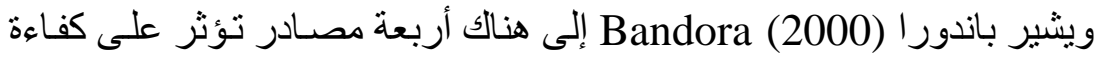

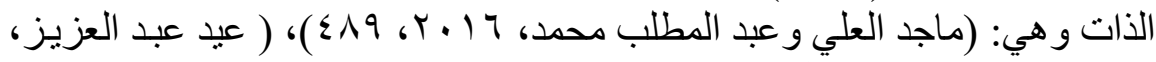

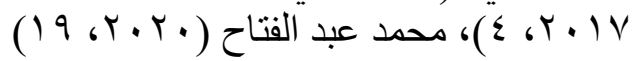

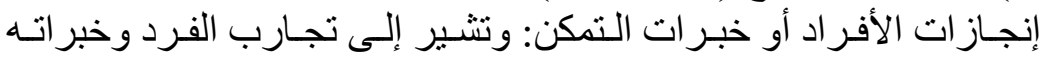

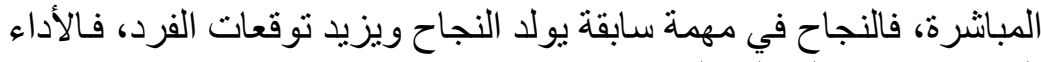
الناجح يزيد من لفاعلَية الذاتية.

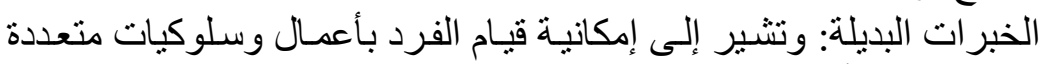
عندما يلاحظ أن من يشبهونه قادرين على القيان القيام به و العكس.

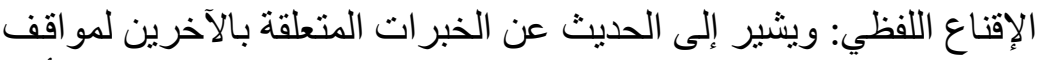

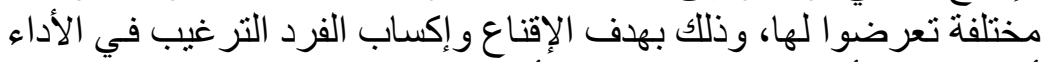
أو العمل والتأثير على سلوكه خلال أداء المهية.

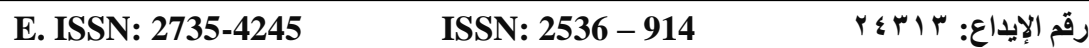

المجلة معرفة علي دوريات بنك المعرفة المصرى، و Edu Search دار المنظومة 
الاستثارة الانفعالية: وتشير إلى حالة الفرد عند أدائهه لبعض المهام لمعرفة المادة

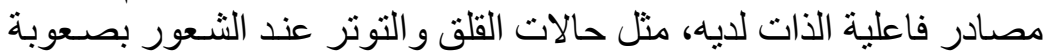
المهـة مدمان.

وقد اهتمت العديد من الدراسات بتنمية الكفاءة الذاتيـة لدى المتعلمين من خـلال

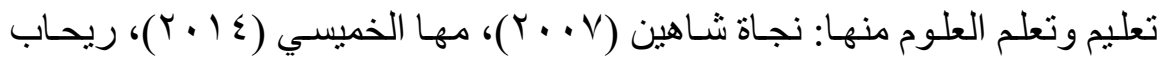

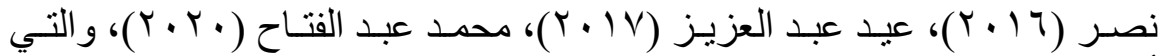

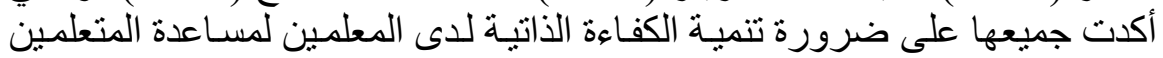

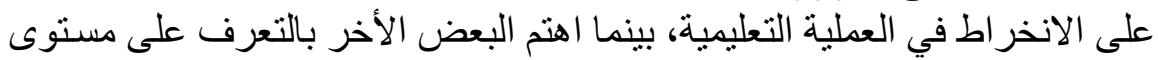

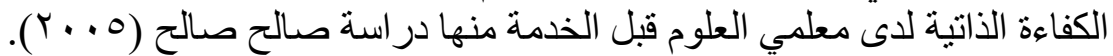

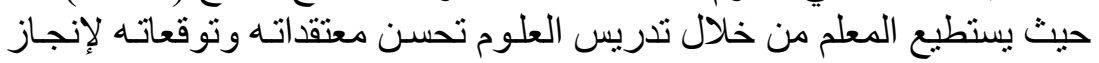

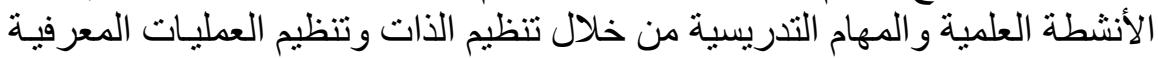
ومن ثم توجيه الذات إلى تحديد الأهداف واختيـار ات وتفضيلات التهن محددة لاستكمال المهةة و إنجاز ها، و المثابرة لبذل الجهد وتخطى العهى العقبات مع تخفيف الثعور بالقلق.

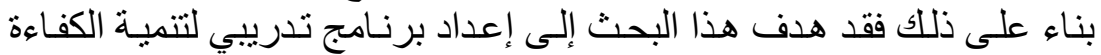

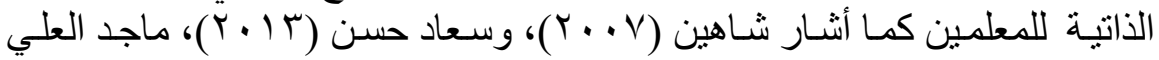

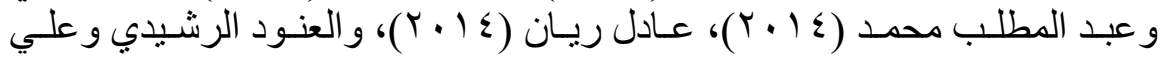

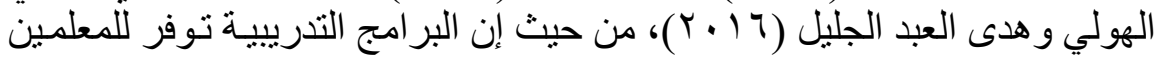

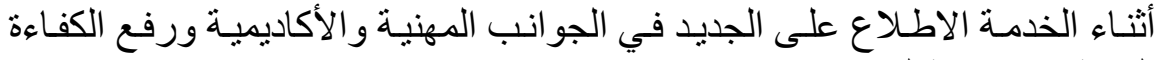

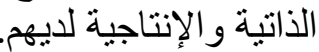

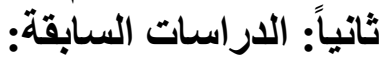

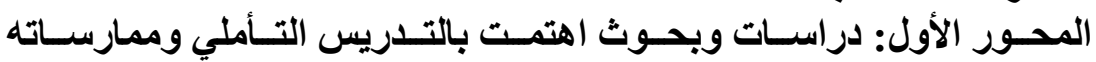

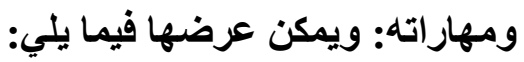

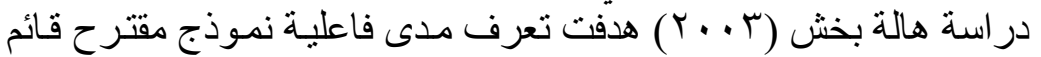

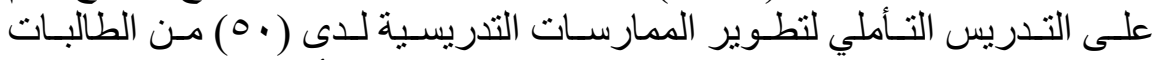

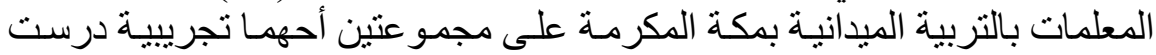

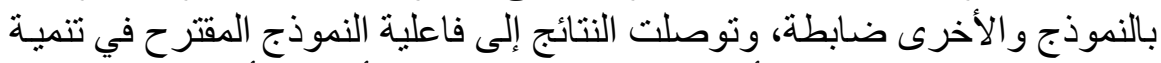

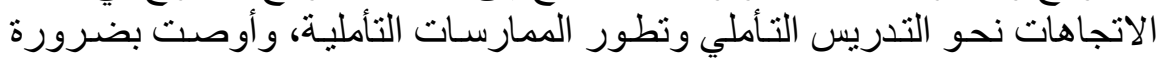
تضمين التدريس التأملي ببراتج امج إعداد المعلم.

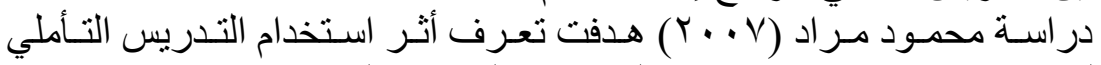

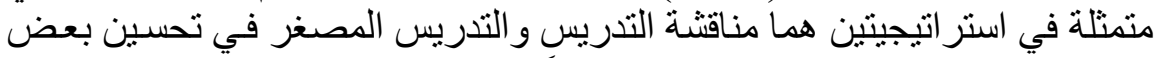

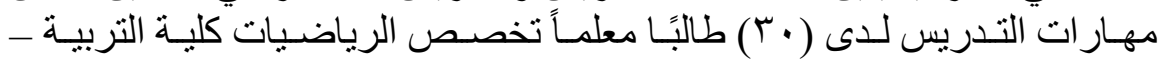

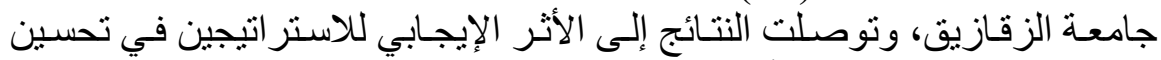

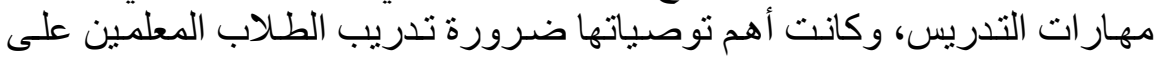
استخدام التدريس التأملي وتضمين استر اتيجياتها بالمقررات اتهات.

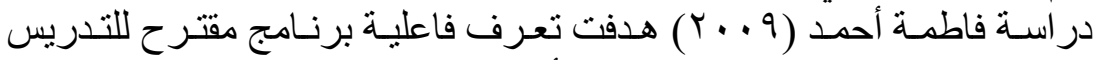

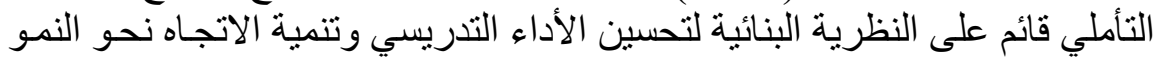
E. ISSN: 2735-4245
ISSN: 2536 - 914

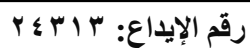
المجلة معرفة علي دوريات بنك المعرفة المصرى، و Edu Search دار المنظومة 
المهنـي لـدى عينـة مـن الطالبـات المعلمـات شـعبة الاقتصـاد المنزلـي بكليـة التربيـة

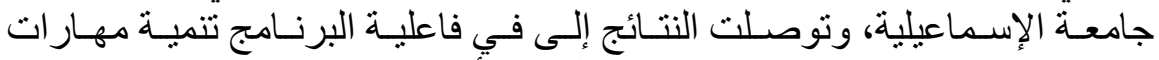

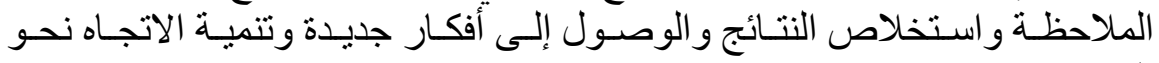
المهنة.

در اسة كوثر بلجون ( • ( • ) هدفت تعرف العلاقة بين ممارسـات التدريس

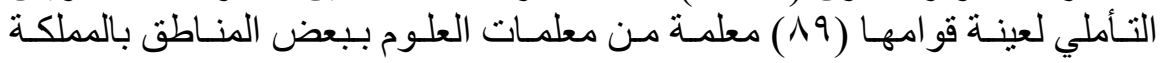

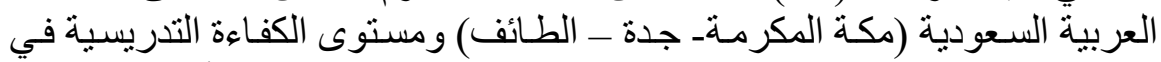

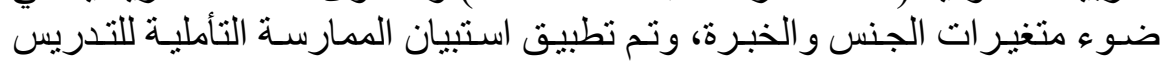

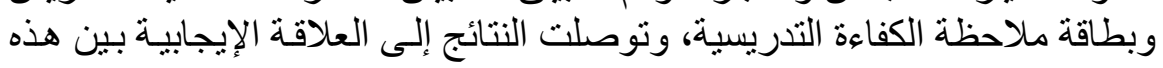

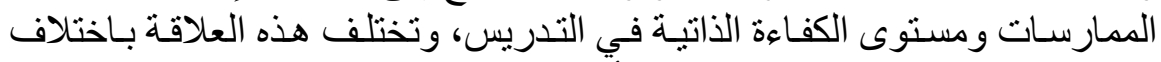

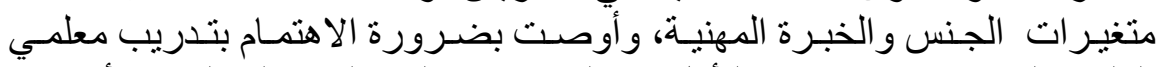

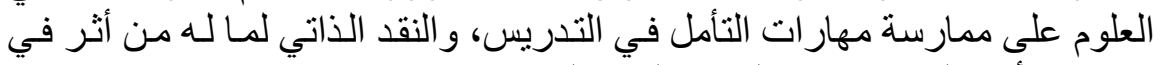
تحسين الأداء المهني ورفع الكفاءة الذاتية لديهم.

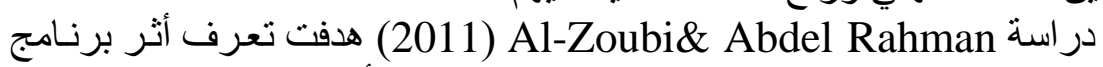
تدريبي في تحسين الكفاءة التدريسية لدى ( • (0) معلمًا بـالأردن، وتم استخدام بطاقة

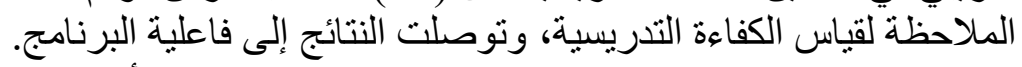

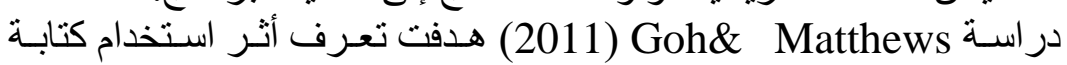

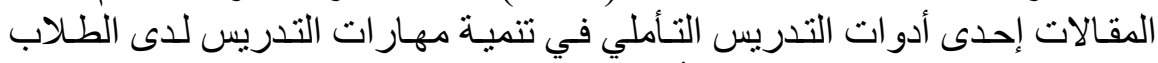

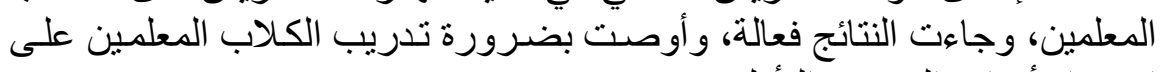
استخدام أدو ات التدريس التأملي.

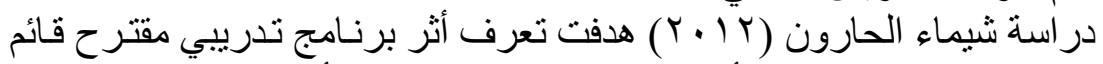

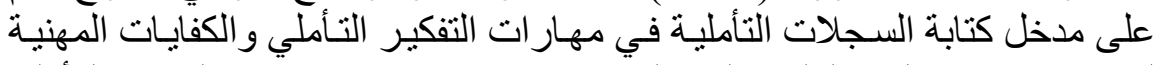

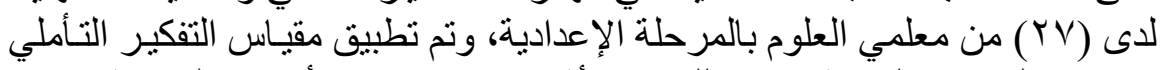

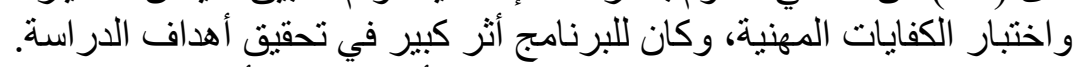

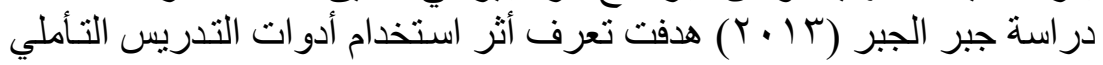

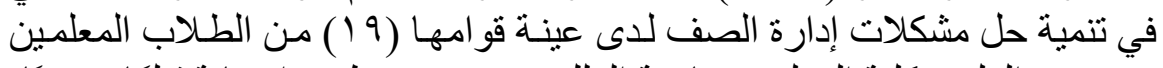

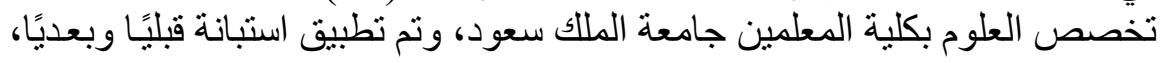

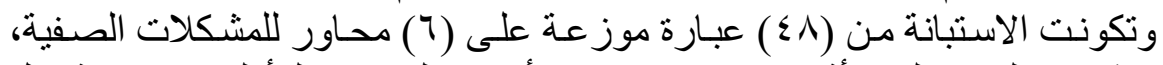

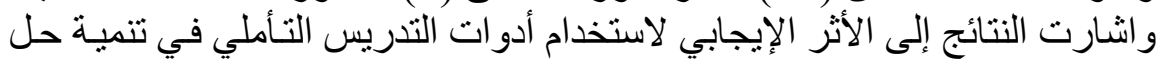

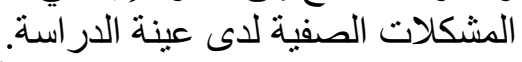

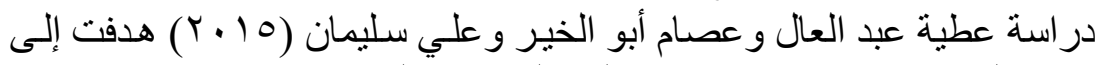

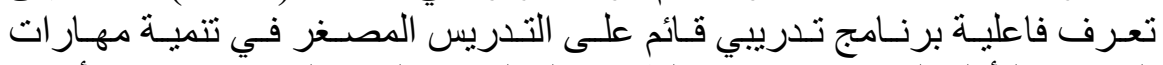

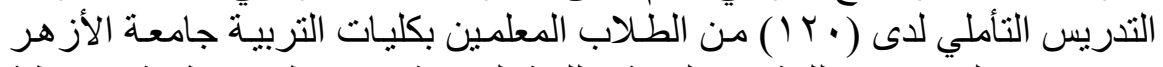

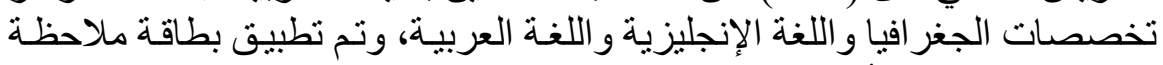
مهار ات التدريس التأملي واختبار تحصيلي للجوانب المعرفيـة للمهار ات، ومقيـاس
E. ISSN: 2735-4245
ISSN: $2536-914$

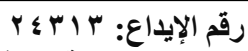
المجلة معرفة علي دوريات بنك المعرفة المصرى، و Edu Search دار المنظومة 


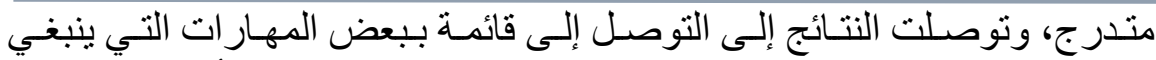
تو افر ها لدى العينة، وفاعلية البرنامج في تنمية مهار ات التدريس التأتوفي.

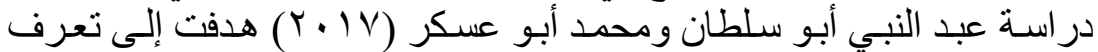

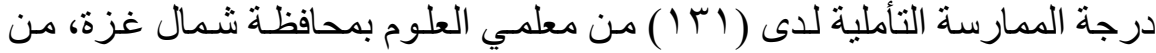

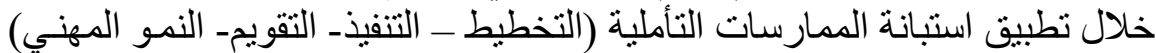
، وتوصلت النتائج إلى ارتفاع مستوى الممارسات التأملية لدى المعلمين بشكل عـام وفي مهارة التنفيذ بشكل أكبر.

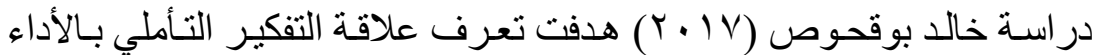

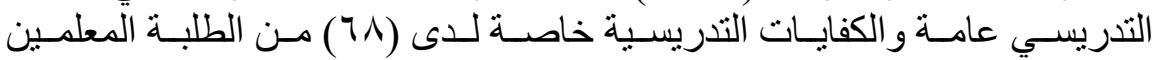

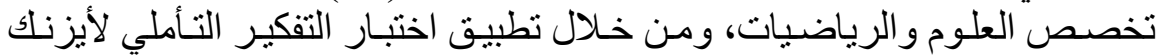

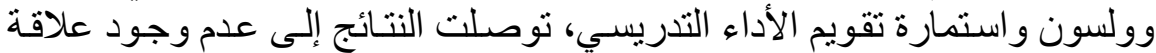

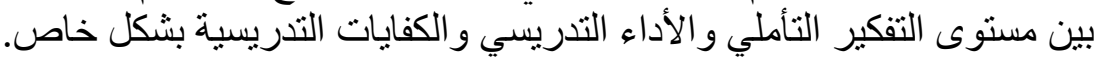

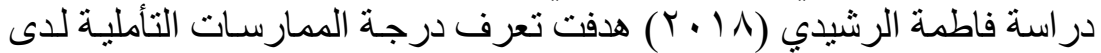

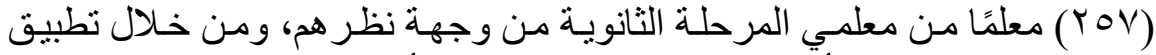

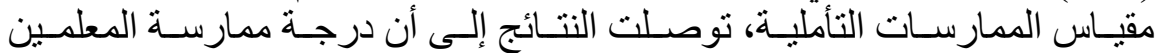

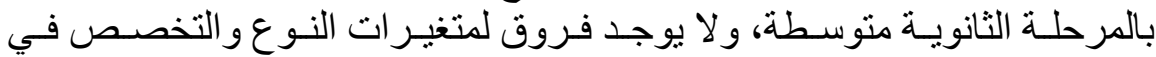
مستوى الممارسات.

المحور الثاني: الدراسات التي اهتمث بتثمية الكفاعة الذاتية لاتى المعلمين:

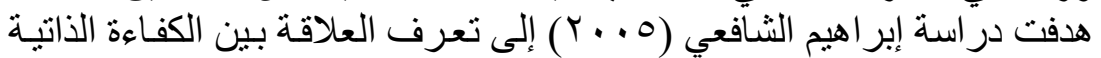

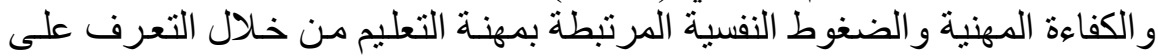

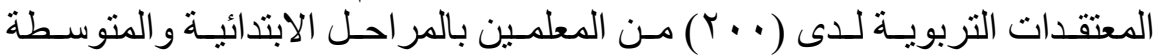
و الثانوية وطلاب كلية التربية، وتوصلت النتائج إلى وجود علقة طردية بـدية بين الكفاءة

الذاتية و الكفاءة المهنية.

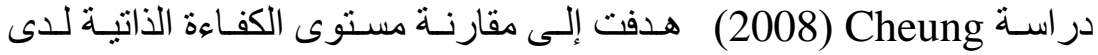

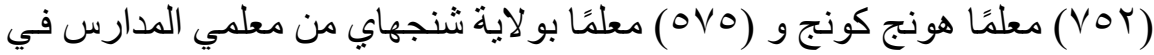

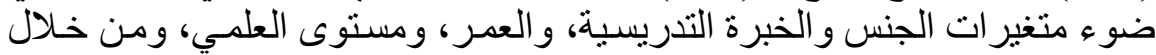

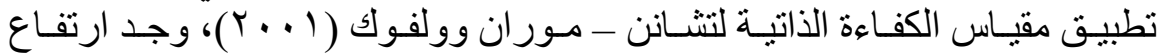

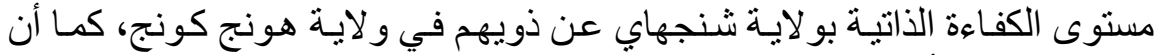

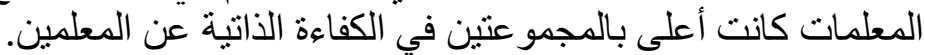

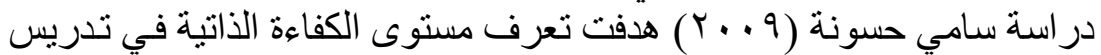

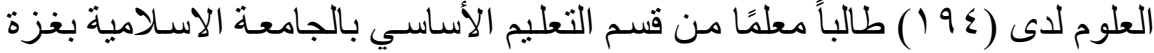

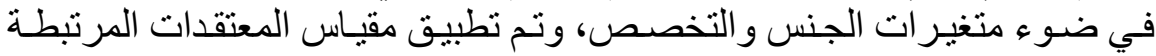
بكفاءة العلوم، وتوصلت النتائج إلى تو افر الكفاءة الذاتية بدرجة متوسط غلى مرتى مرتفع

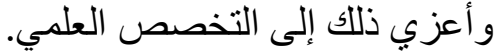

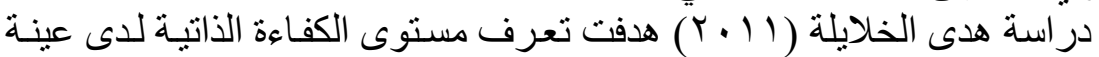

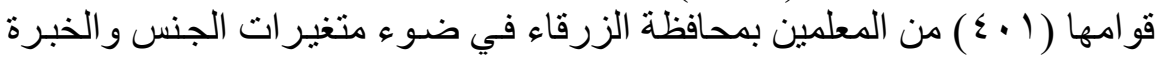
E. ISSN: 2735-4245
ISSN: 2536 - 914

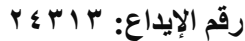
المجلة معرفة علي دوريات بنك المعرفة المصرى، و Edu Search دار المنظومة 


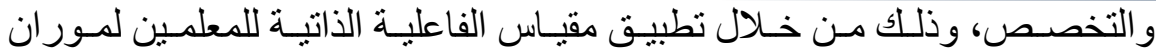

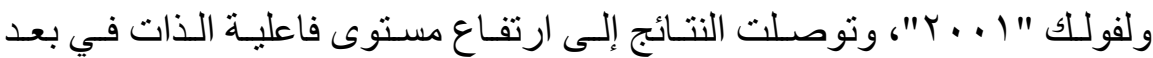
الإدارة الصفية، و أقلها في بعد مشاركة الطلاب في العملية التعليمية.

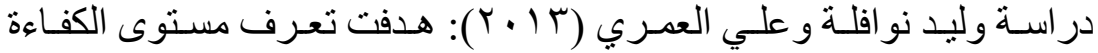

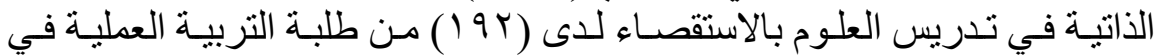
جامعة اليرموك في ضـوء متغير ات الجنس و التقدير بالجامعـة، وتم تطبيق مقيـاس

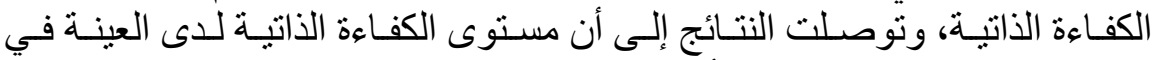
تدريس العلوم بالاستقصاء كان أقل من المستوى المقبول ( •^^\%).

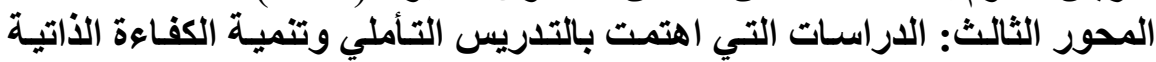

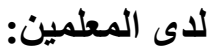
در اسة Buss (2010) هدفت إلى تقصي مستوى الكفاءة الذاتية لدى الطلاب

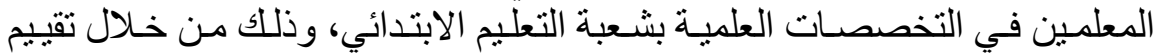
ممارساتهم التدريسية، وتم إعداد مقياس الكفاءة الذاتية، وتوصلت التتائج إلى تلى تدني

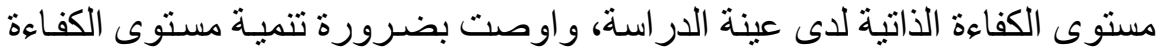

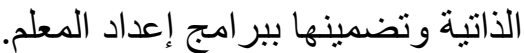

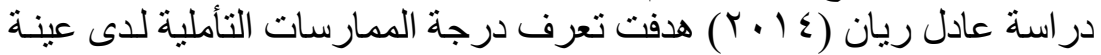

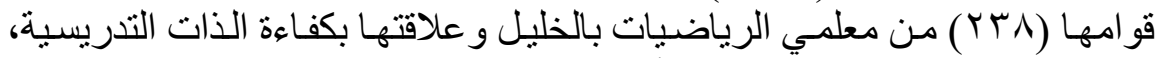

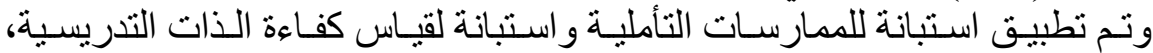

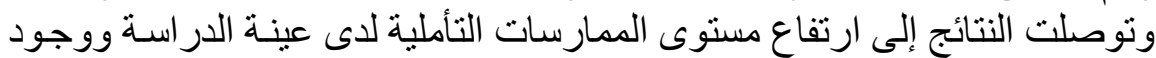
علاقة موجبة بين المتغيرين.

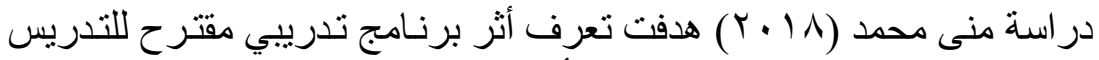

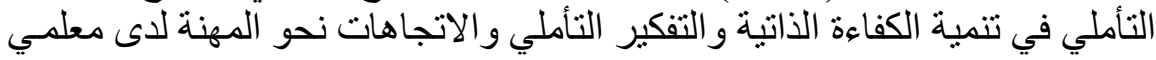

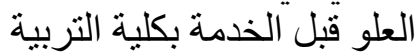

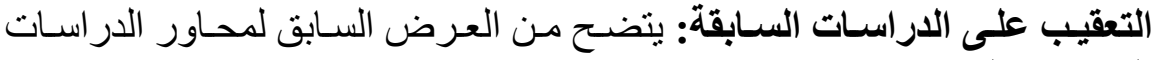

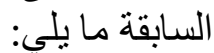

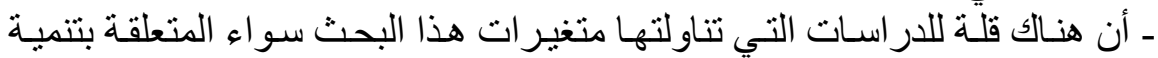

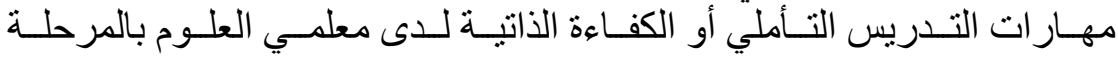

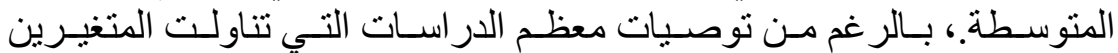

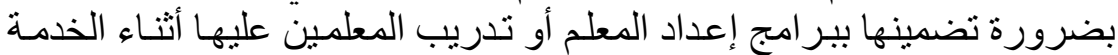
وفي العلوم خاصة لما تحتاجه أنشطته للتأمل.

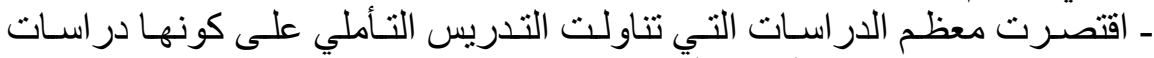

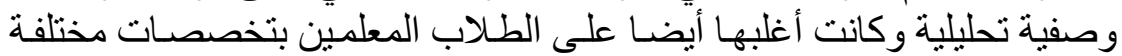

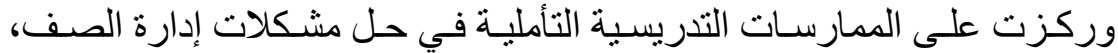
وقلمسا إن وجدت در اسـة تجريبيـة لتدريب معلمي العلـوم خاصـة على مهـار ات التدريس التأملي.

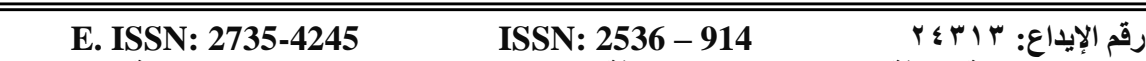
المجلة معرفة علي دوريات بنك المعرفة المصرى، و Edu Search دار المنظومة
} 
ـ كذلك الدر اسـات التـي اهتمـت بالكفـاءة الذاتيـة كانـت در اسـات وصـفية تحليليـة،

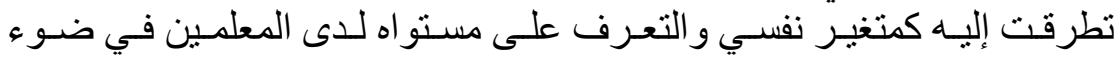

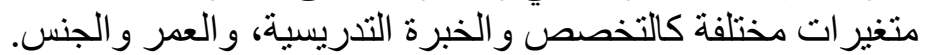

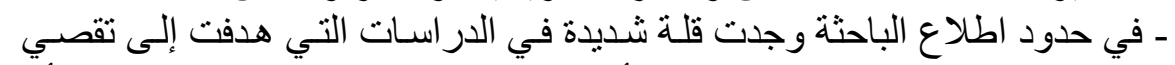

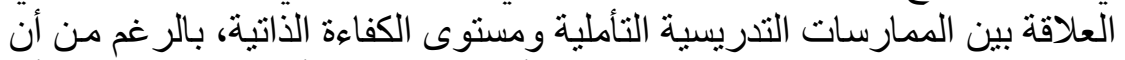

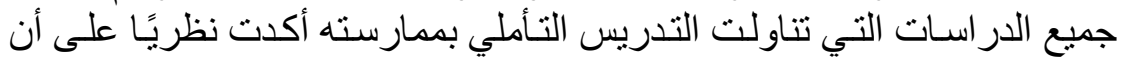
هنا كعلاقة إيجابية بين هاذين المتغيرين، ولم تبحت فئ تجريبيًا.

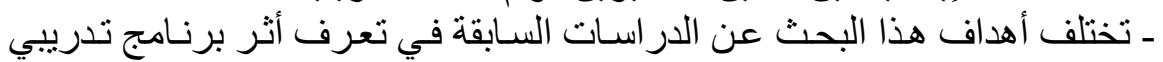

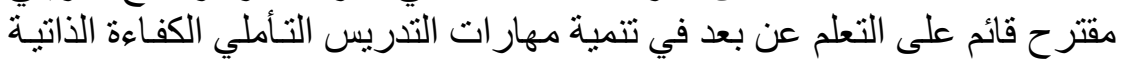

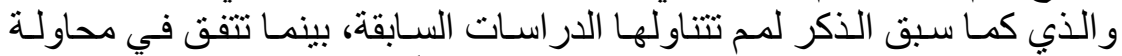
التعرف على العلاقة بين المتغيرين نظريًا وتجريبياً. الإجراعات المنهميـة للبحث: للتوصـل إلى الإجابـة عن أسئلة البحثث تم القيـام

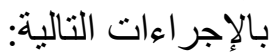

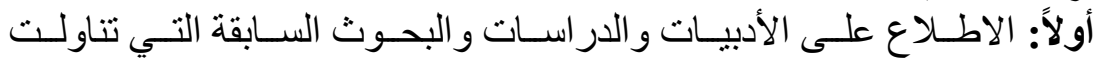

$$
\text { متغير ات البحث. }
$$

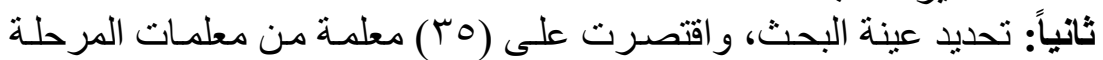

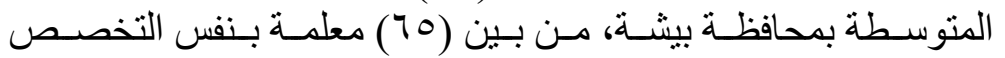

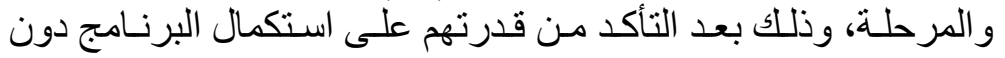

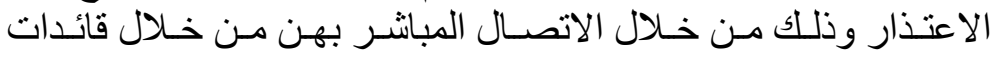

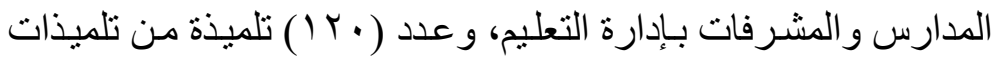
المعلمات عينة البحث اللاتي سيطبق عليهن مقياس التفكير التأملي.

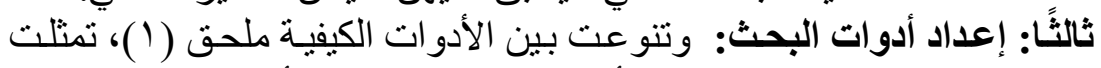

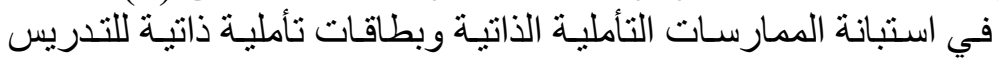

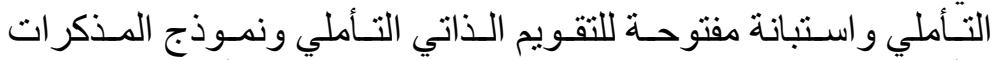

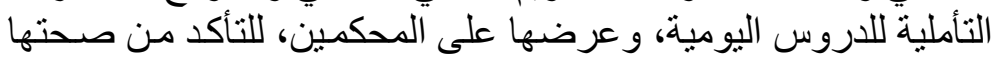

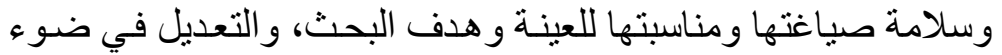

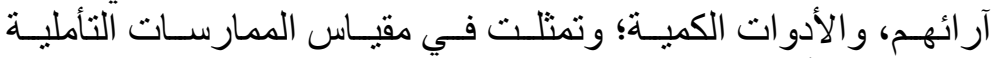

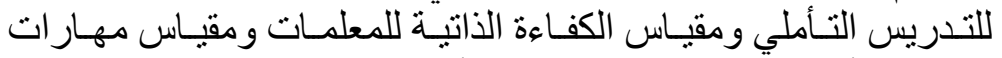

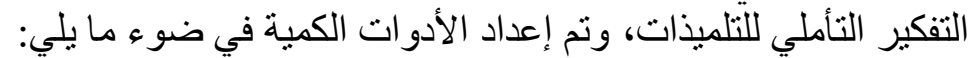
-إعداد مقياس ممارسات التلريس التأملي، وذلك في ضو ضو مايلي:

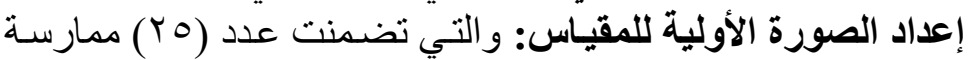

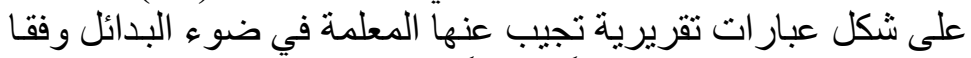

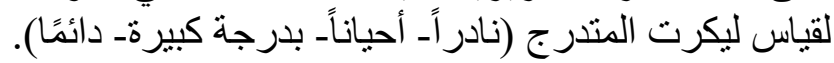
حساب صدق المقياس: وذلك من خلابل المثل

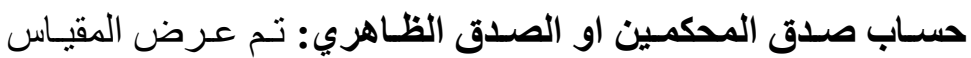

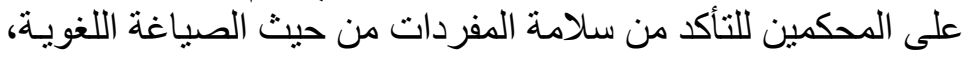

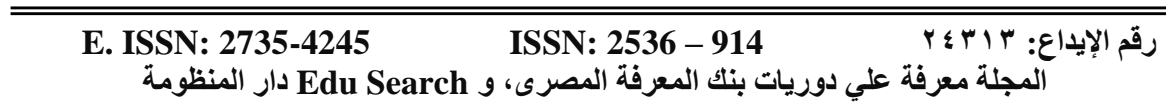


و مناسبة البدائل لكل مفردة وسلامتها اللغوية، التأكد أن المقياس وضـع

من أجل تحقيق الهدف منهه، وتم حذف مفردة غير و اضحة الصياغة الصنة

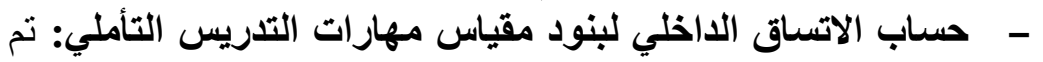

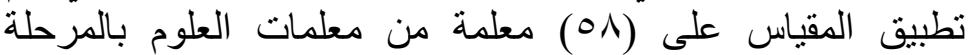

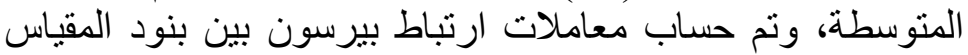

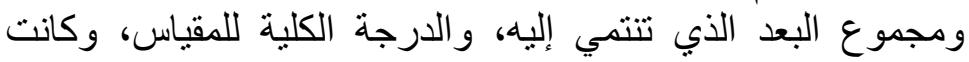

$$
\text { النتائج كما هي مبنية في الجدول (1) (ل). }
$$

جدول معامات الاتساق الداخلي لبنود مقياس مهارات التدرببس التأملي

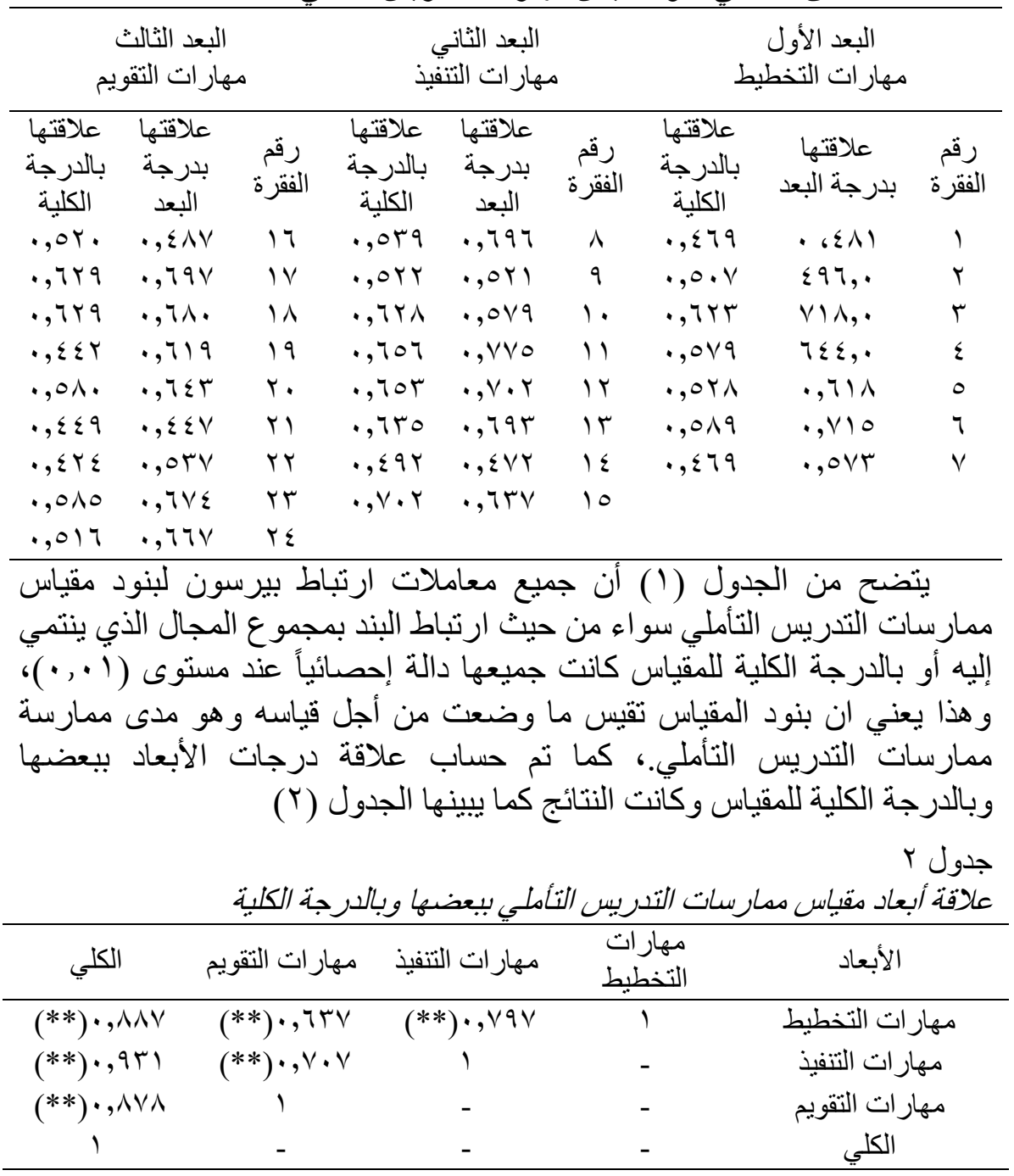




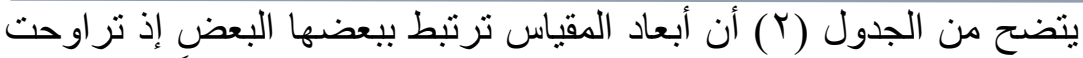

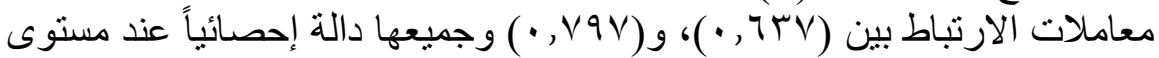

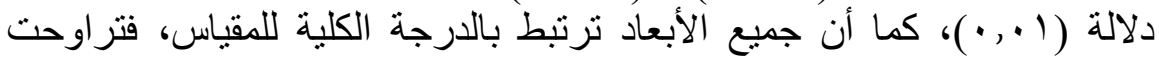

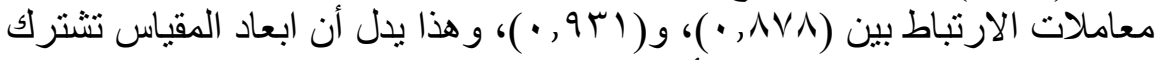
جميعها في قياس ما وضعت من أجل فياسه.

- ســاب ثبـات المقيـاس: تـم حسـاب ثبـات مقيـاس مهــار ات التـدريس التـأملي

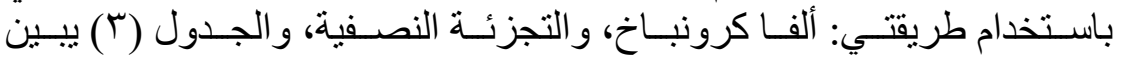

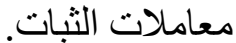

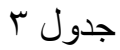
معاملات ثبات مقياس مهار ملت التنربس التأملي بطريقتي ألفا كرونباخ والتجزئة النصفية التهية معامل الثبات بعد التصحيح بمعادلة سبير مان بر اون التص

معامل بيرسون بين النصفين
معامل ألفا كرونباخ معامل

م أبعاد المقياس

\begin{tabular}{|c|c|c|c|c|}
\hline$\cdot, V V$ & . Tr & $\cdot, V_{1}$ & مهار اتخطيط & 1 \\
\hline$\cdot, V \varepsilon$ & $\cdot, 01$ & $\cdot, \wedge$. & مهار ات التنفيذ & r \\
\hline$\cdot, \sqrt{ } \times 4$ & $\cdot, 7)$ & $\cdot, \mathrm{VA}$ & مهار ات التقويم & $r$ \\
\hline$\cdot, \lambda)$ & $\cdot, 7 \wedge$ & $\cdot, 9$ & اللرجة الكلية & //I \\
\hline
\end{tabular}

يتضح من الجدول (ب) أن معاملات ثبات الأبعاد بطريقة ألفا كرونباخ

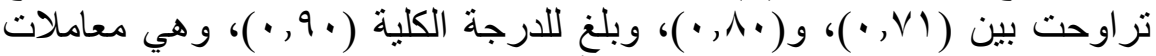

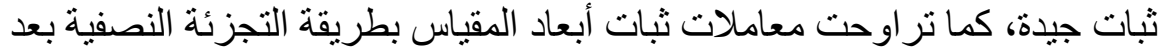

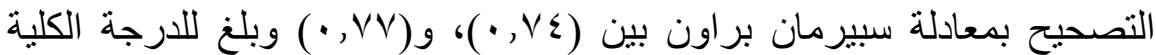

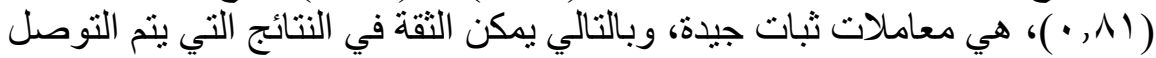
إليها باستخدام المقياس.

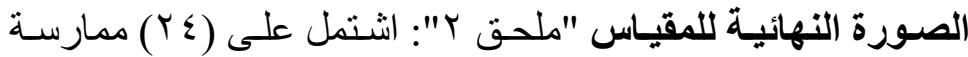

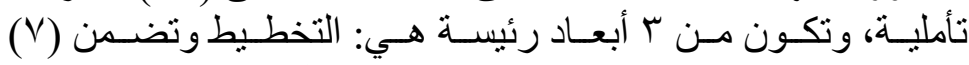

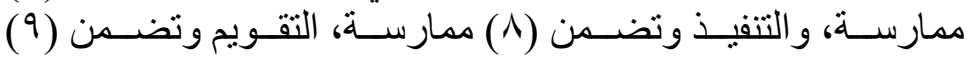
ممار مسة.

ـ إعداد الاختبار التحصيلي المعرفي للبرنامج، وذلك في ضوء الخطو ات التالية:

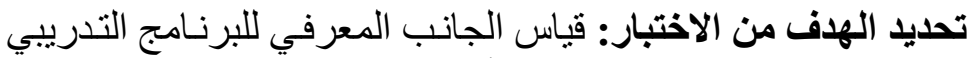
المقترح في ممارسات التدريس التأملي.

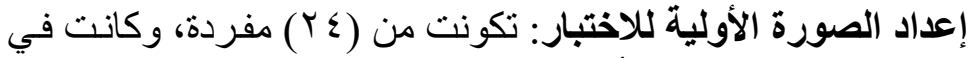

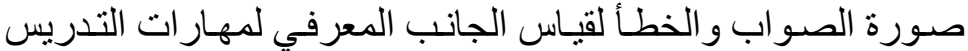
التأملي. حساب صدق الاختبار: وذلك من خلال:
E. ISSN: 2735-4245
ISSN: 2536 - 914

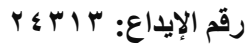
المجلة معرفة علي دوريات بنك المعرفة المصرى، و Edu Search دار المنظومة

$1 \wedge$. 
- حساب صدق المحكمين: تم عرض الاختبار على المحكمين للتأكد من سلامة

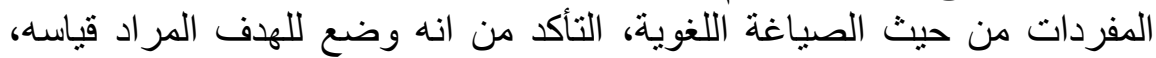
و مناسبته للمستويات المعرفية التي تم بناء المفردات في ضونئها (التذكر - الفهم).

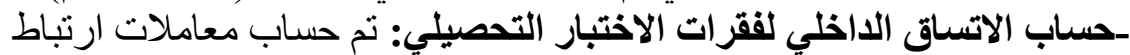

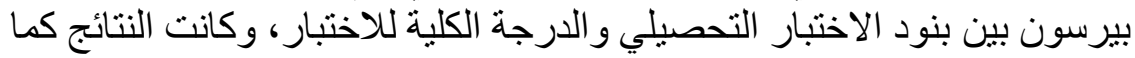

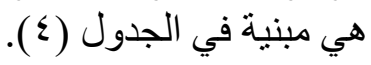

جدول

\begin{tabular}{|c|c|c|c|c|c|}
\hline التمبيز & رقم الفقرة & التمييز & رقم الفقرة & التمبيز & الفقرة \\
\hline., 007 & IV & $\cdot, \xi \wedge \varepsilon$ & 9 & $\cdot, 7 \leqslant$. & 1 \\
\hline עדז, • & 11 & $\cdot, \varepsilon r \leqslant$ & 1. & . & r \\
\hline., $0 \leq \leqslant$ & 19 &., $0 \wedge \mathrm{V}$ & 11 & $\cdot, \Sigma \vee T$ & r \\
\hline ., or 9 & $r$. &.,$\leqslant 7$. & ir & q & $\varepsilon$ \\
\hline • & YI & $\cdot, \leqslant \wedge \uparrow$ & IT & $\cdot, 0 \leqslant \leqslant$ & 0 \\
\hline., 007 & r &., 011 & $1 \varepsilon$ &., $0 . r$ & 7 \\
\hline., 007 & r &., $0 \mathrm{~V}$. & 10 &.,$\Sigma \ldots$ & V \\
\hline., $0 \wedge$. & $r \varepsilon$ & $\cdot, \leq \leqslant 0$ & 17 & $\cdot, \Sigma T V$ & $\wedge$ \\
\hline
\end{tabular}

يتضح من الجدول (ع) أن جميع معاملات ارتباط بيرسون لبنود الاختبار

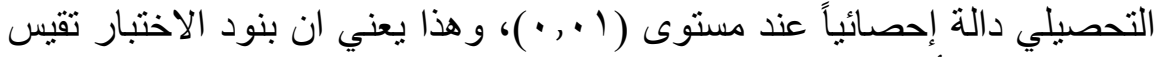
ما وضعت من أجل قياسه.

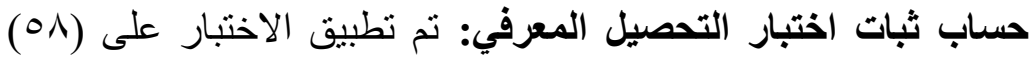

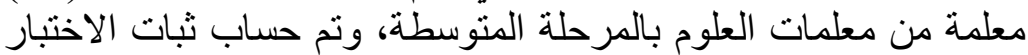

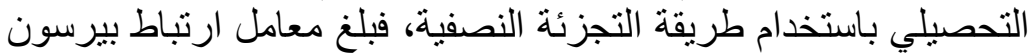
بين نصفي الاختبار (70, • ) وبعد التصحيح بمعادلة سبيرمان بان براون

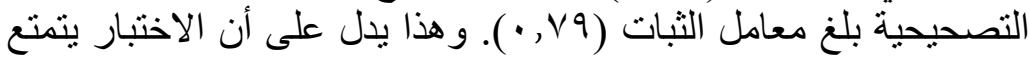
بدرجة مقبولة من الثبات. حساب معاملي السهولة والصعوبة لفقرات الاختبار: تم حساب معاملي

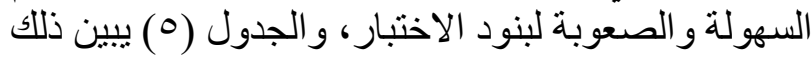

\begin{tabular}{|c|c|c|c|c|c|}
\hline السـهولة & الصعوبة معاملة & رقم الفقرة & السهولة & الصعوبة & الفقرة \\
\hline$\cdot, r \Lambda$ & $\cdot, T Y$ & $1 \pi$ &., $0 \leqslant$ &., 00 & 1 \\
\hline$\cdot, \mu \wedge$ & $\cdot, T Y$ & $1 \varepsilon$ & $\cdot, \varepsilon$. & $\cdot, 7$. & r \\
\hline - , $\varepsilon$. & - 7 . & 10 & • , & $\cdot, 79$ & r \\
\hline$\cdot, O Y$ & $\cdot, \sum \wedge$ & 17 & $\cdot, \varepsilon \vee$ & .,OT & $\varepsilon$ \\
\hline •, $\leqslant 1$ &., 09 & IV & • &., 79 & 0 \\
\hline
\end{tabular}

E. ISSN: 2735-4245

ISSN: 2536 - 914

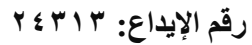

المجلة معرفة علي دوريات بنك المعرفة المصرى، و Edu Search دار المنظومة 
المجلة المصرية للتربية العلمية المجلد الرابع والعشرون العدد الرابع أكتوبر اب.rم

\begin{tabular}{|c|c|c|c|c|c|}
\hline السهولة & الصعوبة معلة & رقم الفقرة & السهولة & الصعوبة معامل & الفقرة \\
\hline$\cdot, \leqslant V$ & $\cdot, 0 r$ & 11 & $\cdot, \varepsilon \cdot$ &., 7. & 7 \\
\hline$\cdot, \Sigma 1$ & $\cdot, 09$ & 19 & Tr, & $\cdot, T V$ & V \\
\hline$\cdot, \leqslant \wedge$ & - , Or & $r$. & سז, • & $\cdot, T V$ & $\wedge$ \\
\hline$\cdot, \leqslant V$ & •, Or & YI & $\cdot, \varepsilon 1$ &., 09 & 9 \\
\hline$\cdot, \leqslant T$ & $\cdot, 0 \mathrm{~V}$ & rr & 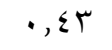 &., $0 \mathrm{~V}$ & 1. \\
\hline$\cdot, T_{1}$ & $\cdot, 79$ & Tr & דז, • & $\cdot, 7 \varepsilon$ & 11 \\
\hline$\cdot, \leqslant 1$ & $\cdot, 09$ & $r \varepsilon$ & $\cdot, M_{1}$ &., 79 & ir \\
\hline
\end{tabular}

يتضح من الجدول (0) أن جميع فقرات الاختبار التحصيلي تتمتع بمعاملات

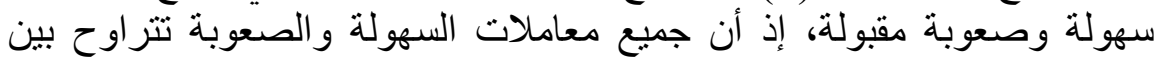

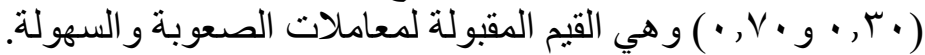
رابعًا: حساب معامل تمييز الاختبار التحصيلي: ولانيز

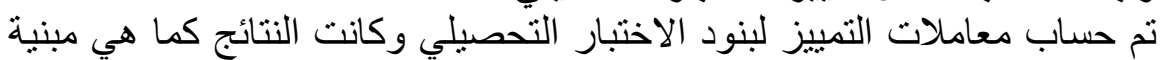

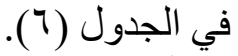
جدول 1 معاملات التمبيز لبنود اختبار التحصبل المعرفي.

\begin{tabular}{|c|c|c|c|c|c|}
\hline معامل التمييز & رقم الفقرة & معامل التمبيز & رقم الفقرة & معامل التمبيز & رقم الفقرة \\
\hline$\cdot, \leqslant 9$ & IV & $\cdot, \varepsilon Y$ & 9 &., 09 & 1 \\
\hline . & 11 & هـ, . & 1. & r, & r \\
\hline$\cdot, \leqslant \wedge$ & 19 & r, or & 11 & $\cdot, \S)$ & r \\
\hline . & $r$. & • & ir & $\cdot, \S \vee$ & $\varepsilon$ \\
\hline . & r) &.,$\Sigma Y$ & r & $\cdot, \leqslant \wedge$ & 0 \\
\hline$\cdot, \leqslant 9$ & rr & $\cdot, \leqslant 0$ & $1 \varepsilon$ & $\cdot, \leq \leqslant$ & 7 \\
\hline., 0 . & rr &., 01 & 10 & חז, . & V \\
\hline , or & $r \varepsilon$ & $\cdot, r v$ & 17 & $\cdot, r V$ & $\Lambda$ \\
\hline
\end{tabular}

يتضح من الجدول (†) أن جميع معاملات التمييز لبنود الاختبار التحصيلي تتمتع بمعاملات تمييز مقبولة.

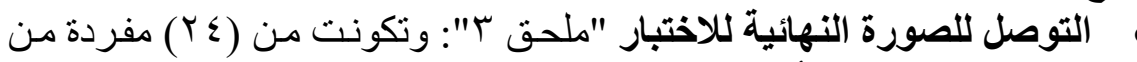

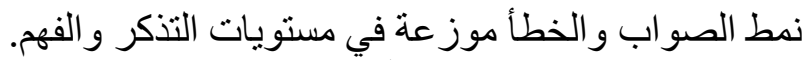

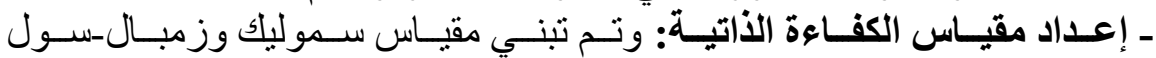
ويـودر(Smolleck, Zembal-Saul, Yoder, 2006) بدر اســة النوافلــة

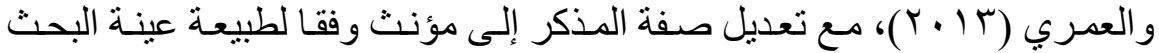

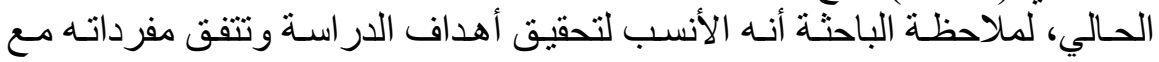

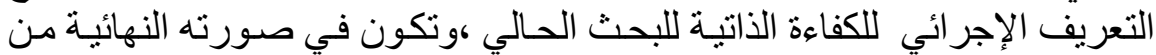

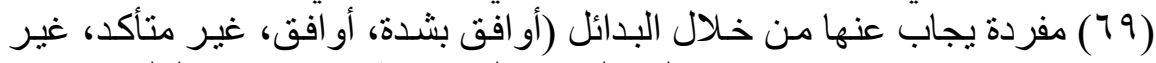

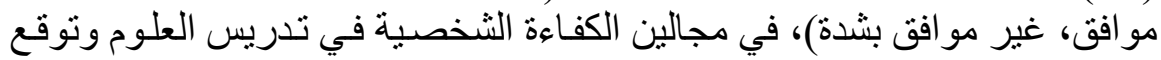

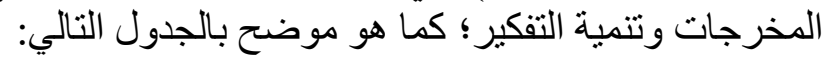

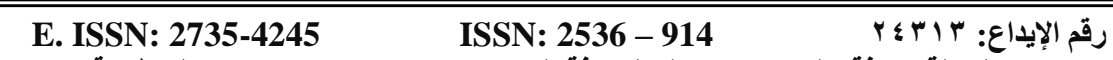
المجلة معرفة علي دوريات بنك المعرفة المصرى، و Edu Search دار المنظومة 


\begin{tabular}{|c|c|c|}
\hline & \multicolumn{2}{|c|}{ مواصفات مقباس الكفاءة الذاتبة } \\
\hline الكفاءة الذاتية في توقع المخرجات & الكفاءة الذاتية الثخصية & 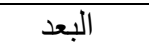 \\
\hline وتتميةً التفكير & في تدريس العلوم & الفرعي \\
\hline$-71-79-09-70-71-77-1-_{-}-7$ & $-\mu T_{-1}-1 T_{-}-1 \cdot-\varepsilon \cdot-11-r \cdot$ & \\
\hline$-\varepsilon 0{ }_{-} 0 V_{-}-q-r q-01-r q-\varepsilon \Lambda_{-} 0$. & $-\left\{Q_{-} r\left|-_{-} 0_{-}\right| r_{-}-7 V-|V-r-r|\right.$ & \\
\hline$-0 T-T \leq-0 Y-r \cdot-1 T-01-Y 9-T$. & $-\varepsilon-\Gamma \tau_{-} Y \tau_{-} 0 \leqslant-\varepsilon \varepsilon-1 \leqslant-r \Lambda$ & | المعردات \\
\hline$-0 T-10-\varepsilon T_{-} 00-\varepsilon V V_{-} \Lambda_{-} \leqslant 1-T \leqslant$ & 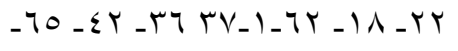 & \\
\hline$-Y V \_r \varepsilon$ & س & \\
\hline ro & r乏 & 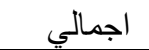 \\
\hline
\end{tabular}

هساب صدق المقياس: وذللك من خلال:

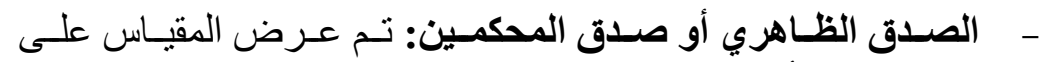

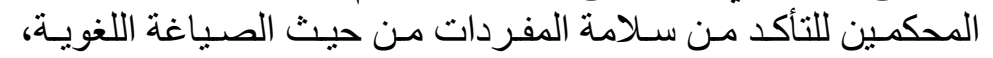

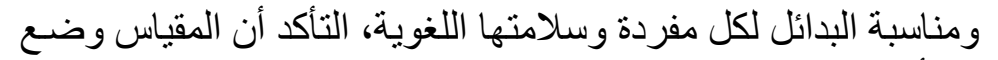

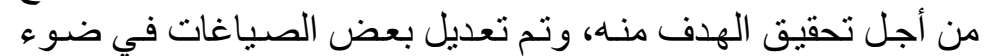

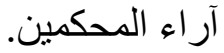

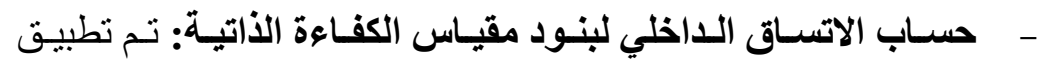

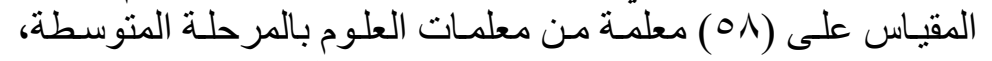

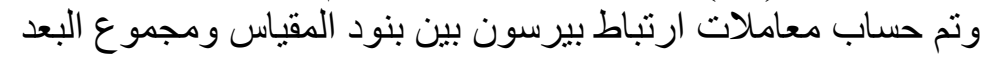

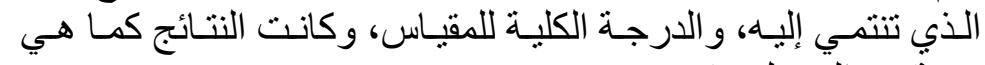

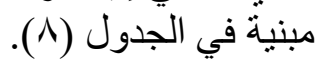

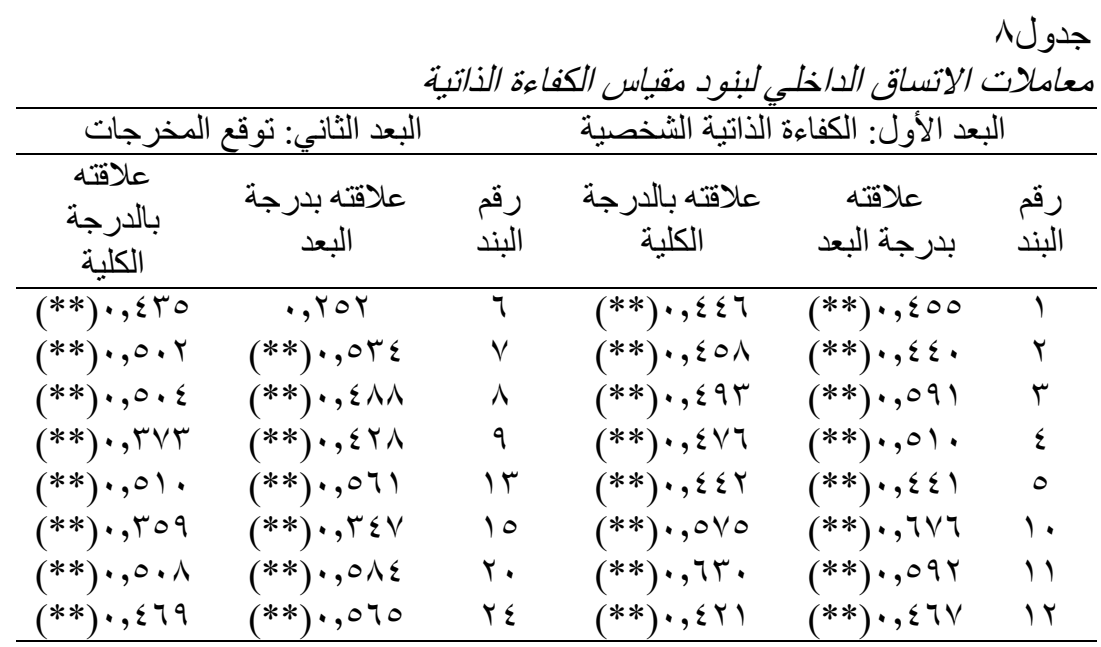

E. ISSN: 2735-4245

ISSN: 2536 - 914

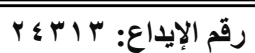

المجلة معرفة علي دوريات بنك المعرفة المصرى، و Edu Search دار المنظومة 
المجلة المصرية للتربية العلمية المجلد الرابع والعشرون العدد الرابع أكتوبر اب.rم

\begin{tabular}{|c|c|c|c|c|c|}
\hline \multicolumn{3}{|c|}{ البعد الثاني: توقع المخرجات } & \multicolumn{3}{|c|}{ البعد الأول: الكفاءة الذاتية الشخصية } \\
\hline عالالدرجة & علاقته بدرجة & البند & علاقته بالدرجة & بدرجة البعد & رلبند \\
\hline$(* *) \cdot, \leqslant \wedge\urcorner$ & $(* *) \cdot, 079$ & ro & $(* *) \cdot, \varepsilon \wedge \varepsilon$ & $(* *) \cdot$, Or. & $1 \varepsilon$ \\
\hline$(* *) \cdot, 0 \wedge \wedge$ & $(* *) \cdot, T Y 1$ & YV & $(* *) \cdot, \Sigma \vee \wedge$ & $(* *),, \leqslant 90$ & 17 \\
\hline$(* *), 0 \leqslant r$ & $(* *) \cdot, T$ T & $r \wedge$ & $(* *) \cdot, 0 \leq V$ & $(* *),, 70 \wedge$ & IV \\
\hline$(* *),, \uparrow, \varepsilon$ & $(* *) \cdot, 7 \cdot 1$ & $r q$ & $(* *) \cdot$, or. & $(* *) \cdot, 0 \wedge r$ & 11 \\
\hline$(* *),, \leq \vee \leqslant$ & $(* *) \cdot, 07 V$ & $r \varepsilon$ & $(* *) \cdot, \varepsilon \cdot r$ & $(* *),$, OV & 19 \\
\hline$(* *), 01 r$ & $(* *) \cdot$, OVT & ro & $(* *) \cdot$, or & $(* *), 070$ & YI \\
\hline$(* *) \cdot, 00 r$ & $(* *) \cdot, 701$ & $r q$ & $(* *) \cdot$, or. & $(* *),, T \leq V$ & Yr \\
\hline$(* *) \cdot, 009$ & $(* *) \cdot$, Tor & $\varepsilon 1$ & $(* *) \cdot, \Sigma r V$ & $(* *),, \leqslant \vee 0$ & rr \\
\hline$(* *),, 09$. & $(* *) \cdot, 7 \vee \leqslant$ & $\leqslant 0$ & $(* *) \cdot$, orq & $(* *),$, O $\wedge$ & $r T$ \\
\hline$(* *)$, , $\leqslant$ 苑 & $(* *) \cdot, 0 \vee 9$ & $\leqslant 7$ & $(* *) \cdot, \leqslant 7 \vee$ & $(* *),$, o 1 & r. \\
\hline (**), , Or & $(* *) \cdot, 0.9$ & $\Sigma V$ & $(* *) \cdot, \varepsilon \cdot 1$ & $(* *),, \leqslant$ O & ו \\
\hline$(* *) \cdot, 094$ & $(* *) \cdot, \pi T$ Tז & $\varepsilon \Lambda$ & $(* *) \cdot$, זчג & $(* *),, \leq 7)$ & rr \\
\hline$(* *),, \leqslant \wedge 0$ & $(* *) \cdot, \uparrow \wedge \leq$ & 0. & $(* *) \cdot, \Sigma V T$ & $(* *) \cdot, 014$ & سم \\
\hline$(* *), 074$ & $(* *) \cdot$, , & 01 & $(* *) \cdot, 019$ & $(* *), 0, r$ & די \\
\hline$(* *),, \leq \leqslant \Gamma$ & $(* *) \cdot, \leqslant 94$ & or & $(* *) \cdot, 0.7$ & $(* *),$, orv & re \\
\hline$(* *),, \varepsilon \backslash \Gamma$ & $(* *) \cdot, \Sigma V T$ & or & $(* *) \cdot, \leqslant 79$ & $(* *),, \leqslant \vee\urcorner$ & rᄉ \\
\hline$(* *),, \leq \varepsilon$. & $(* *) \cdot, 0 \leqslant 9$ & 00 & $(* *) \cdot, 0, \varepsilon$ & $(* *),, \leq 0$. & $\varepsilon$. \\
\hline$(* *)$, or. & $(* *) \cdot, 0 \wedge 9$ & 07 & $(* *) \cdot, \varepsilon \cdot 1$ & $(* *),, \leqslant 09$ & $\varepsilon r$ \\
\hline$(* *), 0,011$ & $(* *) \cdot, 00 \leqslant$ & or & $(*) \cdot, r \vee 1$ &., 191 & $\varepsilon r$ \\
\hline$(* *) \cdot, \leqslant \leqslant r$ & $(* *) \cdot, 0 \wedge$ & $\Delta \wedge$ & $(* *) \cdot$, Tor & $(* *) \cdot, T \vee$. & $\varepsilon \varepsilon$ \\
\hline$(* *),, \leqslant \Gamma$. & $(* *) \cdot, \leqslant V \Gamma$ & 09 & $(* *) \cdot, 07 V$ & $(* *) \cdot, 09 \mathrm{~V}$ & $\varepsilon q$ \\
\hline$(* *),, \leq \leqslant 1$ & $(* *) \cdot, \leqslant 7 r$ & 7. & $(* *) \cdot, \leqslant$ Or & $(* *)$, or & $0 \leqslant$ \\
\hline$(* *) \cdot, \varepsilon \backslash r$ & $(* *) \cdot, \leqslant \vee 0$ & 71 & $(* *) \cdot, 01 r$ & $(* *),, 0 \wedge$. & $7 r$ \\
\hline$(* *),, \Sigma) \wedge$ & $(* *) \cdot$, rTV & $7 \varepsilon$ & $(* *) \cdot, r V r$ & $(* *), 0, V$ & אדי \\
\hline$(* *),, \leq r \varepsilon$ & $(* *) \cdot, \leqslant \leqslant r$ & 77 & $(* *) \cdot, \leqslant \leqslant 7$ & $(* *),, \Sigma \cdot r$ & 70 \\
\hline$(* *) \cdot, 0, r$ & $(* *) \cdot, \leqslant \leqslant \wedge$ & 71 & $(* *) \cdot, \leqslant r V$ & $(* *),, \leqslant 09$ & TV \\
\hline$(* *) \cdot, \leqslant \curlyvee \wedge$ & $(* *) \cdot, \Gamma \leq \varepsilon$ & 79 & & & \\
\hline
\end{tabular}

يتضح من الجدول (^) أن معاملات ارتباط بيرسون لبنود مقياس الكفاءة

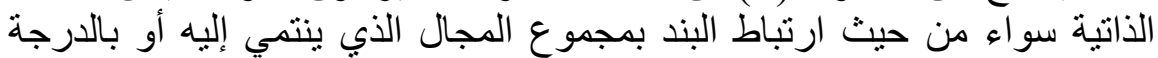

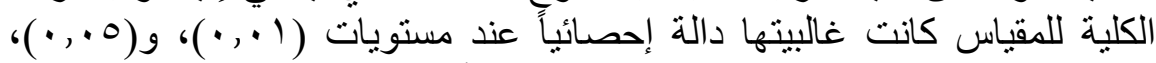
و هذا يعني ان بنود المقياس تقيس ما وضعت من أجل قياسه و هو مهار ات التدريس

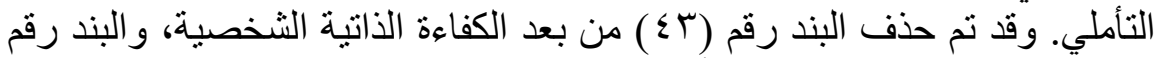

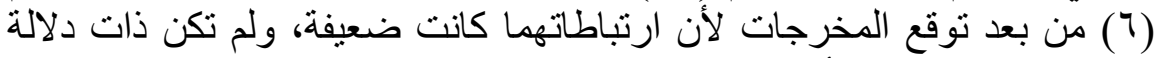

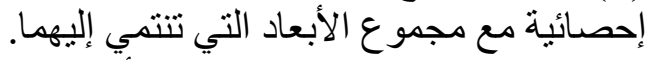

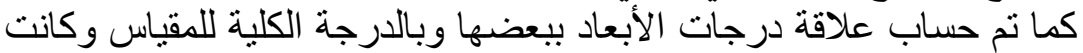

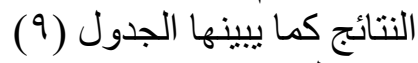

جدول (9)

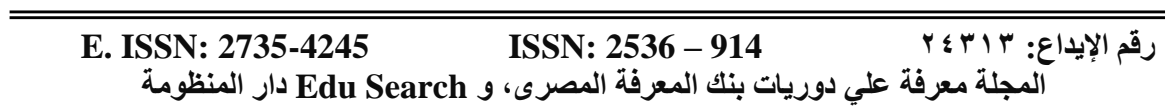

$1 \wedge \varepsilon$ 
المجلة المصرية للتربية العلمية المجلد الرابع والعشرون العدد الرابع أكتوبر اץ.rم

\begin{tabular}{|c|c|c|c|}
\hline & \multicolumn{3}{|c|}{ بيبين علاقة بُعدي مقياس الكفاءة الذاتية ببعضهها وبالدرجة الكلية } \\
\hline الكلي & توقع المخرجات & الكفاءة الذاتية & الأبعاد اد \\
\hline$(* *) \cdot, 9 r$. & $(* *) \cdot, \vee \cdot \varepsilon$ & 1 & الكفاءة الذاتية الثخصية \\
\hline$(* *) \cdot, 9 r 7$ & 1 & - & توقع المخرجات \\
\hline 1 & - & - & الكلي \\
\hline
\end{tabular}

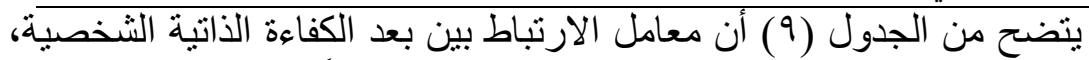

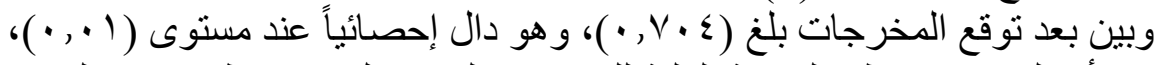

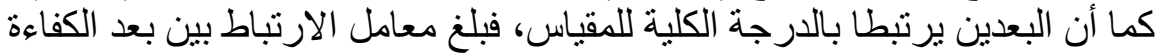

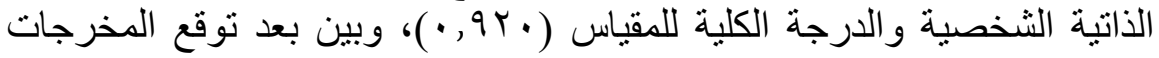

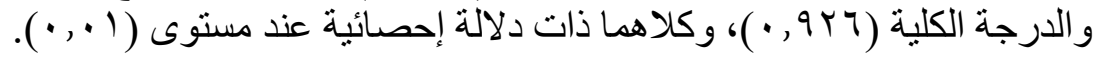

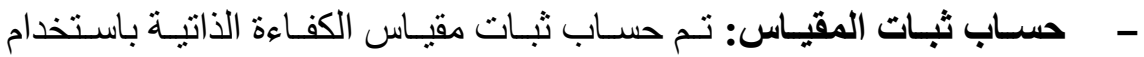

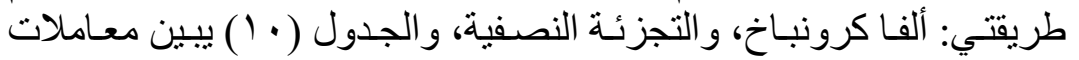

$$
\text { جدول الثبات. }
$$

\begin{tabular}{|c|c|c|c|c|}
\hline جزئة النصفية & بيرسون بين & كرونباخ ألفامل & أبعاد المقياس & r \\
\hline$\cdot, \lambda r$ & $\cdot, \nabla \cdot$ & - ,9r & الكفاءة الذاتية & 1 \\
\hline$\cdot, \wedge$. & • , TV & $\cdot, 94$ & توقع المخرجات & r \\
\hline$\cdot, \lambda)$ & $\cdot, 71$ & $\cdot, 90$ & الثبات الكلي للمقياس & $/ / /$ \\
\hline
\end{tabular}

معاملات ثبات مقياس الكفاءة الذاتبة بطريقتي ألفا كرونباخ و التجزئة النصفية.

يتضح من الجدول ( • () أن معاملات ثبات بُعدي المقياس بلغت (r 9 , • ) لكل

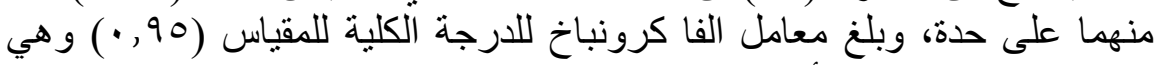
معاملات ثبات مرتفعة، أما معاملات ثبات المقياس بطريقة التجزئة النصفية فقد بلغ

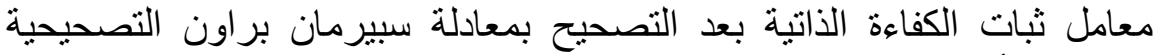

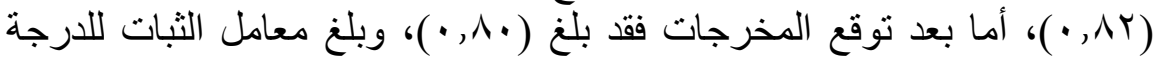
الكلية للمقياس (1) ( • ) وهي معاملات ثبات جيدة، وبالتالي يمكن الثقة في النتائج التي يتوصل إلبها المقياس. الصورة النهائية للمقياس: تكونت من (TV) مفردة، (ع ب) للبعد الأول الكفاءة

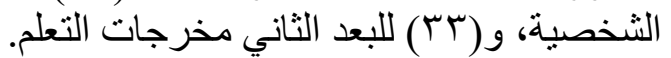

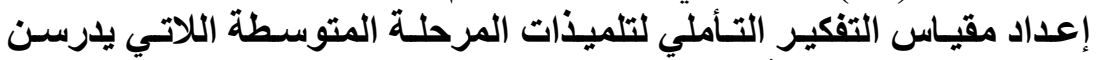

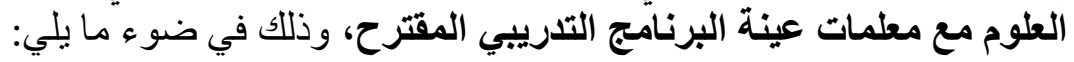

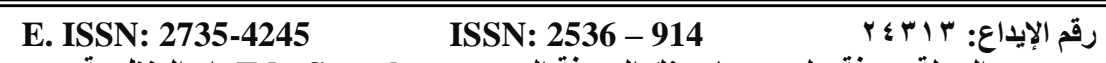
المجلة معرفة علي دوريات بنك المعرفة المصرى، و Edu Search دار المنظومة 
تحديـــ الهـدف مـن المقيـاس: تعـرف مسـتوى التفكيـر التـأملي لـدى التى

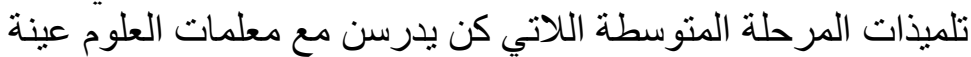
البحث.

إعداد الصورة الأولية للمقياس: وتكونت من ( • (ب) مفردة موز عة في

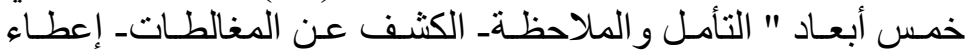

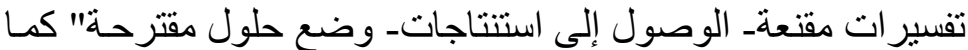
هو موضح بالجدول التالي:

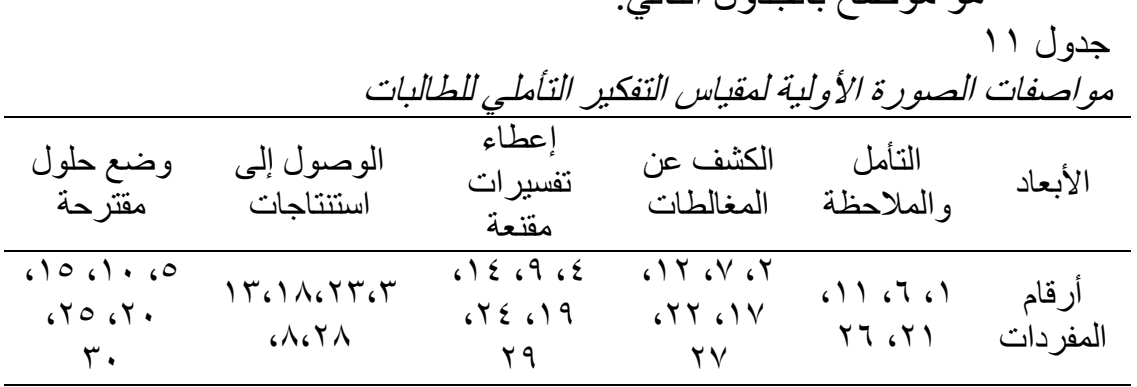

\section{صدق المقياس: تم حساب الصدق من خلال:}

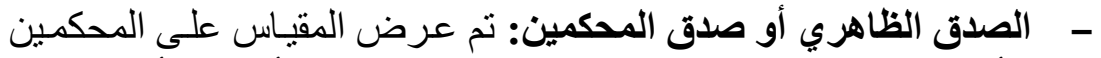

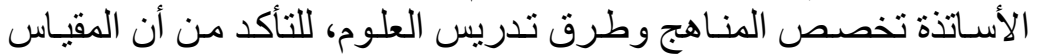

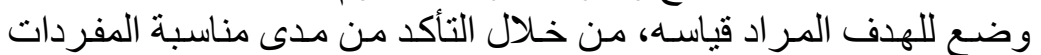

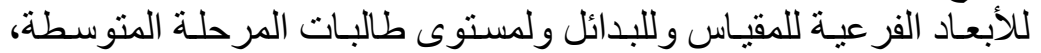
وتم تعديل بعض الصياغات اللغوية. - - حساب الاتساق الداخلي لبنود مقياس التفكير التأملي للطالبات: تم تطبيق

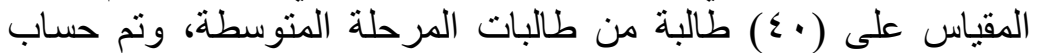
معاملات ارتباط بيرسون بين بنود المقياس ومجموع البعد الذي تنتمي وني إليه، والدرجة الكلية للمقياس، وكانت النتائج كما هي مبنية في الجدول

\begin{tabular}{|c|c|c|c|c|c|c|c|}
\hline $\begin{array}{l}\text { بالدرجة الكلية } \\
\text { بلاقة }\end{array}$ & بدرجة البعد & رقفرة & البعد & بالارجة الكلية & بدرجة البعد & الفقرة & البعد \\
\hline$(*) \cdot, \uparrow \wedge$. & $(* *) \cdot$, OrV & $\pi$ & & $(* *) \cdot, \leqslant 90$ & $(* *) \cdot, \vee \cdot \wedge$ & 1 & \\
\hline$(*) \cdot, r \leq q$ & $(* *) \cdot$, orv & 11 & & q צד, •(**) & $(* *) \cdot, T \vee r$ & 7 & \\
\hline$(* *) \cdot, 001$ & $(* *) \cdot, 7 \leq 7$ & r & $f:=$ & $(* *),, 0 \leqslant r$ & $(* *) ., 09$. & 11 & 9 \\
\hline$(* *) \cdot, \leqslant q$. & $(* *) \cdot, \vee \backslash \vee$ & $r$ & 3 & $(* *),, 7) 7$ & $(* *),, \vee \wedge r$ & r) & \\
\hline$(* *) \cdot, \leqslant 00$ & $(* *) \cdot, \vee \vee q$ & $\wedge$ & ᄀ & $(* *) \cdot, \leqslant r_{0}$ & $(* *) \cdot, 0 r r$ & $r y$ & $\therefore$ \\
\hline$(*) \cdot, r \leqslant q$ & 0.284 & $r \Lambda$ & & $(*) \cdot, r q r$ & $(* *) \cdot, \leq \leqslant 1$ & $r$ & כ. \\
\hline
\end{tabular}

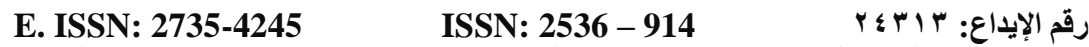 \\ المجلة معرفة علي دوريات بنك المعرفة المصرى، و Edu Search دار المنظومة}


المجلة المصرية للتربية العلمية المجلد الرابع والعشرون العدد الرابع أكتوبر اب.rم

\begin{tabular}{|c|c|c|c|c|c|c|c|}
\hline 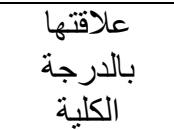 & بدرجة البعد & الفقرة & البعد & $\begin{array}{l}\text { بالارجة الكلية } \\
\text { علاقة }\end{array}$ & بدرجة البعد & الفقرة & البعد \\
\hline$(* *) \cdot, \Sigma \Upsilon \Gamma$ & $(* *) \cdot$, OY & 17 & & $(* *) \cdot, 000$ & $(* *) \cdot, \vee Y \Sigma$ & $\mathrm{V}$ & \multirow{11}{*}{ 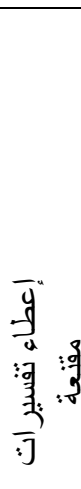 } \\
\hline$(* *),, 01$. & $(* *) \cdot, \tau \vee \wedge$ & 。 & . & $(* *) \cdot, \leqslant 00$ & $(* *) \cdot, \leq \vee \leq$ & ir & \\
\hline$(* *) \cdot, \leqslant \vee \wedge$ & וזד, • (**) & 1. & 2 & $(* *) \cdot, \tau) r$ & $(* *),,\rceil, \Sigma$ & IV & \\
\hline$(* *) \cdot, \vee \backslash$ & $(* *) \cdot, 099$ & 10 & 1 & . rrq & $(* *) \cdot, \leqslant \mu \wedge$ & rr & \\
\hline$(* *) \cdot, \leqslant \vee \wedge$ & $(* *) \cdot, \vee>9$ & r. & 8 & $(* *) \cdot, 0.7$ & $(* *) \cdot, T) \vee$ & TV & \\
\hline$(* *) \cdot, \leqslant \curlyvee q$ & $(* *) \cdot$, OVY & ro & & $(* *) \cdot, \vee \vee$. & $(* *),, \vee \wedge$. & $\varepsilon$ & \\
\hline$(* *),, \leq 77$ & $(* *) \cdot, 794$ & r. & רד: & $(* *) \cdot, \leqslant \wedge \varepsilon$ & $(* *)$, , тา & 9 & \\
\hline$/ / / / / /$ & $/ / / / / /$ & $/ / / / / /$ & $/ / / / / /$ & $(* *) \cdot, 001$ & $(* *), T)$. & $1 \leq$ & \\
\hline$/ / / / / /$ & $/ / / / / /$ & $/ / / / / / /$ & $/ / / / / /$ & $(* *) \cdot, 7 \leq 1$ & $(* *) \cdot, 79$. & 19 & \\
\hline$/ / / / / /$ & $/ / / / / /$ & $/ / / / / /$ & $/ / / / / /$ & $(* *),, \tau, r$ & $(* *),, O \wedge \vee$ & $r \varepsilon$ & \\
\hline$/ / / / / /$ & $/ / / / / /$ & $/ / / / / /$ & $/ / / / / /$ & $(* *) \cdot, \varepsilon \mid r$ & $(* *) \cdot$, Or & rq & \\
\hline
\end{tabular}

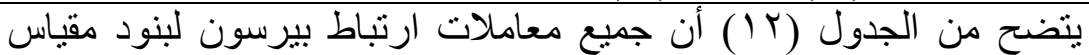

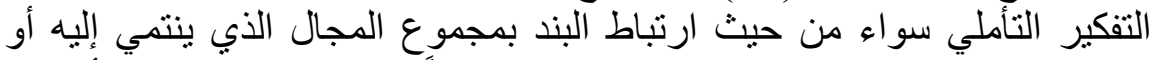

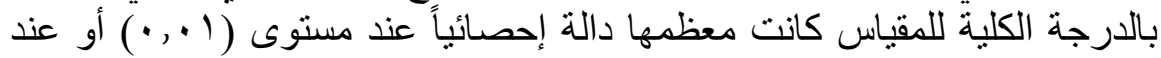

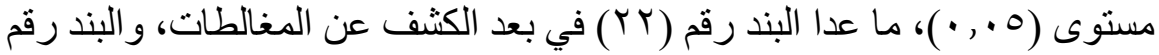

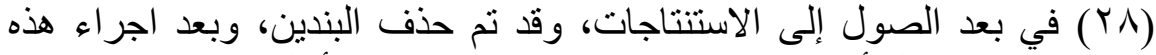
الخطوة يكمن القول أن بنود المقياس تقيس ما وضعت من أجل فياسه وهو الأن التفكير التأملي للطالبات. كما تم حساب علاقة درجات الأبعاد ببعضها وبالدرجة الكلية للمقياس وكانت

$$
\text { النتائج كما يبينها الجدول (r) }
$$

\begin{tabular}{|c|c|c|c|c|c|c|}
\hline \multirow[b]{2}{*}{ الكلي } & \multicolumn{6}{|c|}{ علاقة أبعاد مقباس مهار ات التنربس التأملي ببعضها وبالدرجة الكلبة } \\
\hline & إعطاء حلول مقترل & 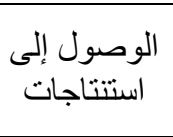 & تفسير إعلاء & الكشثف عن المغات & 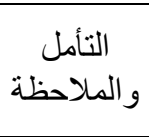 & الأبعاد \\
\hline .,人Yт &.,$\leqslant 7$. &.,$\leqslant 7$. & ., ^r० & ת & 1 & التأمل و الملاحظة \\
\hline •, & ., &.,$\leqslant 99$ & $\cdot, V \leq r$ & 1 & - & الكشف عن \\
\hline$(* *) \cdot, \wedge 94$ & $(* *) \cdot, 0 \wedge 1$ & $(* *)$, oro & 1 & - & - & إعطاء تفسير ات \\
\hline$(* *) \cdot, \vee \leq \wedge$ & $(* *),, \leqslant \Psi ।$ & 1 & - & - & - & الوصنتاجات إلى \\
\hline
\end{tabular}

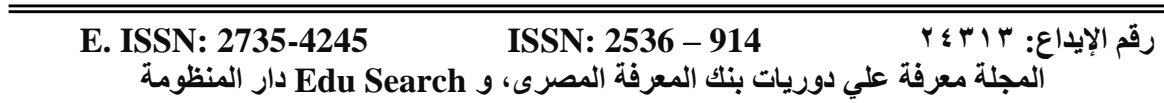




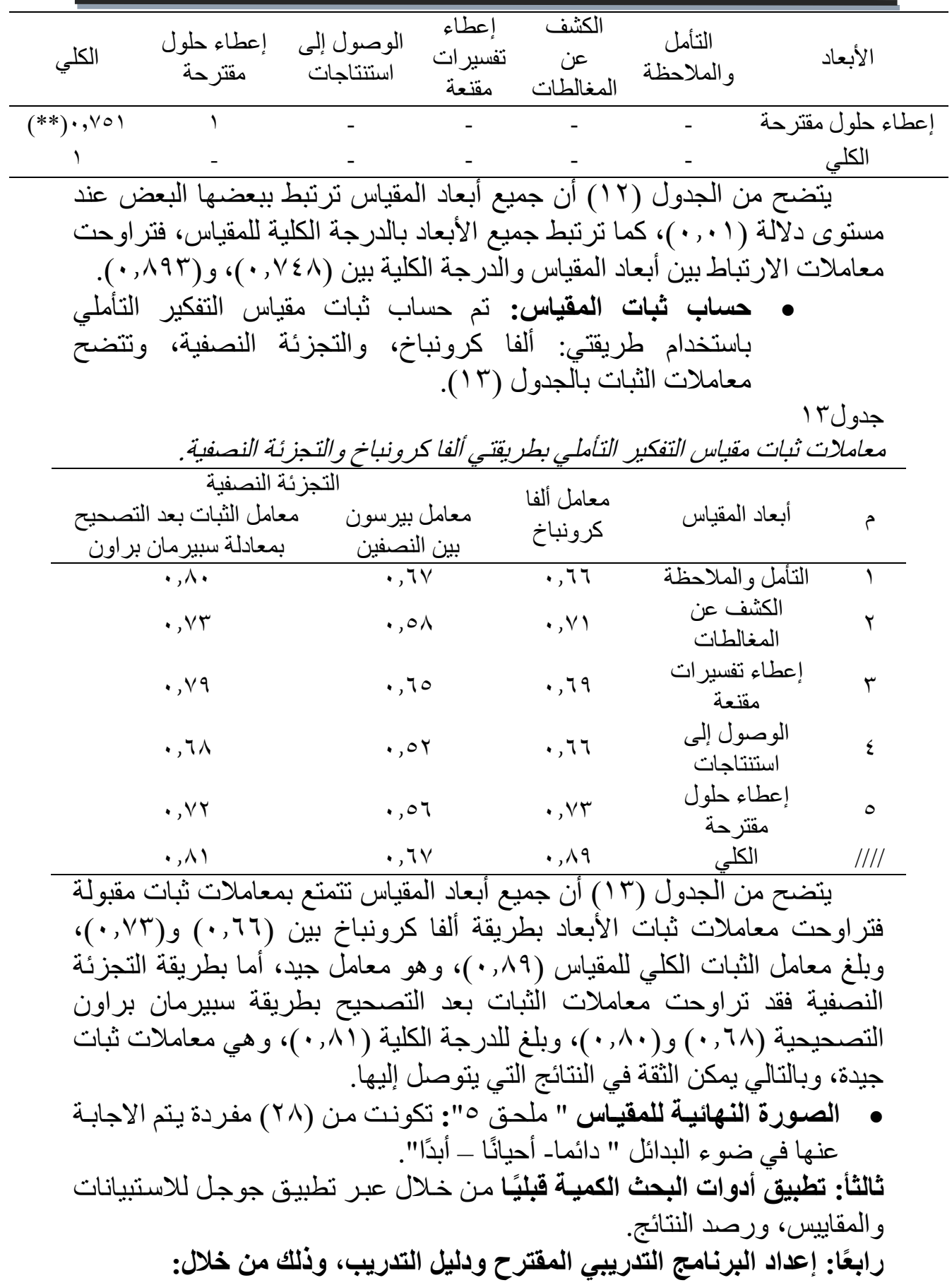

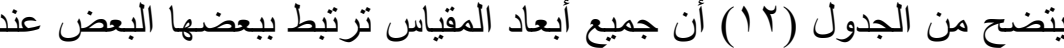

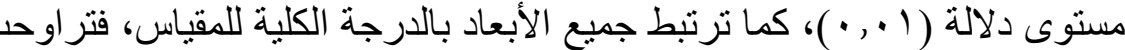

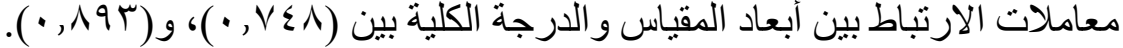

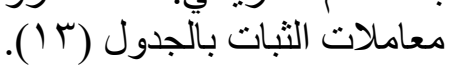
جدول مبات

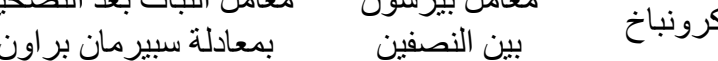


ـ تحديـ الهـدف العـام للبرنـامج: وهـو تتميـة مهار ات التـدريس التـأملي و الكفـاءة الذاتية لدى معلمات العلوم.

ـ تحديد محتوى البرنامج وجلساته: تم تحديد محتوى البرنـامج بعدا لاطلاع على التى

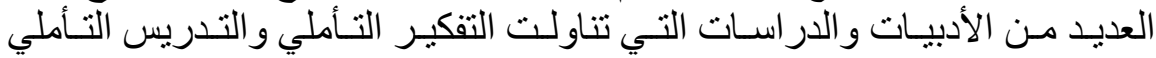

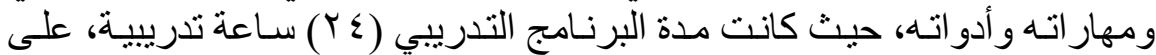

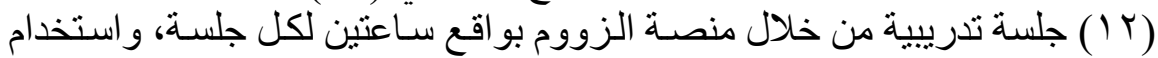

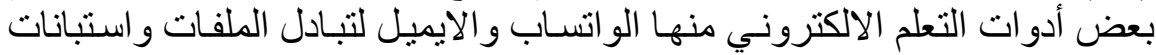

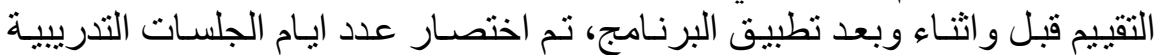

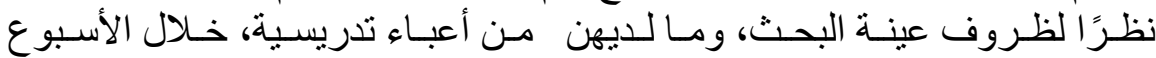

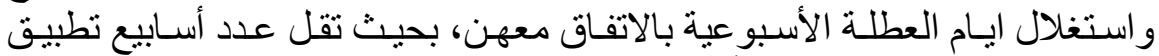

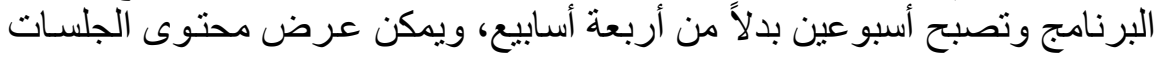

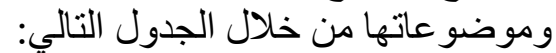

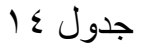

\begin{tabular}{|c|c|c|}
\hline بالدقيقة & محور الجلسة & الجلسة \\
\hline ir. & جلسة تمهيدية للتعريف بالبرنامج & 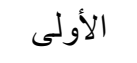 \\
\hline ir. & مفهوم التدريس التأملي و أنشطة & 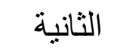 \\
\hline ir. & أدوات التدريس التأملي & 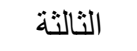 \\
\hline ir. & خطو ات التدريس التأملي & الر ابعة \\
\hline ir. & استر اتيجيات التدريس التأملّي & الخامسة \\
\hline IT. & التقييم الذاتي لتحسين الأداء التدريسي & السادسة \\
\hline ir. & الممارسات آلتأملية & السابعة \\
\hline 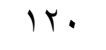 & الممارسات التأملية وتقييم الزملاء & 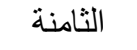 \\
\hline$i r$ & الممارسات التاملية وكتابة التقارير & التاسعة \\
\hline Ir. & تأملات وتحسين الأداء التدريسي & العاثرة \\
\hline ir. & تأملية وختامية & الحشرية \\
\hline ir. & تقييم البرنامج & الثانية عشر \\
\hline
\end{tabular}

ـ تطبيق البرنـامج التدريبي: تم تنفيذ البرنـامج عبر منصسة زووم (ZOOM) بدايـة

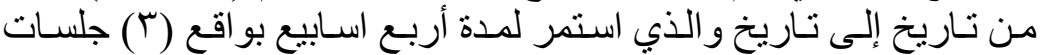

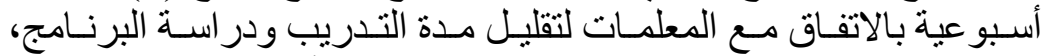

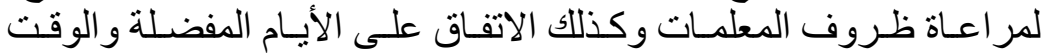

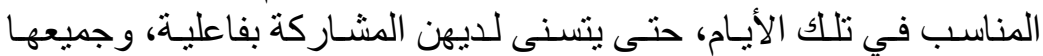
موضحة بدليل البرنامج ملحق (V).

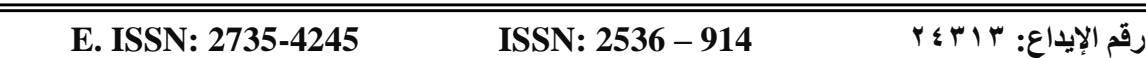
المجلة معرفة علي دوريات بنك المعرفة المصرى، و Edu Search دار المنظومة
} 


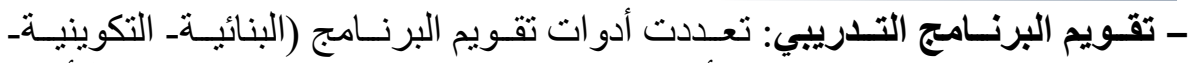

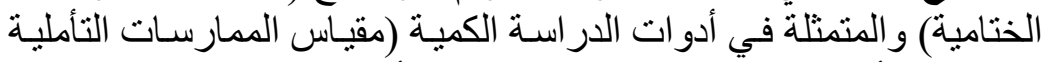

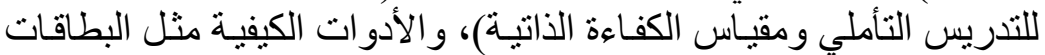

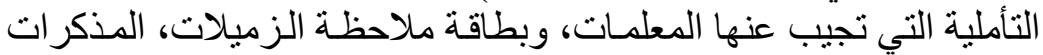
اليومية التأملية، كتابة المقالات وجميعها موضحة بدليل البرنـامج التدريبي

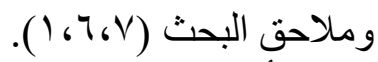

خامسًا: تطبيث أدوات البحث بعديًا بنفس طريقة التطبيث القبلي من خـلال استبيانات

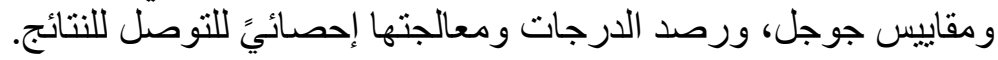
نتائج البحث: ـالإجابة عن السؤال الفرعي الأول: وذلك من خـلال اختبار صحة الفرضين الأول

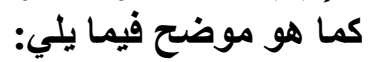

أولاً: اختبار صحة الفرض الأول: وينص هذا الفرض على "توجد علاقة موجبة

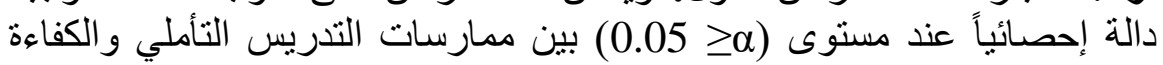

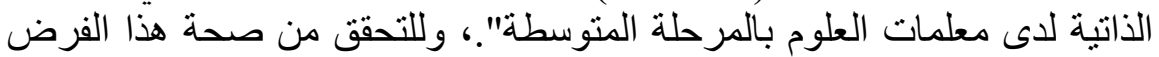

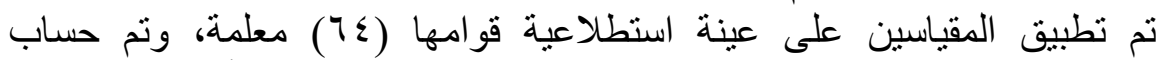
معاملات ارتباط بيرسون Pearson Correlation بين أبعاد المقين إنياسين ودرجتيهما الكلية، والجدول (10) يبين ذلك. بلك.

جدول 10

معاملات ارتباط بيرسون بين مدارسات التدرببس التأملي والكفاءة الذاتبة لدى معلمات

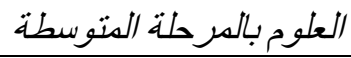

\begin{tabular}{|c|c|c|c|c|}
\hline \multicolumn{4}{|c|}{ مهار ات التدريس التأملي } & \multirow{2}{*}{ الكفاءة الذاتية } \\
\hline الكلي & التقويم & التنفيذ & التخطيط & \\
\hline$(* *)$, , १५० & $(* *) \cdot$, , ז. & $(* *) \cdot$, 人тr & $(* *) \cdot$, 人า० & الكفاءة الثخصية الذاتية \\
\hline$(* *) \cdot, 090$ & $(* *) \cdot, \leq 9 \leq$ & $(* *) \cdot, 011$ & $(* *) \cdot, 7 \leq 1$ & توقع المخرجات \\
\hline$(* *) \cdot, \wedge r q$ & $(* *),, \vee Y \nearrow$ & $(* *),, \vee \circ \varepsilon$ & $(* *)$, , Y o & الكلي \\
\hline
\end{tabular}

- - مجود علاقة موجبة بين الدرجة الكلية لممارسات التدريس التأملي،

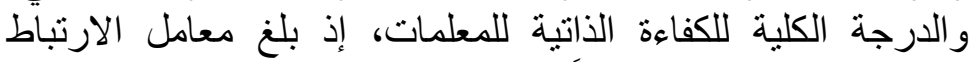

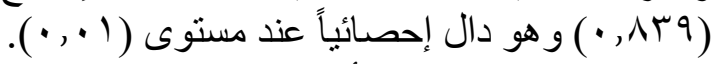

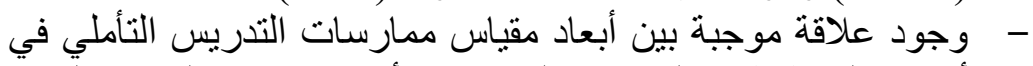

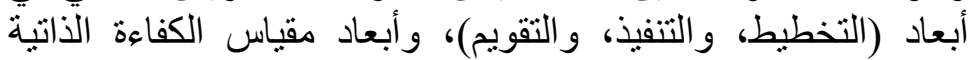

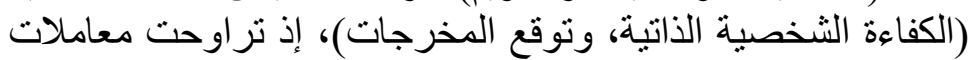

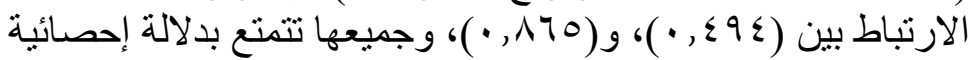

$$
\text { عند مستوى (1 ( • (•). }
$$

\footnotetext{
رقم الإيداع: ISSN: 2735-4245

المجلة معرفة علي دوريات بنك المعرفة المصرى، و Edu Search دار المنظومة
} 


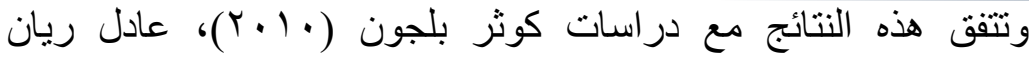

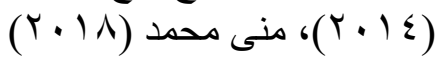

ـالإجابة عن السؤال الفرعي الثاني: وذلك من خلال اختبار صحة الفرضين الثاني

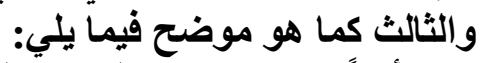
أو لاً: اختبار صحة الفرض هوض الثاني وينص على " يوجد فرق دال إحصائيًا عند مستوى (0.05 0 (2) بين متوسطي درجات عينة البحث في التطبيقين القبلي

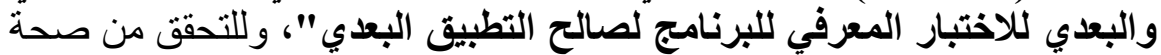
هذا الفرض تم حساب الاختبار التائي لعينتين مرتبطتين Paired Samples Test و الجدول (7 1 ) يبين ذلك. قيمة t ودولتها للفرق بين القياسبن القبلي والبعدي للاختبار المعرفي للبرنامج التدربيجي م $=\dot{0}$

\begin{tabular}{|c|c|c|c|c|c|c|}
\hline الأثنر & القر ار & التائية & الحرجية & الانحر افياري & الحستوسطي & القياس \\
\hline \multirow{2}{*}{$\cdot, 91$} & \multirow{2}{*}{ دال (1 •, •) } & \multirow{2}{*}{$r \wedge, q$} & \multirow{2}{*}{$r \varepsilon$} & T,TT & 11,01 & القبلي \\
\hline & & & & $1, \vee \wedge$ & $r 1, .7$ & البعدي \\
\hline
\end{tabular}

يتضح من الجدول (7 ( ) أن القيمة التائية للفرق بين متوسطي القياسين القبلي و البعدي لاختبار التحصيل المعرفي للمعلمات بلغت (ب,

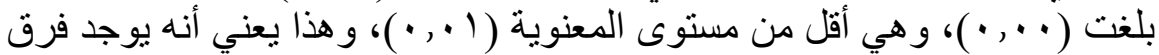

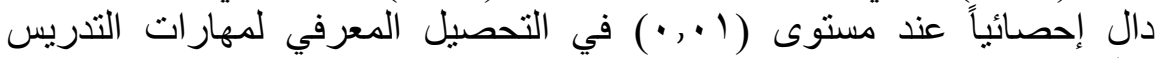

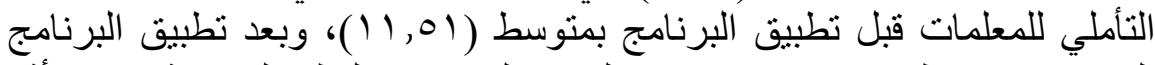

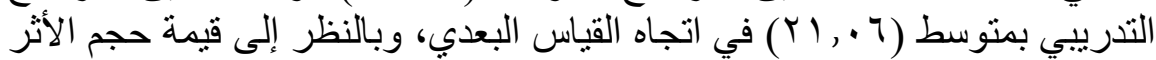

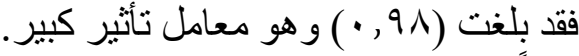

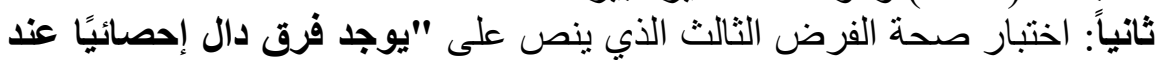
مستوى (0.05 0 (ب) بين متوسطي درجات عينة البحث في التطبيقين القبلي

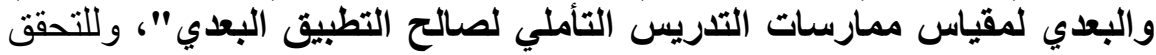
من صحة هذا الفرض تم حساب الاختبار التائي لعينتين مرتبطتين Paired Samples Test

IV جدول قبية t ودولتها للفرق بين القياسبن القبلي والبعدي لمقياس مدارسات التدربيس التأملي |لمعلمات

\begin{tabular}{|c|c|c|c|c|c|c|c|}
\hline الأثر & مستوى الدلالة & التائية & الحرية & الانحر افياري & الحستوسي & القياس & الأبعاد \\
\hline$\cdot, V T$ & $(\cdot, \cdot 1)$ & $1 \cdot, r V$ & $r \varepsilon$ & $\begin{array}{l}r, q 1 \\
1, \lambda 1\end{array}$ & $\begin{array}{l}19, r_{T} \\
r 0, r_{1}\end{array}$ & البعدي & التخطبط \\
\hline$\cdot, \wedge \varepsilon$ & $(\cdot, \cdot 1)$ & $\Pi \pi, \varepsilon \varepsilon$ & $r \varepsilon$ & $\varepsilon, \wedge r$ & $r \cdot, q)$ & القبلي & التنفيذ \\
\hline
\end{tabular}

E. ISSN: 2735-4245 ISSN: 2536 - 914

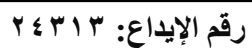
المجلة معرفة علي دوريات بنك المعرفة المصرى، و Edu Search دار المنظومة 


\begin{tabular}{|c|c|c|c|c|c|c|c|}
\hline الأثج & مستوى الدلالة & التائية & الحرية & الانحر افياري & الحستوسطي & القياس & الأبعاد \\
\hline & & & & $r, r q$ & Y^, q & البعدي & \\
\hline$\cdot, \wedge 0$ & $(\cdot, \cdot 1)$ & $M, \wedge \varepsilon$ & ז & $\begin{array}{l}\varepsilon, r q \\
1, \vee q\end{array}$ & $\begin{array}{l}r \varepsilon, r q \\
r, r, r\end{array}$ & البعدي القبلي & التقويم \\
\hline$\cdot, \wedge \mathrm{V}$ & $(\cdot, \cdot 1)$ & $10, Y 1$ & r & $\begin{array}{l}11,{ }^{\prime} \\
0, r\end{array}$ & $\begin{array}{l}7 \leqslant, \leqslant 7 \\
\wedge T, \leqslant q\end{array}$ & البعدي القبلي & الكلي \\
\hline
\end{tabular}

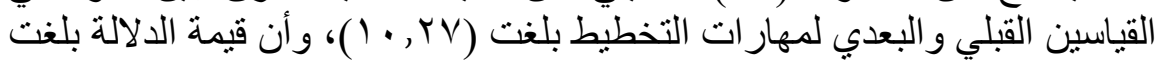

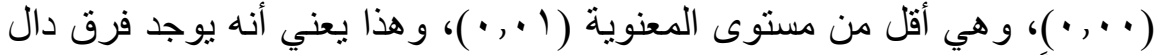

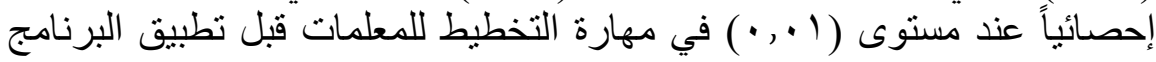

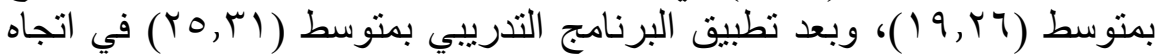

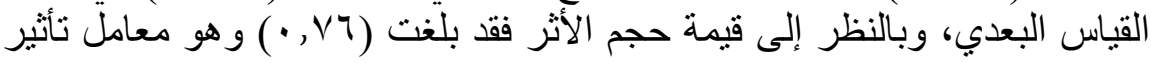

- - أن القيمة التائية للفرق بين متوسطي القياسين القبلي و البعدي لمهارة التنفيذ كبير.

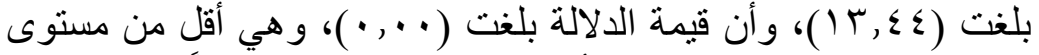

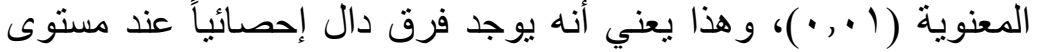

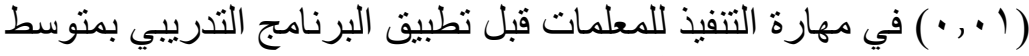

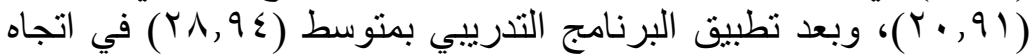

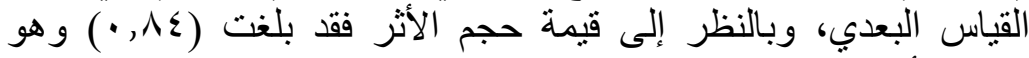
معامل تأثبر كبير. - - أن القيمة التائية للفرق بين متوسطي القياسين القبلي والبعدي لمهارة

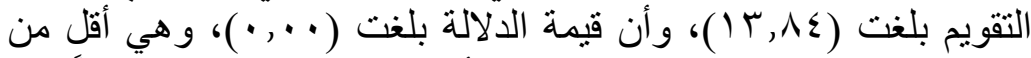

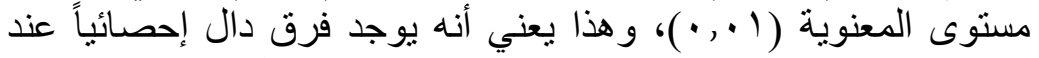

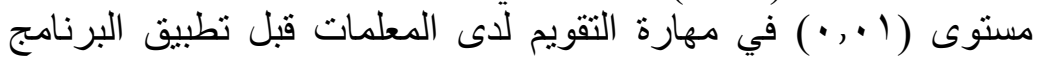

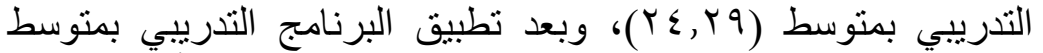

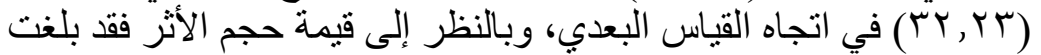
(10)

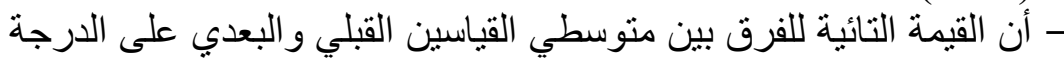

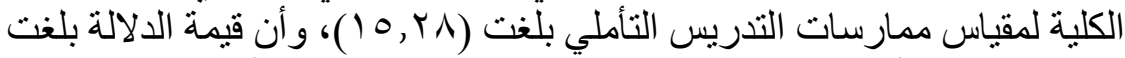

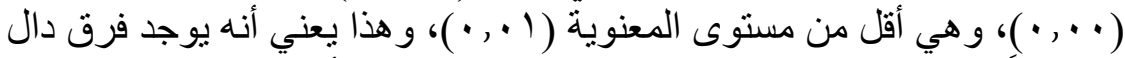

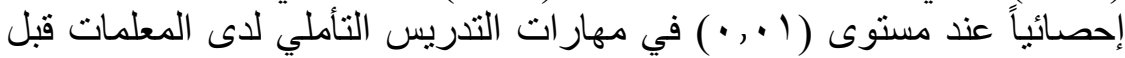

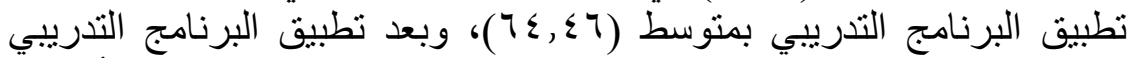

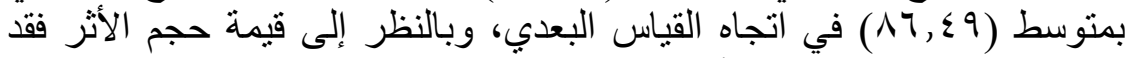

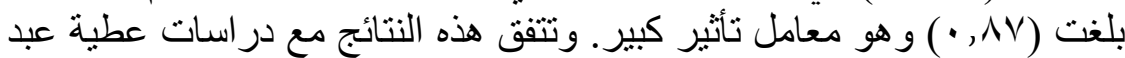

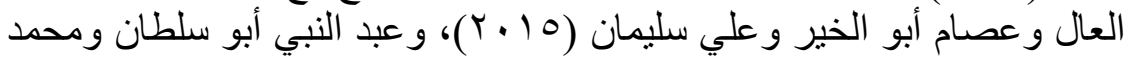

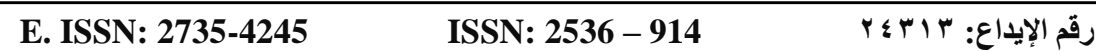
المجلة معرفة علي دوريات بنك المعرفة المصرى، و Edu Search دار المنظومة
} 
أبو عسكر (Y P IV) و التي أجربت على معلمي العلوم بشمال غزة، ومنى محمد

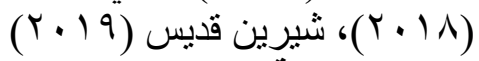

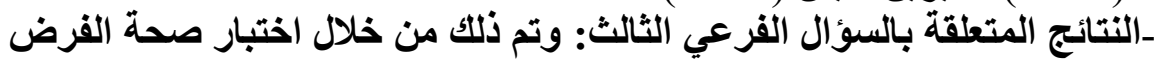

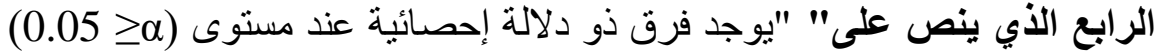

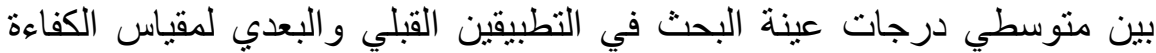

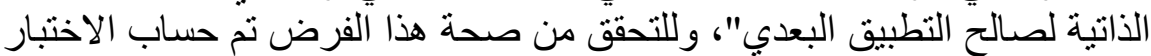

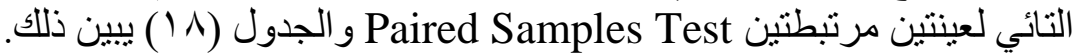

جدول (1) (1)

قبية tودلالتها للفرق بين القياسين القبلي والبعدي للكفاءة الذاتية للمعلدات ن= هب

\begin{tabular}{|c|c|c|c|c|c|c|c|}
\hline الأثجر & مستوى & التائية & الحرجية & الالنحرياري & الحستوسطي & القياس & الأبعاد \\
\hline \multirow[b]{2}{*}{$\cdot, 9$. } & \multirow[b]{2}{*}{$(\cdot, \cdot 1)$} & \multirow[b]{2}{*}{$1 V, .0$} & \multirow[b]{2}{*}{ T\& } & 10,97 & qr,Ar & القبلي & الكفاءة \\
\hline & & & & $11, \leqslant 1$ & 1 & البعدي & الذخصية \\
\hline \multirow{2}{*}{$\cdot, 91$} & \multirow{2}{*}{$(\cdot, \cdot 1)$} & \multirow{2}{*}{$11,9}$. & \multirow{2}{*}{ T纟 } & $17, Y 7$ & $1 \cdot r, \Lambda$. & القبلي & توقع \\
\hline & & & & 11,49 & lor, 9V & البعدي & المخرجات \\
\hline \multirow{2}{*}{ • , 94} & \multirow{2}{*}{$(\cdot, \cdot 1)$} & \multirow{2}{*}{ r.,Or } & \multirow{2}{*}{ T纟 } & $r \wedge, 90$ & 197, 197 & القبلي & \multirow{2}{*}{ الكلي } \\
\hline & & & & 11,97 & $r q \varepsilon, 7$. & البعدي & \\
\hline
\end{tabular}

- - أن القيمة التائية للفرق بين متوسطي القياسين القبلي والبعدي لبعد الكفاءة

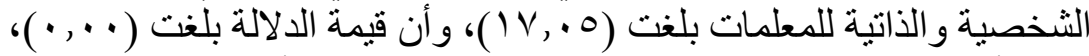

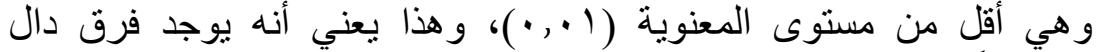

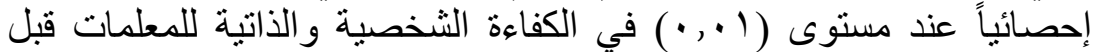

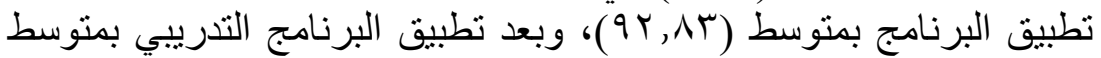

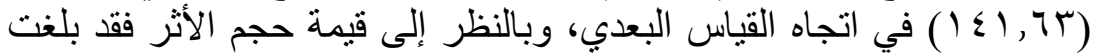

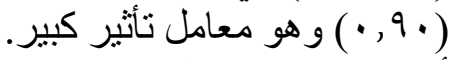
-أن القيمة التائية للفرق بين متوسطي القياسين القبلي والبعدي لبعد توقع

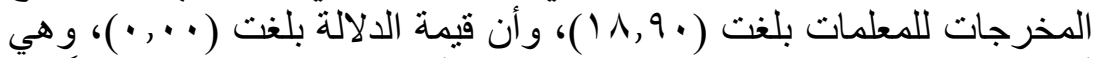

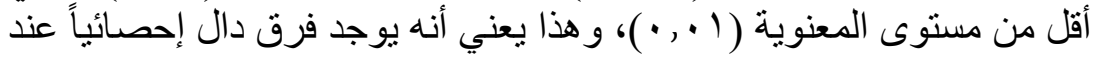
مستوى (1 ( ) • ) في توقع المخرجات للمعلمات قبل تطبيق البرنامج بمتوسط

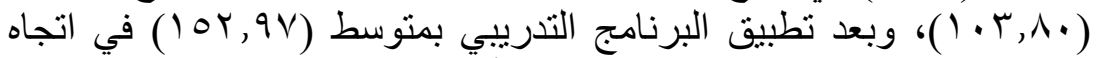

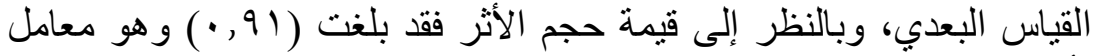
تأثير كبير. -أن القيمة التائية للفرق بين متوسطي القياسين القبلي و البعدي للارجة الكلية

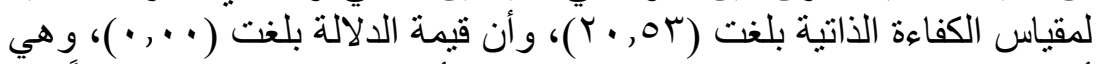
أقل من مستوى المعنوية (1 ( , • )، و هذا بعني أنه يوجد فرق دال إحصائياً عند

\footnotetext{
E. ISSN: 2735-4245 $\quad$ ISSN: 2536-914

المجلة معرفة علي دوريات بنك المعرفة المصرى، و Edu Search دار المنظومة
} 
مستوى ( 1 ( , • ) في الدرجة الكلية للكفاعة الذاتية للمعلمات قبل تطبيق البرنامج

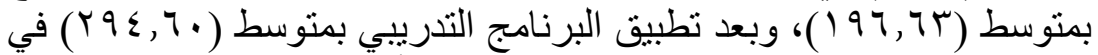

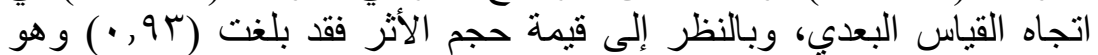

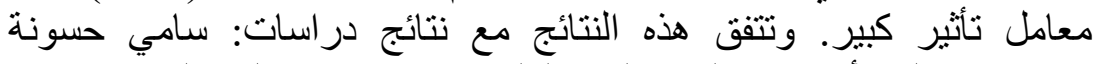

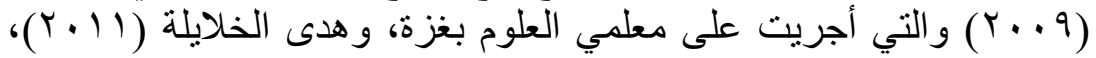

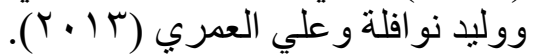

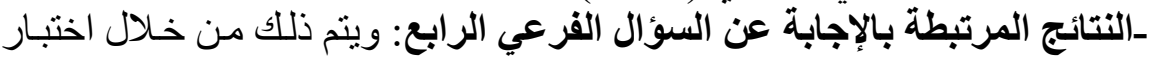

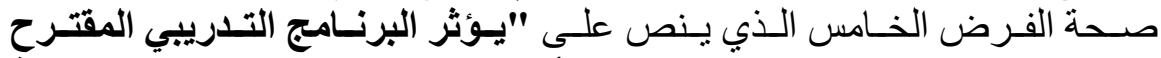
للمعلمات على مستوى مهارات التفكير التأملي لدى طالبـات معلمـات العلوم عينة

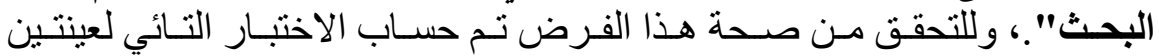
مرتبطتين Paired Samples Test و الجدول (9 1 ) يبين ذلك. جدول 19

\begin{tabular}{|c|c|c|c|c|c|c|c|}
\hline الأثجز & مستوى الدلالة & التائية & الحرية & الانحعيار افي & الحستوسطي & القياس & الأبعاد \\
\hline$\cdot, \vee \wedge$ & $(\cdot, \cdot 1)$ & $r \cdot, r_{\Lambda}$ & 119 & $\begin{array}{l}r, r . \\
1, r)\end{array}$ & $\begin{array}{l}1,7 . \\
11,94\end{array}$ & البعدي & و الملاحظة \\
\hline$\cdot, \vee \wedge$ & $(\cdot, \cdot 1)$ & $r \cdot, O V$ & 119 & $\begin{array}{l}r, \ldots \\
1,0 \leq\end{array}$ & $\begin{array}{l}\wedge, 9 \wedge \\
\mid r, \wedge \varepsilon\end{array}$ & البعدي القبلي & الكشف عن \\
\hline$\cdot, \vee q$ & $(\cdot, \cdot 1)$ & r), ro & 119 & $\begin{array}{l}r, \cdot V \\
1, r .\end{array}$ & $\begin{array}{l}9,1 . \\
M, 01\end{array}$ & البعدي & تفسير ات اتعطاء \\
\hline$\cdot, V_{0}$ & $(\cdot, \cdot 1)$ & $1 \wedge, v$. & 119 & $\begin{array}{l}r, 7 T \\
1,00\end{array}$ & $\begin{array}{l}1 \cdot, r q \\
1 r, \wedge \wedge\end{array}$ & البعدي القبلي & الوصتتاجات \\
\hline$\cdot, \wedge r$ & $(\cdot, \cdot 1)$ & YT,OY & 119 & $\begin{array}{l}r, \Sigma r \\
1, r o\end{array}$ & $\begin{array}{l}1,, 1 \vee \\
1 \leqslant, \vee 9\end{array}$ & البعدي & مقترحة \\
\hline$\cdot, 9$. & $(\cdot, \cdot 1)$ & $r, \lambda r$ & 119 & $\begin{array}{l}V, \lambda T \\
\varepsilon, \cdot T\end{array}$ & $\begin{array}{l}\leq V, 1 \leq \\
77, \cdot 1\end{array}$ & البعدي البلي & الكلي \\
\hline
\end{tabular}

-أن القيمة التائية للفرق بين متوسطي القياسين القبلي والبعدي لبعد التأمل

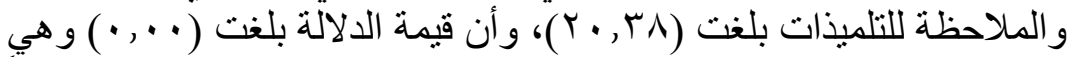
أقل من مستوى المعنوية (1 ( , • )، وهذا يعني أنه يوجد فرق دال إحصائياً

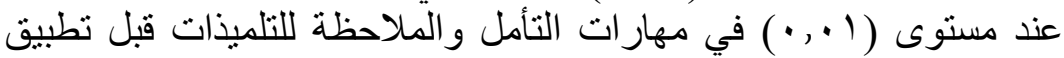

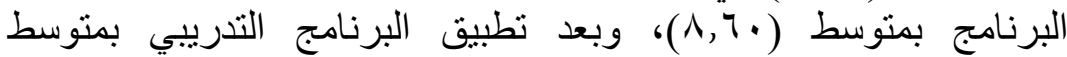
(1 , 9r) و هو معامل تأثير كبير. ( V^)

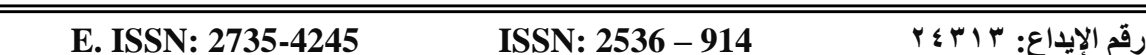
المجلة معرفة علي دوريات بنك المعرفة المصرى، و Edu Search دار المنظومة
} 
- أن القيمة التائية للفرق بين متوسطي القياسين القبلي والبعدي لبعد الكثف البف

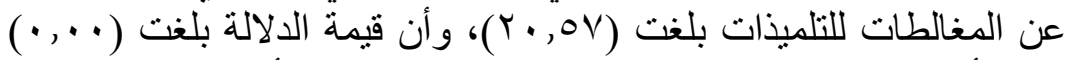
وهي أقل من مستوى المعنوية (1 (, •)، وهذا بعني أنه يوجد فرق دال إحصائياً عند مستوى (1 ( , • ) في مهار ات الكثنف عن المغالطات للتلميذات

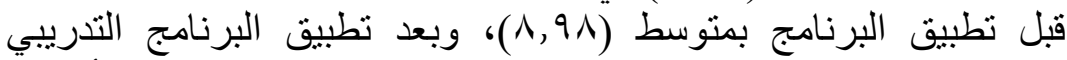

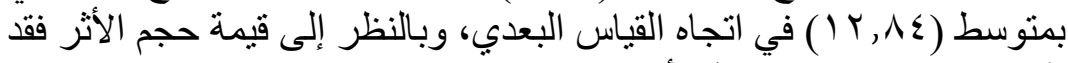

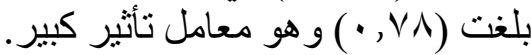
- - أن القيمة التائية للفرق بين متوسطي القياسين القبلي و البعدي لبعد إعطاء

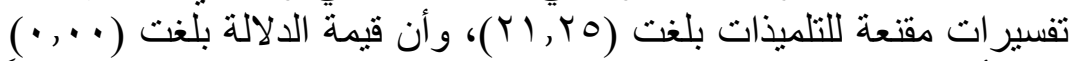

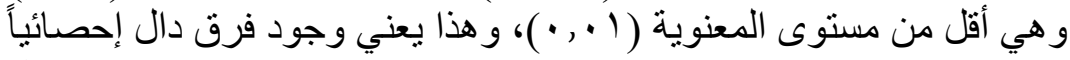

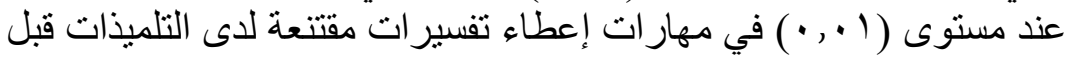

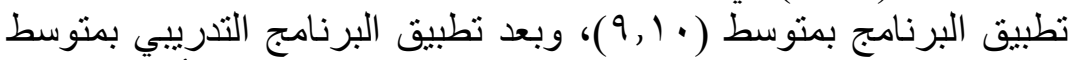
(I Y, ON)

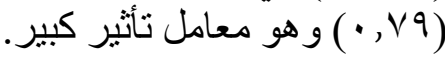

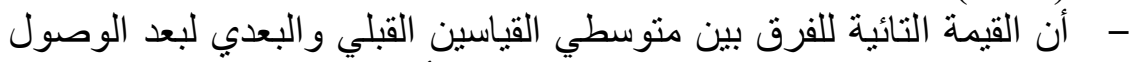

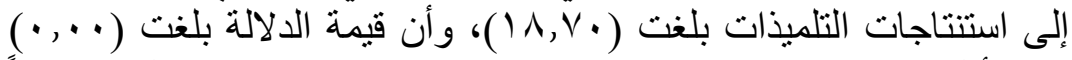
و هي أقل من مستوى المعنوية ( ( . . ·)، و هذا يعني وجود فرق دال إحصائياً

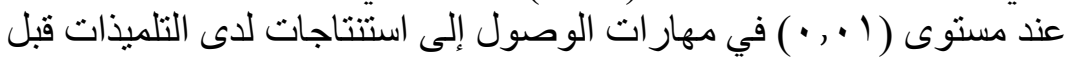

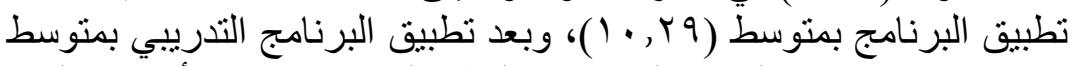

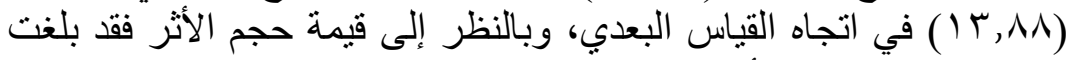
( V0) أن القيمة التائية للفرق بين متوسطي القياسين القبلي والبعدي لبعد وضع

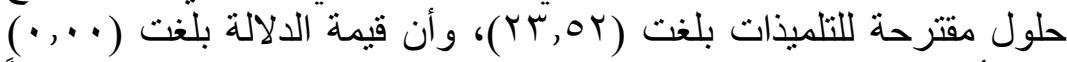
وهي أقل من مستوى المعنوية ( ( , •)، و هذا يعني وجود فرق دال إحصائياً

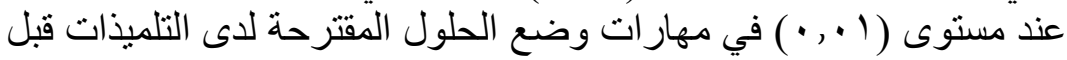

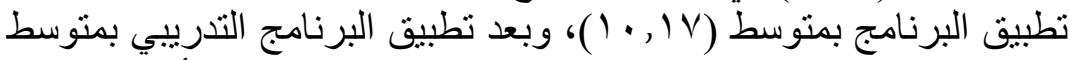
( ع , V9) (Ar) - - أن القيمة التائية للفرق بين متوسطي القياسين القبلي والبعدي للارجة الكلية

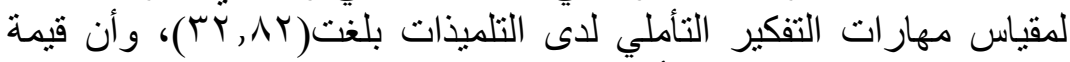

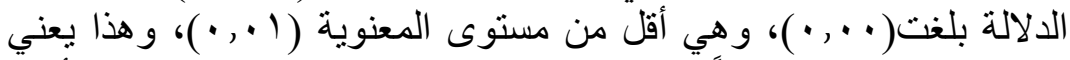

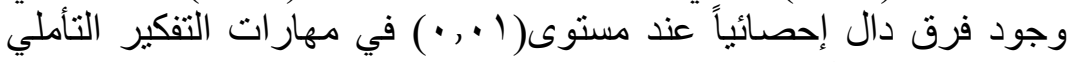

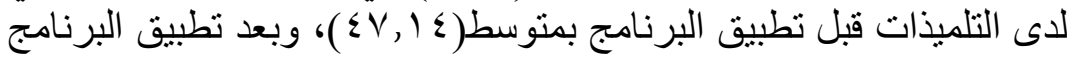

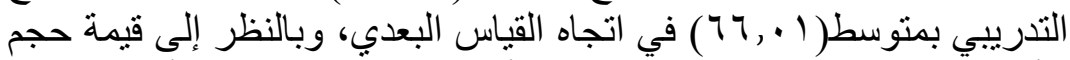

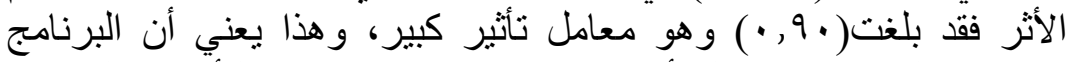
التدريبي للمعلمات كان لله أثر كبير في تحسين التفكير التأملي للتلميذات.

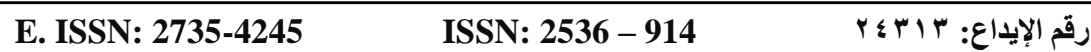

المجلة معرفة علي دوريات بنك المعرفة المصرى، و Edu Search دار المنظومة
} 


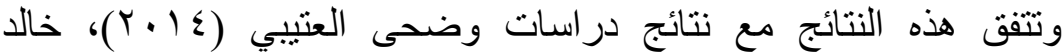

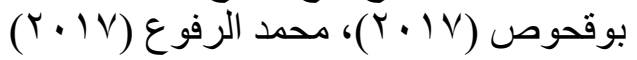

\section{ـ مناقثة النتائج وتفسيرها:}

اتضح من خلال عرض النتائج السابقة فاعلية البرنامج التدريبي المقترح القائم على ونى استخدام المنصات التعليمية عن بعد في تحسين ممارسات التدريس التأملي و الكفاءة

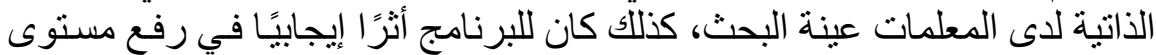

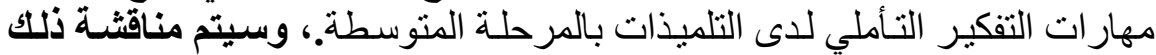
تفصيلا من خلارل ما يلي الفي الئي

أولاً: مناقثة النتائج الكمية: قد ترجع هذه النتائج إلى عدة أسباب أهمها:

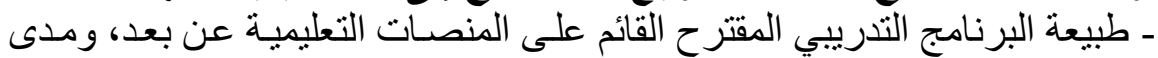

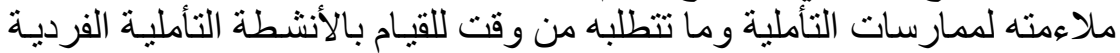

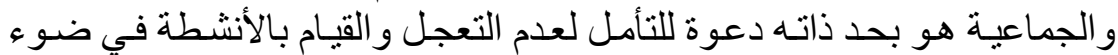

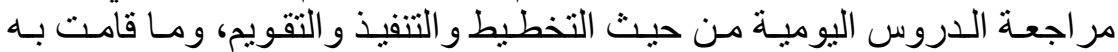
المعلمة من ممارسات خلال تنفيذ جلسات البرنامج، جعل المعلمات لديهن الدئ القدرة

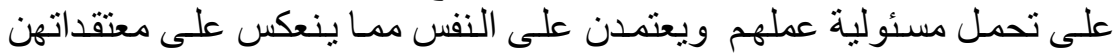

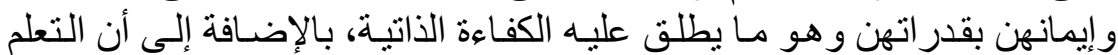

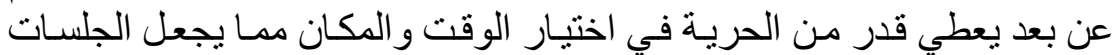
التدريبية أكثر فاعلية، وخاصة عند مند تطبيق أنشطة ملاحظة الزميلات.

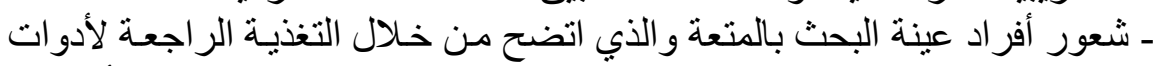

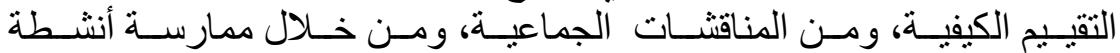

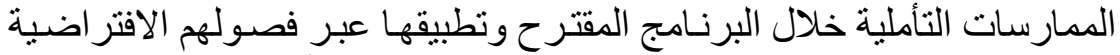

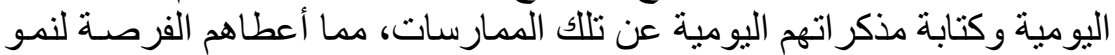

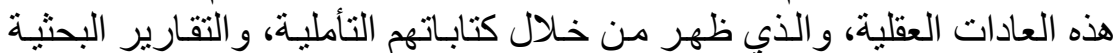

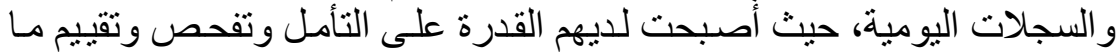

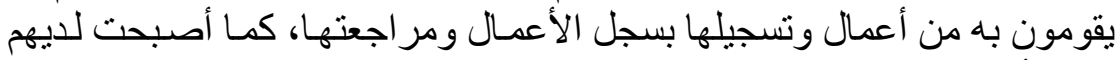

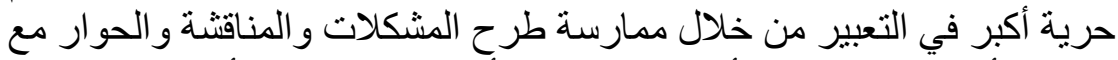

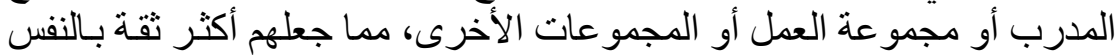

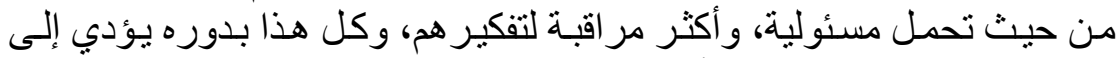

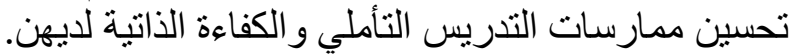

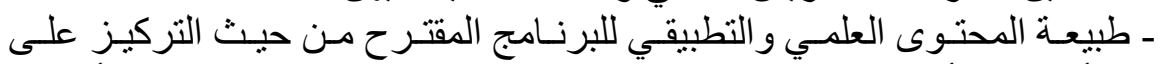

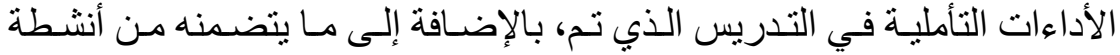

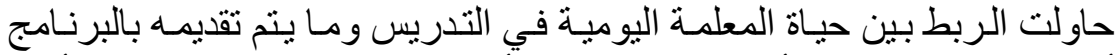

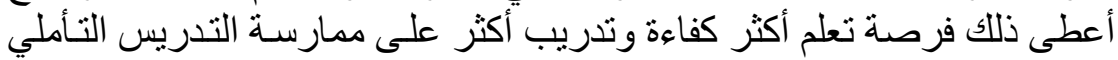
من خلال الوقوف على نقاط القوة وتحسينها وتعزيز نقاط الضعف وفئ

\footnotetext{
E. ISSN: 2735-4245

ISSN: 2536 - 914

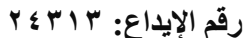

المجلة معرفة علي دوريات بنك المعرفة المصرى، و Edu Search دار المنظومة
} 
ـ المتابعـة المستمرة للقـائم بالتـدريب "الباحثةة" لتطبيت أنشـة الجلسـات التدرييـة

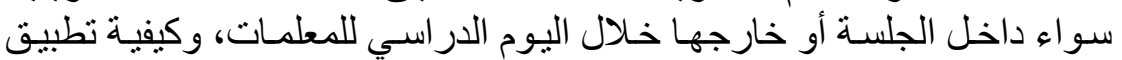

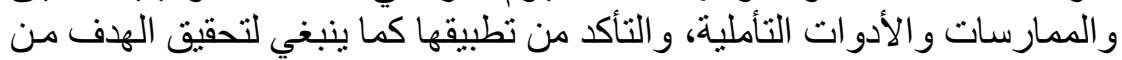

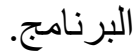

\section{ثانيأ: عرض أهم نتائج التحليل الكيفي ومناقشتها وتفسيرها، كما هو موضـح فيمـا} ـ كَّان هنـاك تـدن ملحوظ، لـدى أفر اد عينـة البحـث، قبـل التـدريب بالبرنـامج، في

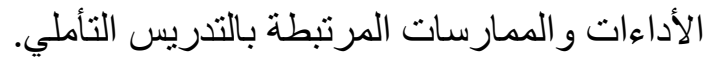

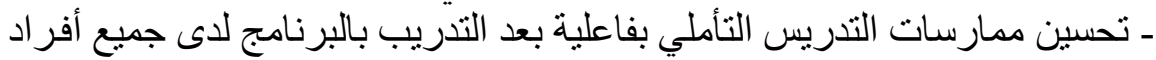

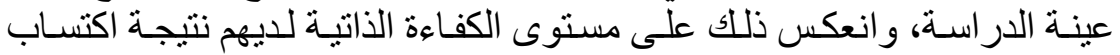
ثقتهم بنفسهم مع ممارسة التدريس التأملي.

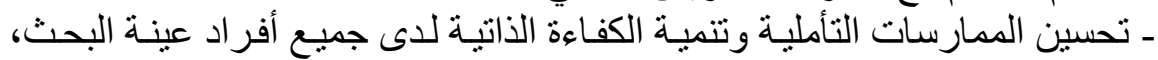

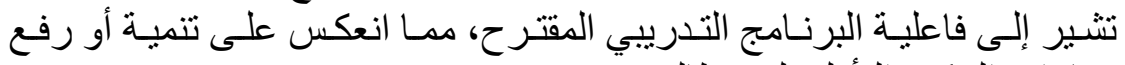
مهار ات التفكير التأملي لدى طاعلي لـالبتهن.

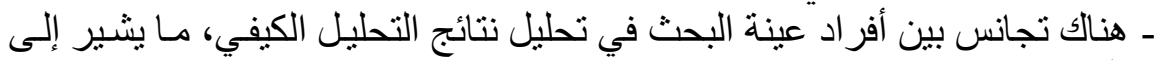
أن التحسن في المتغيرات التابعة يرجع إلى البرنامج التدريبي المقتر ح (المعالجة التجريبية).

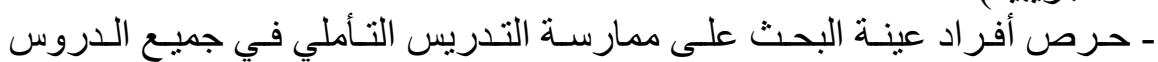

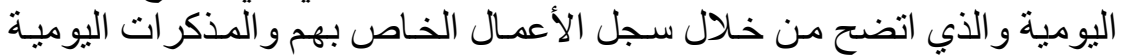

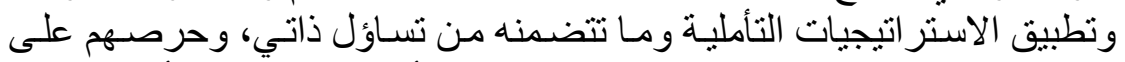

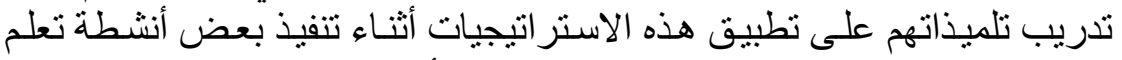
العلوم، مما انعكس على تتمية مهار ات التفكير التأملي لديهن هذه التهن.

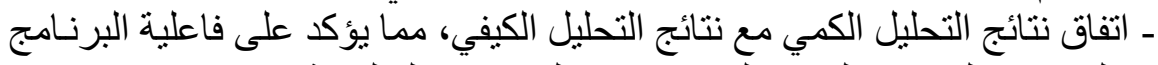

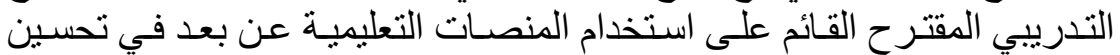

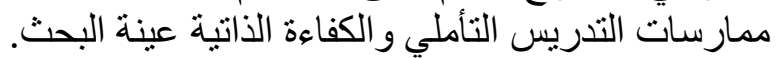

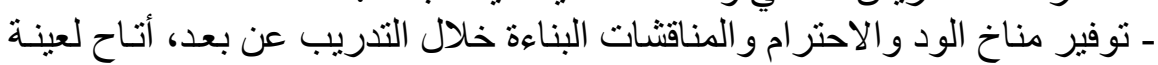

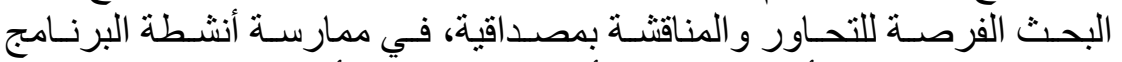

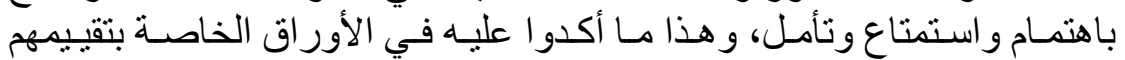
للبرنامج، ومن خلال الاستجابة عن بطاقات التأمل الذاتي.

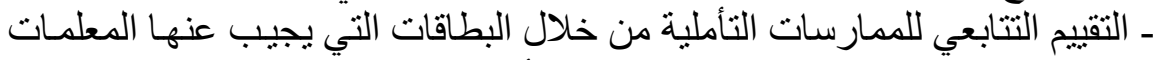

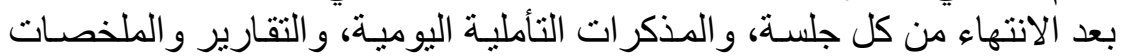

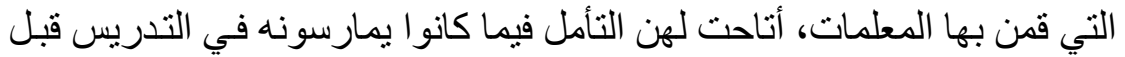

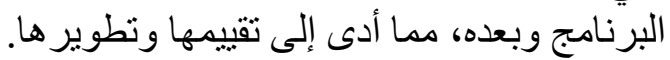

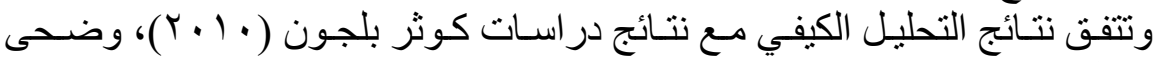

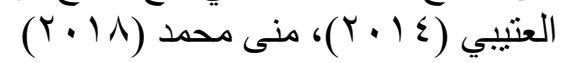

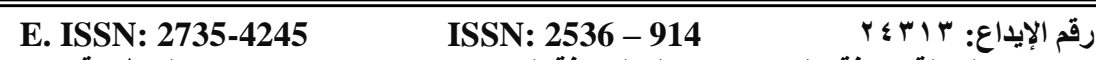

المجلة معرفة علي دوريات بنك المعرفة المصرى، و Edu Search دار المنظومة
} 
التوصيات: في ضوء نتائج البحث، يمكن التوصية بالآتي:

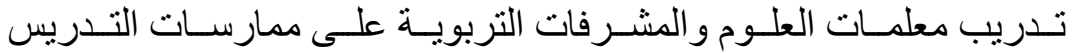

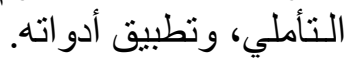

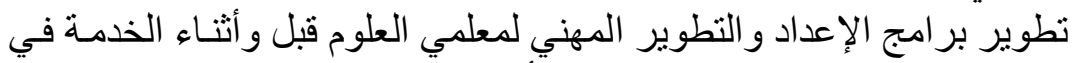

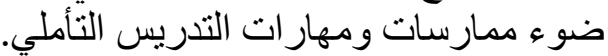

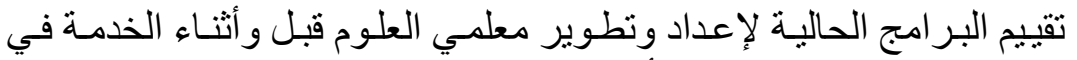

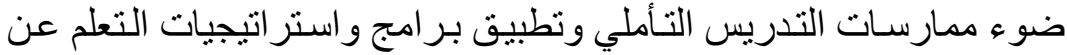
بعد لتحسينها.

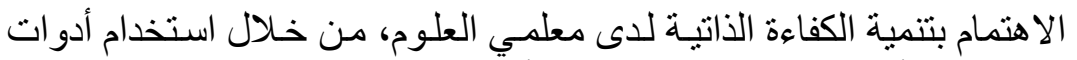
التدريس التأملي وتفعيل الممارسات التأملية. المقترحات: في ضوء ما تم التوصل إليه من نتائج، نم اقتر اح التالي:

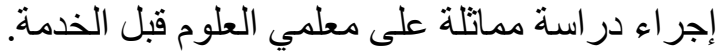

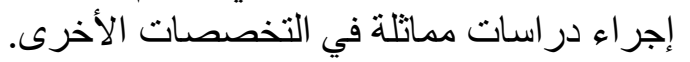
• استخدام بعض أدوات التدريس التأملي في تنمية الكفاءة الذاتية.

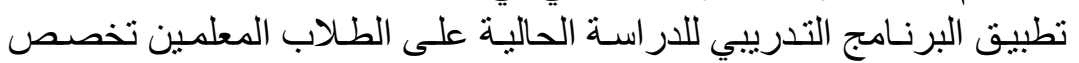

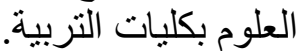
تعرف مدى ممارسة معلمي العلوم أثناء الخدمة لمهار ات التدريس التأملي.

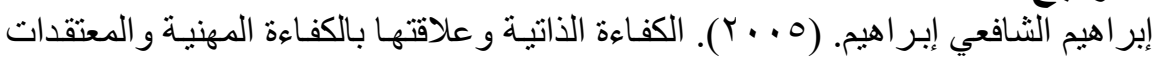

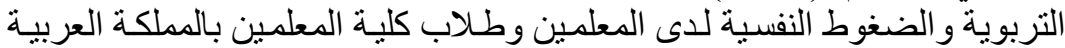

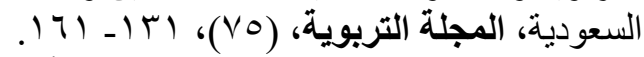

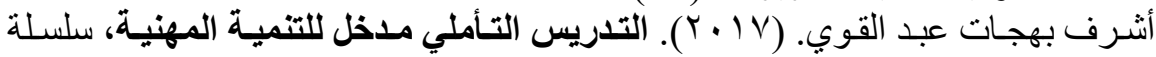

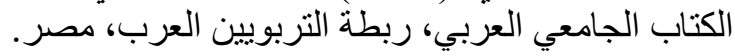

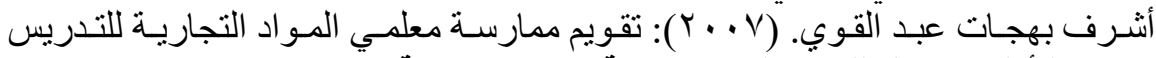

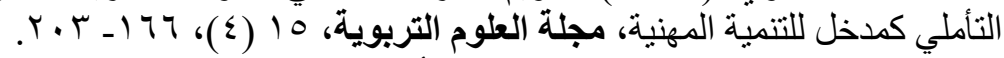

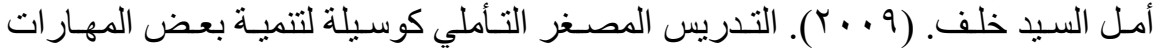

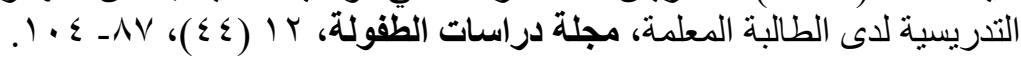

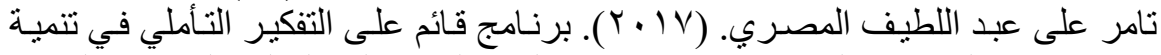

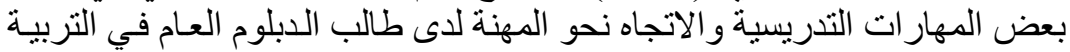

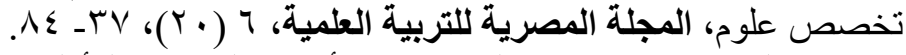

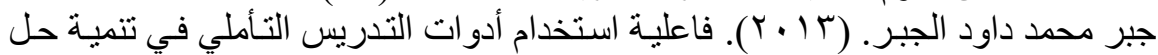

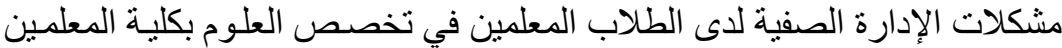

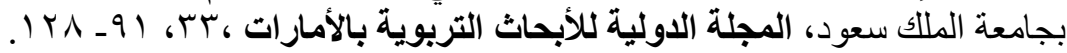

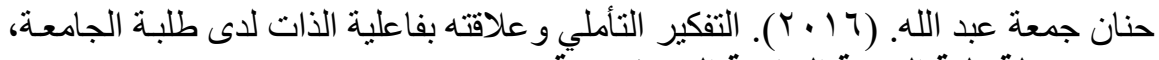

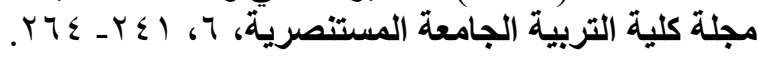

\footnotetext{
E. ISSN: 2735-4245 المجلة معرفة علي دوريات بنك المعرفة المصرى، و Edu Search دار المنظومة
} 


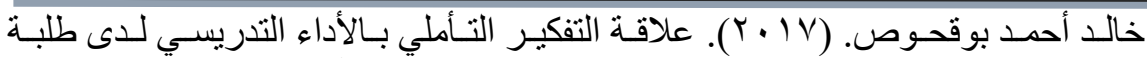

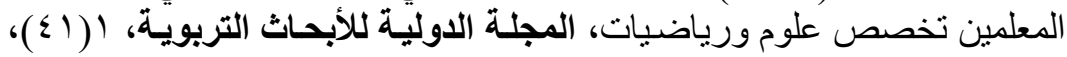

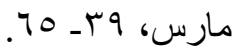

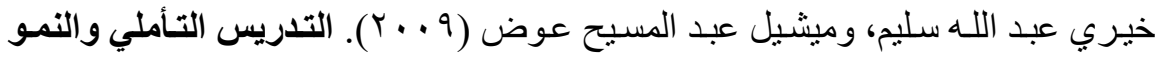

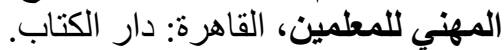

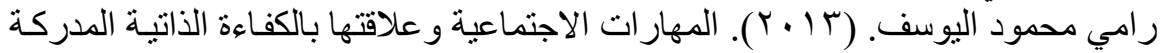

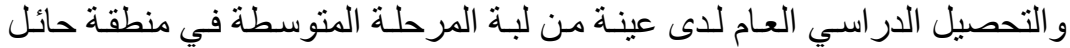

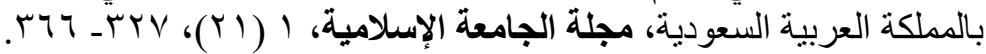

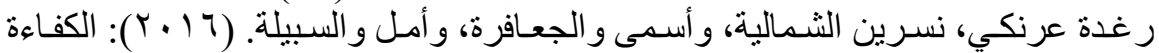

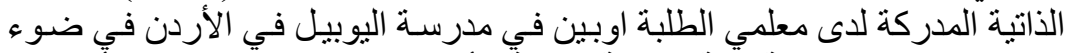

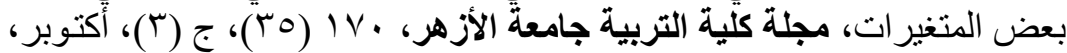
$07 V$ _0 $0 \leq 1$

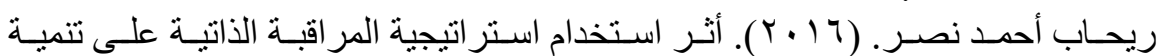

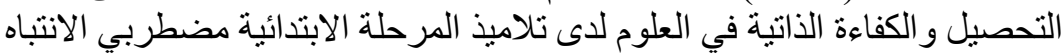

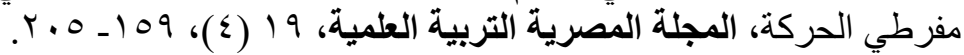

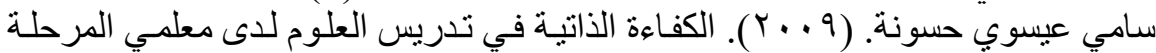

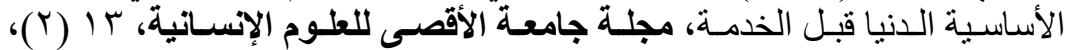

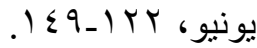

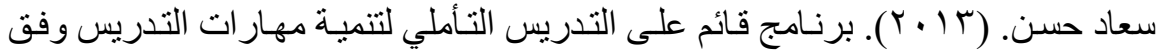

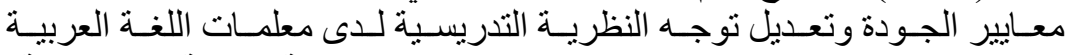

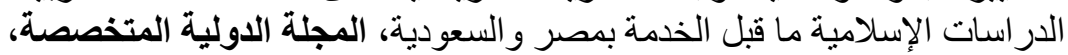

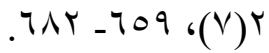

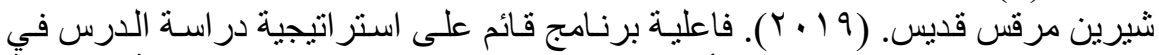

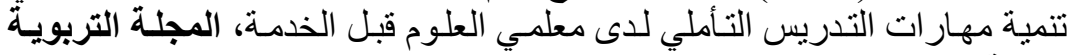

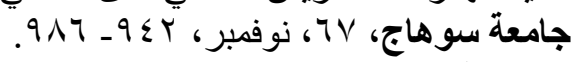

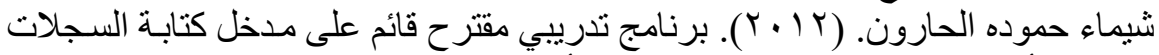

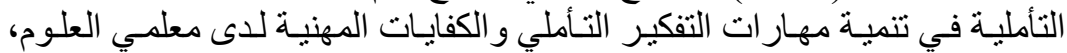

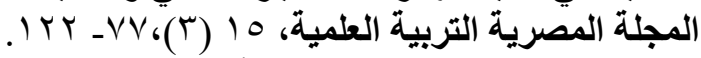

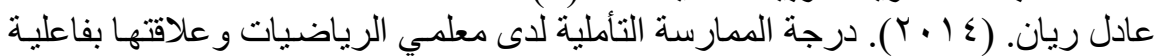

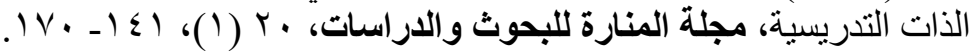

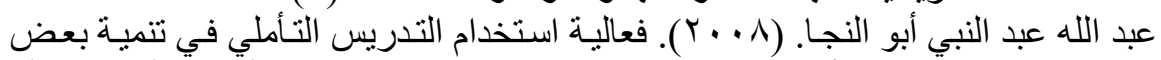

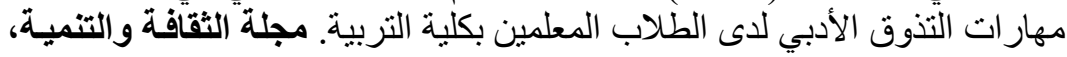

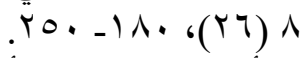

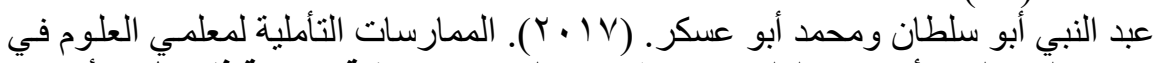

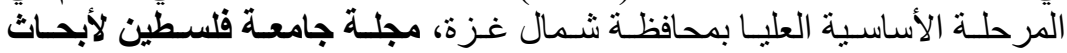

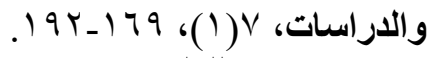

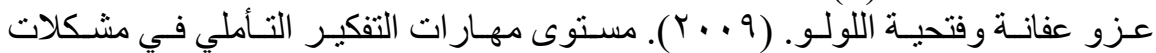

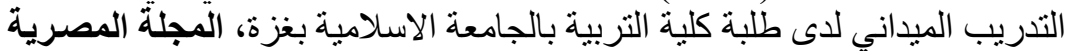

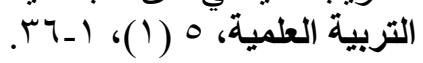




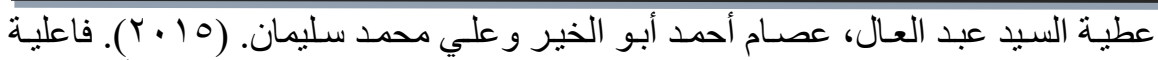

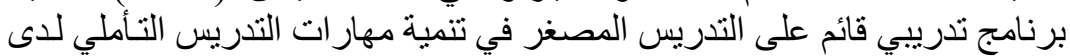

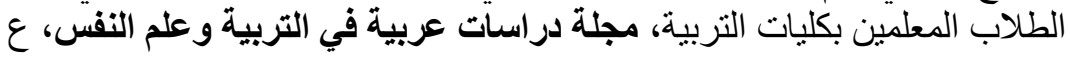

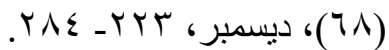

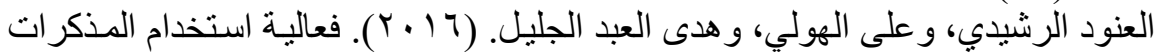

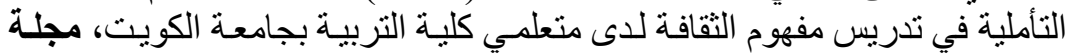

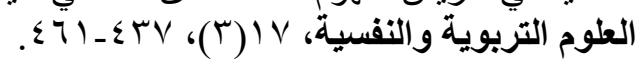

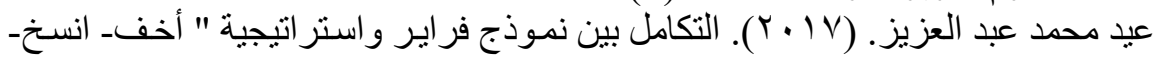

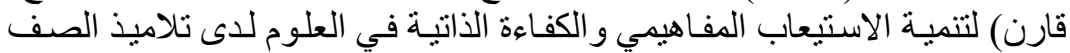

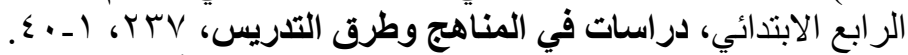

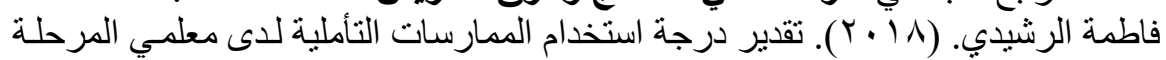

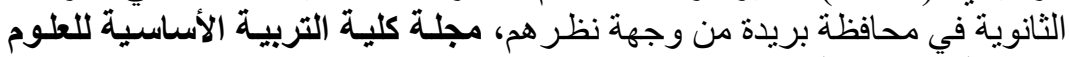

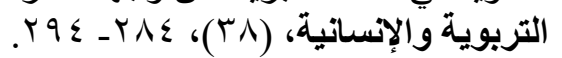

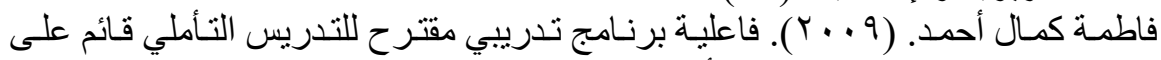

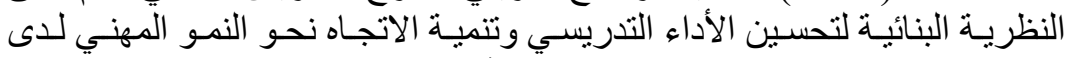

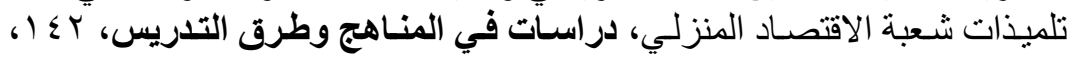
$99-7$. كوثر جميل سالم بلجون. (• ( • ب). مدى إتقان معلمي العلوم لممارسـات التدريس التأملي

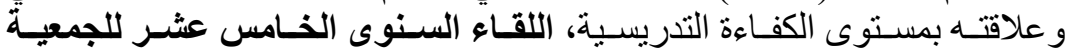

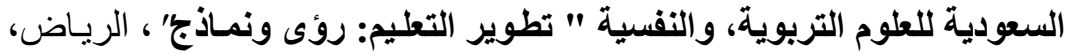

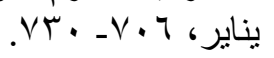
ماجد مصطفى العلي، عبد المطلب عبد القادر ومحمد (7 1 ـ ب). الكفاءة الذاتية و علاقتها

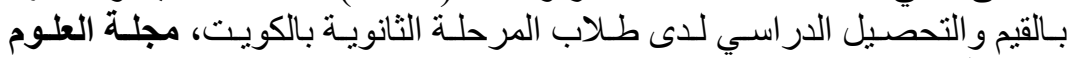

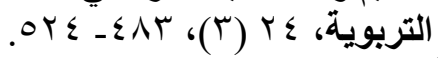

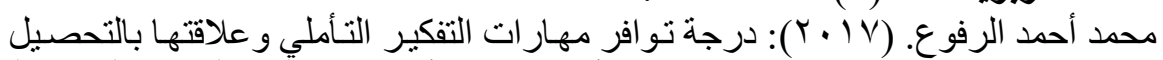

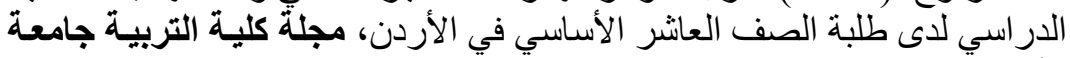

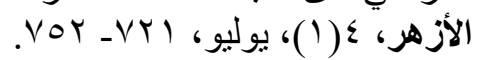

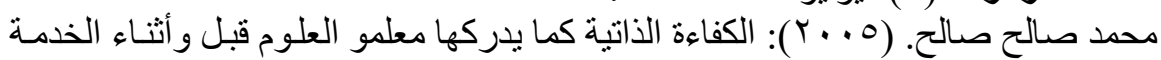

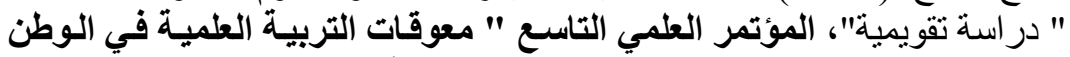

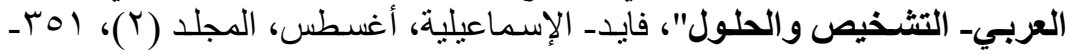
. 7

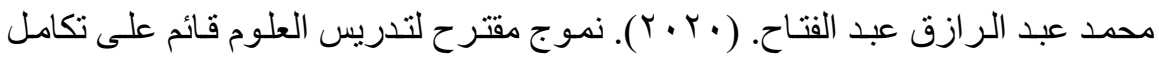

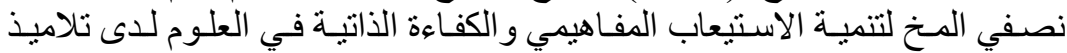

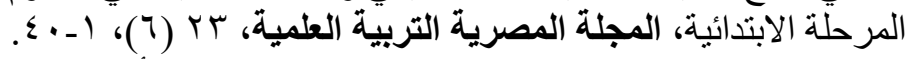

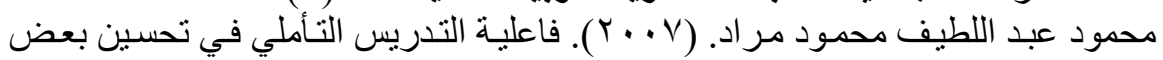

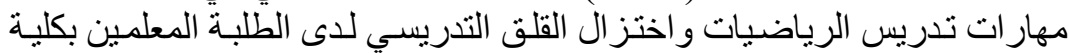

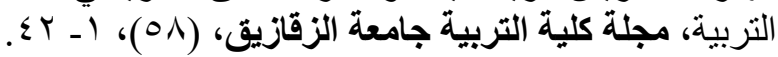

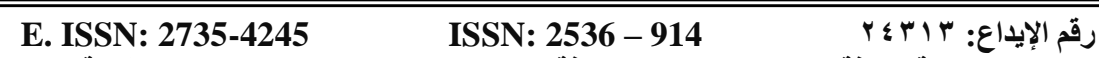
المجلة معرفة علي دوريات بنك المعرفة المصرى، و Edu Search دار المنظومة 
ملاك محمد السليم (9 . . ب). فاعلية التعلم التأملي في تتمية المفاهيم الكيميائية و التفكير

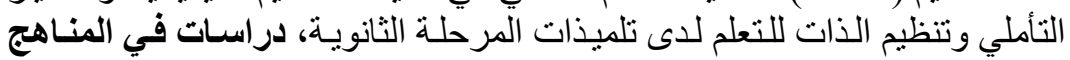

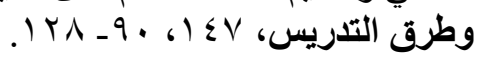

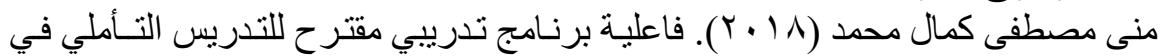

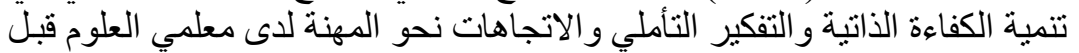

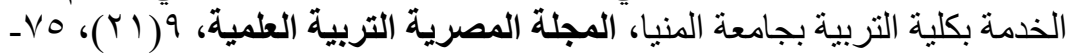

$$
\text { .1.V }
$$

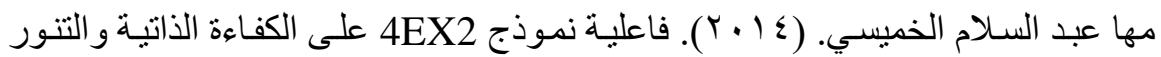

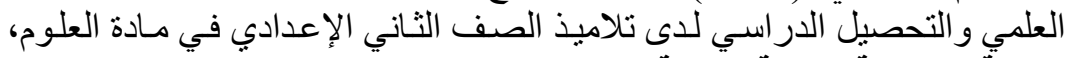

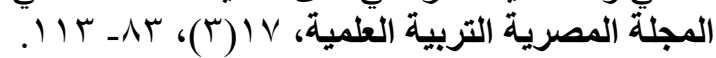

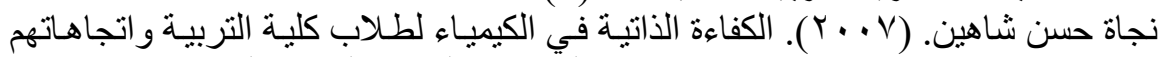

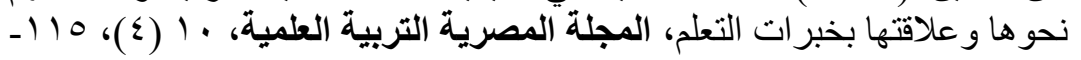
$.1 \leqslant r$ هالة طه عبد الله بخش (ب ( . . ب). فعالية برنامج مقتر ح للتدريس التأملي في تطوير التربية

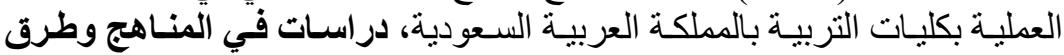

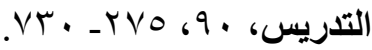

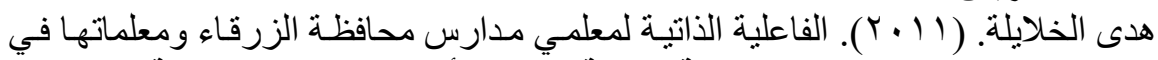

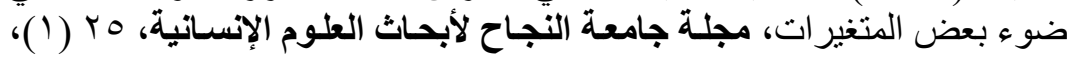
$r \leq-1$

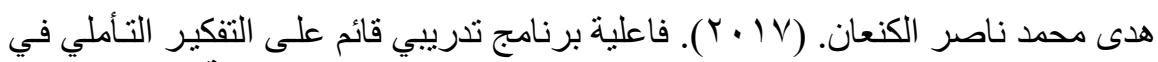

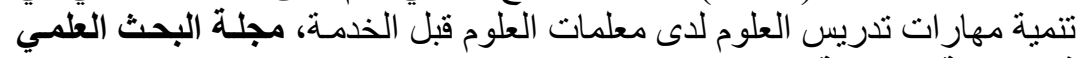

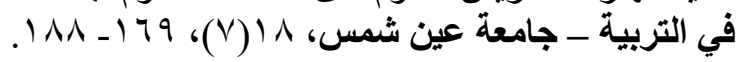

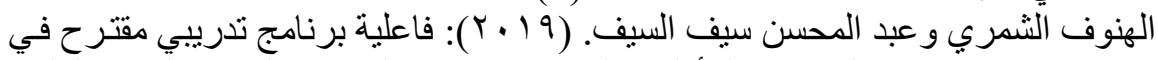

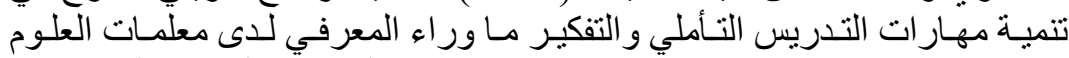

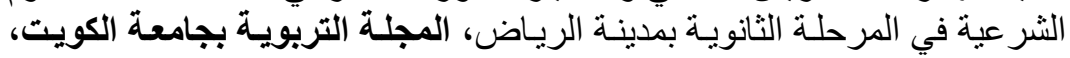

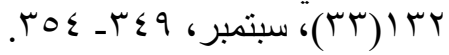

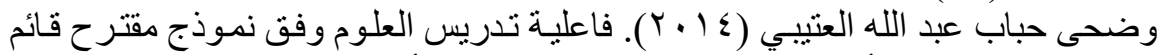

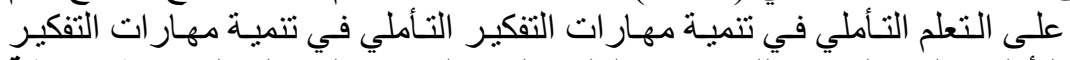

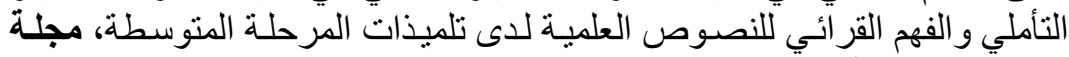

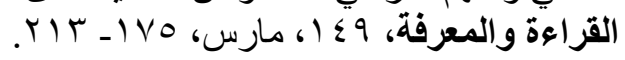

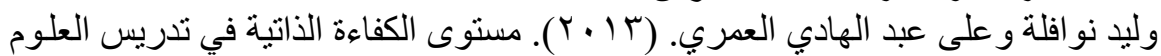

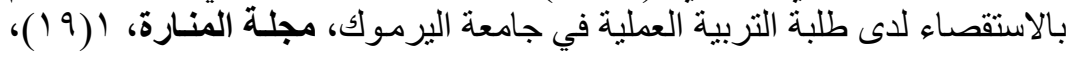
. $\leqslant$ - $-\Lambda$

Ahmed,E \& Al-Khalili,K (2013).The impact of using reflective teaching approach on develop teaching skills of primary science student teachers .The Online Journal of New Horizons in Education, 3(2),58-64.
E. ISSN: 2735-4245
ISSN: $2536-914$

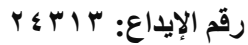
المجلة معرفة علي دوريات بنك المعرفة المصرى، و Edu Search دار المنظومة 
Ainsowrth,P.K (2010). Developing a Self -Evaluating School: $A$ Practical Guide, London: Continuum International Publishing.

Al-Zoubi, S.\& Abdel Rahman (2011). The effects of a training program in improving instructional competencies for special education teachers in Jordon, Educational Research, 2(3), 1021-1030.

Bandura, A. (2000). Cultivate self-efficacy for personal and organizational effectiveness. In E. A. Locke (Ed.). Handbook of principles of organization behaviour, Oxford. UK. Blackwell.

Bannick, A., \& van Dam, J. (2007). Bootstrapping reflection on classroom interactions: Discourse contexts of novice teachers' thinking, Evaluation and Research in Education, 20(2), 81-99.

Blackburn, J. \& Robinson, S. (2008). “Assessment of teacher self efficacy and job satisfaction of early career Kentucky agriculture teachers". Journal of Agricultural Education, 3(49), 1-11.

Buss,R. R. (2010). Efficacy for Teaching Elementary Science and Mathematics Compared to Other Content, School Science and Mathematics, 110(6), 290- 297.

Cheung, H. (2008). Teacher Efficacy. "A comparative study of hong kong and shanghai primary in-service teachers", The Australian Educational Researcher, 35(1), 103-123.

Goh,P., \& Matthews, B. (2011). Listening to the Concerns of Student Teachers in Malaysia during Teachers Practice. Australian Journal of Teacher Education, 36 (3), 92-103.

Gurol, A. (2011). Determining the reflective thinking skills of preservice teachers in learning and teaching process, Energy Education Science and Teaching, part B: Social and Educational Studies, 3(3), 387-402.

Jasper, M., Elliott,P.,\& Kouble, G.(2011). Vital notes for nurses: Professional Deselopment, Reflection and decisionmaking, Hobpken, NJ, USA,: Wiley-Blackwell.

Navaneedhan, C.girija,(2010). Reflective teaching pedagogy as innovative approach in teacher education through open and distance learning, Journal of Media, and Communication Studies, 3(12), 1-27.

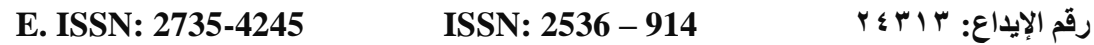
المجلة معرفة على دوريات بنك المعرفة المصرى، و Edu Search دار المنظومة 
Neil, G. (2011). Guidelines for the design and delivery of a SchoolBased Module to Support USD Graduate Teaching assistants (GTA), Demonstrators and tutors UCD Teaching and Learning, 1-38.

Ogonor, B O. \& Badmus, M. M. (2006). Reflective Teaching Practice among Student Teachers: The Case in a Tertiary Institution in Nigeria, Australian Journal of Teacher Education, 31(2), 1-7.

Rodgers,c (2002): Defining reflection: another look at John Dewey and reflective thinking, Teachers College Record, 104, 842866.

Samules,M \& Betts,J.(2007). Crossing the threshold from description to: deconstruction and reconstruction: Using selfassessment to deepen reflection, Reflective Practice, 8(2), 269- 283.

Yost, D \& Sentner, S (2000). An Examination of the construct of critical reflection implication for teacher education programming in the 21 st Century, Journal of Teacher Education, 1(1), 39-50.

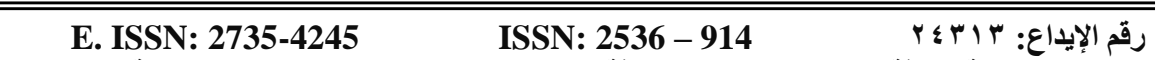

المجلة معرفة علي دوريات بنك المعرفة المصرى، و Edu Search دار المنظومة 